\title{
The anatomy and phylogenetic position of the erythrosuchid archosauriform Guchengosuchus shiguaiensis from the earliest Middle Triassic of China
}

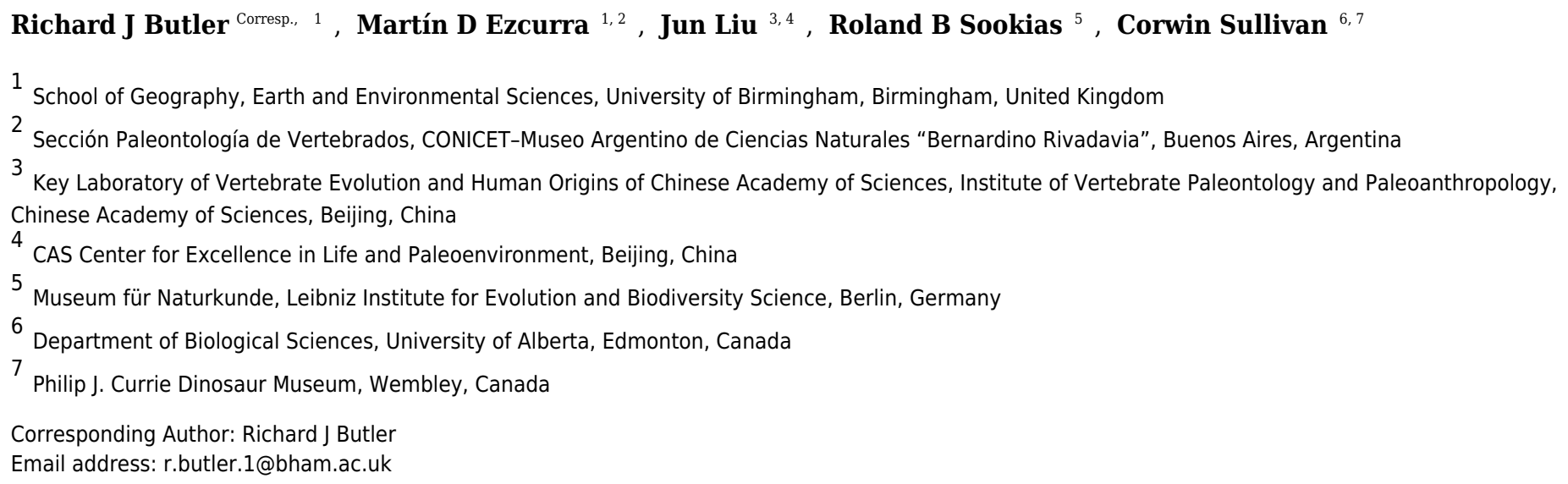

Erythrosuchidae is a clade of early archosauriform reptiles, which were apex predators in many late Early and Middle Triassic ecosystems, following the Permo-Triassic mass extinction. Erythrosuchids had a worldwide distribution, with well-preserved fossil material known from South Africa, European Russia and China. We here redescribe the anatomy and revise the taxonomy of Guchengosuchus shiguaiensis, which is one of the stratigraphically oldest erythrosuchids and is known from a single partial skeleton from the lowermost Middle Triassic (lower Anisian) lower Ermaying Formation of Shanxi Province, China. We provide a new differential diagnosis for Guchengosuchus shiguaiensis, and identify a series of autapomorphies relating to the morphologies of the skull roof and vertebrae. Incorporating updated anatomical information for Guchengosuchus into the most comprehensive morphological phylogenetic analysis available for early archosauromorphs recovers it as an early branching member of Erythrosuchidae, outside of the clade formed by Garjainia, Erythrosuchus, Chalishevia, and Shansisuchus. Fugusuchus hejiapanensis, from the uppermost Lower Triassic to lower Middle Triassic Heshanggou Formation of China, is recovered as the earliest branching member of Erythrosuchidae. 
2 The anatomy and phylogenetic position of the erythrosuchid archosauriform

3 Guchengosuchus shiguaiensis from the earliest Middle Triassic of China

4

5 Richard J. Butler ${ }^{1}$, Martín D. Ezcurra ${ }^{1,2}$, Jun Liu ${ }^{3,4}$, Roland B. Sookias ${ }^{5}$, and Corwin Sullivan ${ }^{3,6,7}$

7 'School of Geography, Earth and Environmental Sciences, University of Birmingham,

8 Edgbaston, Birmingham B15 2TT, UK

9 25ección Paleontología de Vertebrados, CONICET-Museo Argentino de Ciencias Naturales

10 "Bernardino Rivadavia”, Av. Ángel Gallardo 470, C1405DJR, Buenos Aires, Argentina

$11{ }^{3}$ Key Laboratory of Vertebrate Evolution and Human Origins of Chinese Academy of Sciences,

12 Institute of Vertebrate Paleontology and Paleoanthropology, Chinese Academy of Sciences

$13 \quad$ Beijing 100044, China

$14{ }^{4}$ CAS Center for Excellence in Life and Paleoenvironment, Beijing, 100044, China

$15{ }^{5}$ Museum für Naturkunde, Leibniz Institute for Evolution and Biodiversity Science,

16 Invalidenstraße 43, 10115 Berlin, Germany

$17{ }^{6}$ Department of Biological Sciences, University of Alberta, Edmonton, Alberta, T6G 2E9,

$18 \quad$ Canada

19 7Philip J. Currie Dinosaur Museum, Wembley, Alberta, T0H 3S0, Canada

20

21 Corresponding Author:

22 Richard J. Butler ${ }^{1}$

23 Email address: r.butler.1@bham.ac.uk 
25 Abstract: Erythrosuchidae is a clade of early archosauriform reptiles that were apex predators in many late Early and Middle Triassic ecosystems, following the Permo-Triassic mass extinction.

27 Erythrosuchids had a worldwide distribution, with well-preserved fossil material known from 28 South Africa, European Russia and China. We here redescribe the anatomy and revise the taxonomy of Guchengosuchus shiguaiensis, which represents one of the stratigraphically oldest erythrosuchids and is known from a single partial skeleton from the lowermost Middle Triassic

31 (lower Anisian) lower Ermaying Formation of Shanxi Province, China. We provide a new

32 differential diagnosis for Guchengosuchus shiguaiensis, and identify a series of autapomorphies relating to the skull roof and vertebrae. Incorporating updated anatomical information for

Guchengosuchus into the most comprehensive morphological phylogenetic analysis available for early archosauromorphs recovers it as an early branching member of Erythrosuchidae, outside the clade formed by Garjainia, Erythrosuchus, Chalishevia, and Shansisuchus. Fugusuchus Formation of China, is recovered as the earliest branching member of Erythrosuchidae.

\section{INTRODUCTION}

Erythrosuchidae is a clade of early archosauriform reptiles that comprises a small number of species ranging stratigraphically from the late Early to the Middle Triassic (Ezcurra et al., 2013; Ezcurra, 2016). Erythrosuchids were important apex predators in earliest Mesozoic ecosystems, 
47 and are characterised by their proportionately large skulls and hypercarnivorous adaptations

48 (Ezcurra et al., 2013). Although the taxonomic content, phylogenetic position, and

49 interrelationships of Erythrosuchidae have long been unclear, substantial work over the last two

50 decades has greatly increased understanding of the group (Gower, 1997, 2003; Ezcurra et al.,

51 2013; Wang et al., 2013; Gower et al., 2014; Ezcurra, 2016; Ezcurra et al., 2018), and

52 demonstrated a geographic distribution including South Africa (Gower, 2003; Gower et al.,

53 2014), Russia (Ochev 1958; Huene 1960; Gower \& Sennikov, 2000; Ezcurra et al., 2018), China

54 (Wang et al., 2013; Ezcurra, 2016), India (Bandyopadhyay, 1999) and possibly Australia

55 (Ezcurra, 2016). However, the anatomy and taxonomy of several species within the clade remain

56 poorly understood.

One of the least well understood erythrosuchids is Guchengosuchus shiguaiensis from the earliest Middle Triassic of Shanxi, China (Fig. 1). Peng (1991) provided a brief description in Chinese of Guchengosaurus, with a relatively small number of figures, but this taxon has received little subsequent attention and was not included by Parrish (1992) in his analysis of the phylogeny of Erythrosuchidae. Indeed, the first inclusion of this species in a quantitative phylogenetic analysis was by Ezcurra (2016), who recovered it as the earliest branching member of the erythrosuchid clade, making it potentially significant for understanding the origins of the

64 distinctive body plan of the group. Here, we provide a full redescription of the anatomy of

65 Guchengosaurus, revise its taxonomy, and discuss its phylogenetic position in more detail.

67 Institutional abbreviations. BP, Evolutionary Studies Institute (formerly Bernard Price Institute 68 for Palaeontological Research), University of the Witwatersrand, Johannesburg, South Africa; 69 BSPG, Bayerische Staatssammlung für Paläontologie und Geologie, Munich, Germany; GHG, 
70 Geological Survey, Pretoria, South Africa; GMB, Geological Institute, Beijing, China; ISIR,

71 Indian Statistical Institute, Kolkata, India; IVPP, Institute of Vertebrate Paleontology and

72 Paleoanthropology, Beijing, China; MCNAM, Museo de Ciencias Naturales y Antropológicas de

73 Mendoza (J. C. Moyano), Mendoza, Argentina; MCZ, Museum of Comparative Zoology,

74 Cambridge, USA; NHMUK PV, The Natural History Museum, Palaeontology Vertebrates,

75 London, UK; NM QR, National Museum, Bloemfontein, South Africa; PIN, Borissiak

76 Paleontological Institute of the Russian Academy of Sciences, Moscow, Russia; PULR,

77 Paleontología, Universidad Nacional de La Rioja, La Rioja, Argentina; PVL, Paleontología de

78 Vertebrados, Instituto 'Miguel Lillo', San Miguel de Tucumán, Argentina; QM, Queensland

79 Museum, Brisbane, Queensland, Australia; RC, Rubidge Collection, Wellwood, Graaff-Reinet,

80 South Africa; SAM-PK, Iziko South African Museum, Cape Town, South Africa; TM, Ditsong

81 National Museum of Natural History (formerly Transvaal Museum), Pretoria, South Africa;

82 UMZC, University Museum of Zoology, Cambridge, UK; UNIPAMPA, Universidade Federal

83 do Pampa, São Gabriel, Brazil; UTGD, School of Earth Sciences, University of Tasmania,

84 Hobart, Australia; ZPAL, Institute of Paleobiology of the Polish Academy of Sciences, Warsaw,

85 Poland.

87 MATERIALS AND METHODS

89 The phylogenetic relationships of Guchengosuchus shiguaiensis were analysed using the

90 phylogenetic dataset of Ezcurra (2016) as modified by subsequent authors (Ezcurra et al., 2017;

91 Nesbitt et al., 2017; Sengupta et al., 2017; Stocker et al., 2017; Ezcurra \& Butler, 2018; Ezcurra

92 et al., 2018). This data matrix is composed of 116 active terminals and 694 active characters 
93 (character 119 was deactivated before the tree searches following Ezcurra et al., 2017). Here, an

94 additional character state was added to characters 46 and 393 and a few scorings were changed

95 for these characters and for characters 15, 56, 69 and 652 (see Appendix and Supplementary

96 Material). The matrix was analysed under equally weighted maximum parsimony using TNT

97 v.1.5 (Goloboff et al., 2008; Goloboff \& Catalano, 2016). The search initially used a

98 combination of tree-search algorithms including Wagner trees, TBR branch swapping, sectorial

99 searches, Ratchet (perturbation phase stopped after 20 substitutions) and Tree Fusing (5 rounds),

100 until 100 hits of the same minimum tree length were achieved. The best trees obtained were

101 subjected to a final round of TBR branch swapping. Zero length branches in any of the recovered

102 most parsimonious trees were collapsed. The following characters were considered additive

103 (ordered) during the searches, because they represent nested sets of homologies: 1, 2, 7, 10, 17,

$10419-21,28,29,36,40,42,46,50,54,66,71,74-76,122,127,146,153,156,157,171,176,177$,

$105187,202,221,227,263,266,278,279,283,324,327,331,337,345,351,352,354,361,365$,

$106370,377,379,386,387,398,410,424,430,435,446,448,454,458,460,463,470,472,478$,

$107482,483,485,489,490,504,510,516,529,537,546,552,556,557,567,569,571,574,581$,

$108582,588,648,652$ and 662. Branch support was quantified using decay indices (Bremer support

109 values) and a bootstrap resampling analysis, using 1,000 pseudoreplicates and reporting both

110 absolute frequency and GC frequency (that is, the difference between the frequencies of recovery

111 in pseudoreplicates of the clade in question and the most frequently recovered contradictory

112 clade) for each clade (Goloboff et al., 2003). The minimum number of additional steps necessary

113 to generate alternative, suboptimal tree topologies was calculated by constraining the position of

114 Guchengosuchus shiguaiensis in different parts of the tree and rerunning the analysis. 
115 Stereopair photographs of some of the elements of the holotype skeleton of

116 Guchengosuchus shiguaiensis are provided as Supplementary Material, as are reproductions of

117 line drawings by Peng (1991) of parts of the skeleton that are currently unavailable for study.

118 Michael Parrish provided photographs of some parts of the skeleton taken during a visit to IVPP

119 in 1990 that show some of the currently unavailable elements of the skeleton; these photographs

120 are also reproduced in the Supplementary Material.

121

122

123

124 SYSTEMATIC PALAEONTOLOGY

125

126

ARCHOSAURIFORMES Gauthier et al., 1988

ERYTHROSUCHIDAE Watson, 1917 sensu Ezcurra et al., 2010

128

Guchengosuchus Peng, 1991

129

130 Type species. Guchengosuchus shiguaiensis Peng, 1991.

131 Generic diagnosis. As for type and only known species.

132

Guchengosuchus shiguaiensis Peng, 1991

134

135 Holotype. IVPP V8808: left maxilla, partial skull roof, left pterygoid, partial braincase, posterior

136 portion of the right hemimandible, two anterior-middle cervical vertebrae; one probable anterior

137 dorsal lacking most of the centrum; a fragment of presacral vertebra; four cervical and dorsal 
138 ribs; partial right scapula, humerus, ulna, and radius, a metapodial, and an ungual phalanx.

139 Several of the bones originally figured and described by Peng (1991) as part of the holotype

140 could not be located in the collection of the IVPP and may be lost (scapula and limb bones; see

141 below), and other bones have been damaged since the original description (maxilla and

142 pterygoid).

143

144 Locality. Shiguai Village, Gucheng Township, Fugu County, Shanxi Province, People’s

145 Republic of China (Peng 1991; Fig. 1). Peng (1991) reported that all the elements were collected

146 from a $1 \mathrm{~m}^{2}$ area and belong to a single individual.

147

148 Stratigraphic horizon. Lower part of the Ermaying Formation (Peng, 1991). Earliest Anisian

149 (older than 243.53 Ma), early Middle Triassic (Liu et al., 2018; Fig. 1).

150

151 Emended diagnosis. Medium-sized archosauriform distinguished from other archosauromorphs

152 by the following unique combination of features (autapomorphies indicated with an asterisk):

153 maxilla with 14 tooth positions and ankylothecodont tooth implantation; maxilla without

154 maxillo-nasal tuberosity and antorbital fossa; nasal with series of three knob-like convexities

155 dorsal to the facet for the postnarial process of the premaxilla*; parietal with dorsal surface of the

156 base of anterolateral process bearing a subtriangular fossa that extends onto the frontal and is

157 separated from the supratemporal fenestra by a raised edge*; pterygoid without palatal teeth;

158 anterior-middle cervical vertebrae with a strongly transversely convex and rugose distal

159 expansion of the neural spine*; accessory lamina subdivides the postzygapophyseal

160 centrodiapophyseal fossae of the cervical and anterior dorsal vertebrae*; accessory articular 
161 surface for third head of cervical rib positioned at the same height dorsoventrally as the

162 diapophysis*; and scapular blade with strongly concave posterior margin (modified from

163 Ezcurra, 2016).

164

165

ANATOMICAL DESCRIPTION

166 The currently available bones of IVPP V8808 are described and compared in detail based on our

167 own observations, while bones that are currently unavailable or portions of bone that have been

168 damaged since the original description are compared with those of other early archosauriforms

169 based on the original description and figures of Peng (1991).

170

171 Maxilla. The left maxilla is present (Figs 2-3; see also Supplementary Material), and was

172 originally nearly complete and well preserved (Peng, 1991, fig. 1, pl. 1.5; Fig. 4; Supplementary

173 Material), but unfortunately the ascending process has mostly been lost since its original

174 description, and the crowns of maxillary teeth 2, 4 and 6 have also been damaged. The bone is

175 slightly incomplete both at its anterior margin and posteriorly, along the surface for contact with

176 the jugal. As preserved, the maxilla has a length of $165 \mathrm{~mm}$. The minimum dorsoventral height

177 of the maxilla below the antorbital fenestra is $35 \mathrm{~mm}$.

178 The main body of the maxilla is elongate and dorsoventrally narrow. Its ventral margin is

179 very gently convex along the anterior process in lateral view, meaning that the anterior end of the

180 tooth row is slightly upturned relative to the tooth row midpoint. The ventral margin of the

181 maxilla along the horizontal process is straight, but this margin is concave in Garjainia prima

182 (PIN 2394/5, 951/34), Erythrosuchus africanus (BP/1/4680, 5207) and Chalishevia cothurnata

183 (PIN 4366/1). The lateral surface of the maxilla is flat. The anterior process of the maxilla is 
184 anteroposteriorly short, representing approximately $35 \%$ of the total length of the bone as

185 preserved. The dorsal margin of the anterior process and the anterior margin of the ascending

186 process are continuous along a curve that is slightly concave in lateral view (Peng, 1991, fig. 1,

187 pl. 1.5), but to a lesser degree than in Chalishevia cothurnata (PIN 4366/1) and some specimens

188 of Shansisuchus shansisuchus (e.g. IVPP V2508). By contrast, the anterior process is well

189 distinguished from the ascending process by a clear inflexion in Garjainia prima (PIN 2394/5,

190 951/32), Erythrosuchus africanus (BP/1/2529, 5207), Shansisuchus shansisuchus (Young, 1964,

191 figs. 10, 11) and Chalishevia cothurnata (PIN 4366/1). There is no indication of a facet for

192 articulation with the premaxilla along this concave margin, which Peng (1991) identified as the

193 edge of an accessory opening between the premaxilla and the maxilla ('secondary antorbital

194 fenestra') (but see Discussion).

195 The base of the ascending process is situated above crowns $2-5$. Because of the damage

196 to the anterior end of the maxilla, it is not possible to determine if there was a short edentulous

197 section adjacent to the premaxilla, or to confirm the presence or absence of an anteriorly opening

198 notch and/or groove. The ascending process is anteroposteriorly broad and slightly thickened at

199 its posterior margin (Fig. 3). This thickening curves posteroventrally at its base, following the

200 margin of the antorbital fenestra, and fades out immediately ventral to the anterior end of the

201 antorbital fenestra, similar to the condition in Garjainia prima (PIN 2394/5). The lateral

202 thickening of the ascending process is considerably less developed than the probably

203 homologous pillar-like maxillo-nasal tuberosity (sensu Ezcurra, 2016) of Erythrosuchus

204 africanus (BP/1/2529, 5207), Garjainia prima (PIN 2394/5, 951/32), Shansisuchus shansisuchus

205 (IVPP V2501, V2503) and Chalishevia cothurnata (PIN 4366/1). The preserved ventral margin

206 of the antorbital fenestra extends for around $24 \mathrm{~mm}$ and is slightly concave dorsally, resembling 
207 the condition in several basal archosauriforms (e.g. Proterosuchus fergusi: BSPG 1934 VIII 514,

208 RC 96, SAM-PK-11208; Fugusuchus hejiapanensis: Cheng, 1980, fig. 22; Erythrosuchus

209 africanus: $\mathrm{BP} / 1 / 5207)$. As a result, the horizontal process increases slightly in height posterior to

210 the anterior border of the antorbital fenestra. Beyond this point the ventral margin of the

211 antorbital fenestra is broken, so that the maxilla appears to generally taper in dorsoventral height

212 towards its posterior end, but the true profile of the maxilla cannot be determined. At its posterior

213 end, above crowns 11-14, the maxilla is slightly thickened below the area of articulation with the

214 lacrimal and jugal, and this thickening extends from anterodorsal to posteroventral. No antorbital

215 fossa is evident on either the main body of the maxilla or the posterior surface of the base of the

216 ascending process, similar to the condition in Proterosuchus fergusi (BSPG 1934 VIII 514, RC

217 96, SAM-PK-11208), Kalisuchus rewanensis (NM QR 3570) and Fugusuchus hejiapanensis

218 (Cheng 1980, fig. 22). In Chalishevia cothurnata (PIN 4366/1) and Shansisuchus shansisuchus

219 (IVPP V2501, V2503), by contrast, a well-developed antorbital fossa is present on the base of

220 the ascending process and horizontal process. An antorbital fossa is also present in

221 Erythrosuchus africanus (BP/1/5207), but is less extensive.

222 A number of circular foramina pierce the lateral surface of the maxilla. A row of small,

223 irregularly spaced nutrient foramina, seven of which are clearly identifiable although it seems

224 possible that nine or more were present originally, occurs approximately $10 \mathrm{~mm}$ above the

225 alveoli. These foramina are positioned in a single row aligned roughly parallel to the tooth row.

226 The anteriormost foramen is positioned above crown 2 and the posteriormost above crown 9 , the

227 latter opening mainly posteriorly. The other foramina open laterally and ventrally, and in several

228 cases give rise to short grooves that extend ventrally toward the tooth row, resembling the

229 condition in Erythrosuchus africanus, Garjainia prima and Chalishevia cothurnata (Ezcurra, 
230 2016). An additional small foramen is positioned immediately below the concave anterodorsal

231 margin of the anterior process, and yet another lies dorsal to the main row of foramina and below

232 the ascending process at the anteroposterior level of alveolus 3, opening anteroventrally. The

233 texture of the lateral surface of the maxilla is notably rugose, and the rugosity is best developed

234 below the antorbital fenestra and the posterior edge of the base of the ascending process. This

235 rugose texture includes a number of dorsally or posterodorsally trending grooves that emanate 236 from the row of nutrient foramina.

237 The majority of the medial surface of the main body of the maxilla is dorsoventrally

238 convex, resulting in transverse thickening of the maxilla. A thickened ridge extends dorsally

239 from the main body onto the posterior half of the medial surface of the ascending process.

240 Anterior to this thickened ridge, the ascending process forms a transversely compressed and

241 laterally offset sheet, resembling the condition in other archosauriforms (e.g. Kalisuchus

242 rewanensis: QM F8998). Most of this anterior sheet is currently missing, but as figured by Peng

243 (1991, fig. 1B) its medial surface appears to have lacked the deep, well-rimmed fossa present in

244 several eucrocopodan archosauriforms (e.g. Euparkeria capensis: SAM-PK-K6050; Gow, 1970;

245 Teleocrater rhadinus: Nesbitt et al., 2017; Asilisaurus kongwe: Nesbitt et al., 2017; Silesaurus

246 opolensis: ZPAL Ab III/361/26). A similar, transversely compressed and laterally offset sheet is

247 present posterior to the ascending process, forming the dorsal part of the main body of the

248 maxilla, and bounding the antorbital fenestra ventrally. There are no foramina visible on the

249 medial surface, and the palatal process is broken at its base. The preserved portion of the palatal

250 process is situated immediately above the bases of the interdental plates, resembling the

251 condition in several other archosauriforms (e.g. Proterosuchus goweri: NM QR 880;

252 “Chasmatosaurus" yuani: IVPP V36315; Kalisuchus rewanensis: QM F8998; Garjainia prima: 
253 PIN 2394/5; Euparkeria capensis: SAM-PK-6050). By contrast, this process is placed distinctly

254 dorsal to the alveolar margin and adjacent to the anterodorsal margin of the bone in

255 Erythrosuchus africanus (BP/1/4680, SAM-PK-K1098), Asperoris mnyama (NHMUK PV

256 R36615) and several archosaurs (e.g. Yarasuchus deccanensis: ISIR 334-2; Teleocrater

257 rhadinus: Nesbitt et al., 2017; Batrachotomus kupferzellensis: SMNS 52970; Herrerasaurus

258 ischigualastensis: PVSJ 53). The posterior end of the horizontal process is considerably

259 thickened, and possesses a strongly dorsoventrally convex medial surface. A cluster of

260 anterodorsally-to-posteroventrally oriented thin ridges occurs immediately above the bases of the

261 interdental plates, at the level of the sixth to ninth alveoli. This striated surface represents the

262 facet for reception of the posterolateral process of the palatine. The posterior tip of the horizontal

263 process is also covered with a series of thin ridges. In this case, however, the ridges are

264 longitudinal and mark the area of contact with the lateral process of the ectopterygoid, as also

265 occurs in various other saurian reptiles (e.g. Gephyrosaurus bridensis: Evans, 1980;

266 Trilophosaurus buettneri: Spielmann et al., 2008; Rhynchosaurus articeps: NHMUK PV R1236;

267 Garjainia prima: PIN 2394/5; Chanaresuchus bonapartei: PULR 07; Doswellia kaltenbachi:

268 USNM 214823; Parasuchus angustifrons: BSPG 1931 X 502). Dorsal to the thickening of the

269 posterior end of the horizontal process there is a very deep, longitudinal groove that received the

270 jugal and possibly also the lacrimal if the jugal did not participate in the border of the antorbital

271 fenestra. The position of this facet suggests that the antorbital fenestra was relatively long

272 anteroposteriorly.

273 Fourteen teeth were present (assuming that the most anterior preserved crown was the

274 most anterior in the complete specimen), a relatively low maxillary tooth count comparable to

275 those for Garjainia prima (PIN 2394/5: maxillary tooth count 14 or possibly 13), Erythrosuchus 
276 africanus (BP/1/5207: tooth count 11), Chalishevia cothurnata (PIN 4366/1; tooth count 12 or

277 possibly 13), Shansisuchus shansisuchus (Young [1964] described 9 or possibly 10 tooth

278 positions and Wang et al. [2013] described probably 13 teeth) and Euparkeria capensis (Ewer,

279 1965; tooth count 13). By contrast, higher maxillary tooth counts are present in Tasmaniosaurus

280 triassicus (UTGD 54655; >21), Proterosuchus fergusi (BP/1/3993, BSPG 1934 VIII 514, GHG

281231 RC 59, 96, SAM-PK-11208, K140, K10603; tooth count 20-31, depending on ontogenetic

282 stage, Ezcurra \& Butler [2015]), “Chasmatosaurus” yuani (>23 in IVPP V90002 and $\geqslant 29$ in

283 IVPP V2719) and Prolacerta broomi (BP/1/471, Modesto \& Sues, 2004; tooth count 24-25).

284 The largest teeth are situated immediately anterior to the level of the anterior border of the

285 antorbital fenestra, in tooth positions $2-4$. The teeth are all (with the possible exception of crown

286 3) fused to their alveoli by bone of attachment (ankylothecodont tooth implantation), which is

287 covered with fine apicobasally extending striations (Fig. 3). However, it cannot be determined

288 whether the teeth are set in deep sockets, resembling the condition in allokotosaurians (e.g.

289 Azendohsaurus madagaskarensis: Nesbitt et al., 2015; Shringasaurus indicus: Sengupta et al., 290 2017), Prolacerta broomi (Modesto \& Sues, 2004), proterosuchids (e.g. Proterosuchus fergusi:

291 BSPG 1934 VIII 514, RC 59, TM 201), Kalisuchus rewanensis (QM F8998), Garjainia madiba

292 (BP/1/5525) and referred specimens of Garjainia prima (PIN 951/32, 34, 55). By contrast,

293 maxillary tooth implantation appears to be fully thecodont (i.e. deep alveoli and absence of

294 ankylosis) in the holotype of Garjainia prima (PIN 2394/5), Erythrosuchus africanus

295 (BP/1/2529, 4680) and eucrocopodan archosauriforms (Ezcurra, 2016), although computed

296 tomographic (CT) data would be useful to more fully examine implantation in the former two

297 species. Several replacement crowns are visible on the medial surface, above teeth 4, 6, 8 and 10,

298 suggesting an alternating sequence of replacement. The maxillary tooth crowns resemble those 
299 of other carnivorous archosauriforms (e.g. Garjainia prima: PIN 2394/5; Erythrosuchus

300 africanus: NHMUK PV R3592). Crowns are recurved, with their apices positioned distal to the

301 distal margins of their bases, and labiolingually compressed. Fine mesial denticles are present,

302 but are poorly preserved in most cases and appear to be restricted to the apical $30-40 \%$ of the

303 crown. The distal denticles are generally better preserved, and appear to extend along almost the

304 entire distal margin. The denticles have a rectangular outline in labial or lingual view. Enamel

305 wrinkles and blood grooves are absent.

306

307 Nasal. An incomplete left nasal is preserved (Fig. 5; Supplementary Material), and is $133 \mathrm{~mm}$

308 long anteroposteriorly as preserved. The nasal is missing the anterior tip, a substantial posterior

309 portion including the contacts with the frontal and probably also the prefrontal, and parts of the

310 lateral margin, but does not appear to have sustained any damage since its original description by

311 Peng (1991). The nasal is an anteroposteriorly elongated and transversely narrow bone with a

312 straight, slightly dorsoventrally thickened medial margin bearing a groove for articulation with

313 the opposite element. The external surface of the nasal can be divided into distinct medial and

314 lateral parts with different orientations. The medial division is a largely dorsally facing surface

315 that formed much of the anterior part of the skull roof. This surface has a gentle transverse

316 convexity along most of its length, but at its posterior end becomes flattened to slightly

317 transversely concave. The skull roof surface is notably rugose along most of its length,

318 resembling the condition in Garjainia prima (PIN 2394/5), but being considerably less strongly

319 sculptured than in Asperoris mnyama (Nesbitt et al., 2013). The dorsally exposed part of the

320 nasal is broadest posteriorly ( $23 \mathrm{~mm}$ wide) and tapers gradually towards the anterior end of the

321 element ( $15 \mathrm{~mm}$ wide above the facet for the postnarial process of the premaxilla). At the 
322 anterior end a narrow groove is present on the dorsal surface of the nasal adjacent to the midline.

323 This feature may represent the articular facet for the prenarial process of the premaxilla, as

324 occurs in other basal archosauriforms (e.g. "Chasmatosaurus" yuani: IVPP V36315;

325 Erythrosuchus goweri: Gower, 2003; Rhadinosuchus gracilis: Ezcurra et al., 2014).

326 The lateral part of the external surface of the nasal forms the dorsal part of the lateral wall

327 of the preorbital part of the skull, and thus would have faced mostly laterally and slightly

328 dorsally. At the anterior end a small part of the posterodorsal margin of the external naris is

329 preserved. Posteroventral to this, the external surface of the nasal between the external naris and

330 the facet for the postnarial process of the premaxilla is gently concave. This concavity runs

331 parallel to the facet for the postnarial process and is terminated posterodorsally by a short

332 anteroposteriorly extending series of three knob-like rugosities (Fig. 4D) that are not present in

333 Chalishevia cothurnata (PIN 4366/1), Shansisuchus shansisuchus (Young, 1964; Wang et al.,

334 2013), Garjainia prima (PIN 2394/5) or Erythrosuchus africanus (BP/1/5207; NM QR 1473;

335 NHMUK PV R3592). Accordingly, this condition appears to be an autapomorphy of

336 Guchengosuchus.

337 Posteroventral to this concavity is the posterodorsally tapering facet for the postnarial

338 process of the premaxilla. This facet is deepest anterodorsally, and becomes shallower

339 posteroventrally. The facet is relatively narrow, suggesting that the postnarial process was also

340 relatively narrow at its tip as in Chalishevia cothurnata (PIN 4366/1), Shansisuchus

341 shansisuchus (Wang et al., 2013) and Erythrosuchus africanus (BP/1/5207). By contrast, in

342 Garjainia prima the distal tip of the postnarial process of the premaxilla is comparatively broad

343 (PIN 2394/5). Posteroventrally, a very narrow, almost flat surface, representing the lateral

344 exposure of the descending process of the nasal, separates the facet for reception of the postnarial 
345 process of the premaxilla from the facet for reception of the ascending process of the maxilla

346 (see Ezcurra, 2016, character 81). A similarly narrow descending process is present in

347 Erythrosuchus africanus (BP/1/5207) and several other archosauriforms (e.g. Asperoris mnyama:

348 NHMUK PV R36615; Euparkeria capensis: SAM-PK-5867; Turfanosuchus debanensis: IVPP

349 V3237; Gracilisuchus stipanicicorum: MCZ 4117). By contrast, the descending process of the

350 nasal is anteroposteriorly very broad in Garjainia prima (PIN 2394/5), Shansisuchus

351 shansisuchus (Young, 1964; Wang et al., 2013) and Chalishevia cothurnata (PIN 2867/7).

352 Posterior to the descending process of the nasal there is a diagonal ridge, anteroventrally

353 oriented, which delimits anteriorly the facet for reception of the ascending process of the maxilla.

354 This facet becomes deeper posteriorly. As a result, the facet for reception of the ascending

355 process of the maxilla is a medially inset, transversely compressed, ventrally descending sheet of

356 bone situated slightly posterior to the facet for the postnarial process of the premaxilla. This

357 surface for the maxilla is broken posteriorly. The posteriormost preserved part of the lateral

358 margin of the nasal is grooved, perhaps for contact with the lacrimal. The internal surface of the

359 nasal is transversely concave, with no notable ridges or foramina present.

360

361 Frontal. The frontals are largely intact and preserved as part of the articulated section of skull

362 roof, but their anterior ends are missing (Figs 6, 7; see also Supplementary Material). The pair of

363 frontals is considerably anteroposteriorly longer than wide, as occurs in Prolacerta broomi

364 (BP/1/471), Teyujagua paradoxa (Pinheiro et al., 2016), Proterosuchus fergusi (RC 59, 96,

365 BP/1/3993, SAM-PK-K10603), Tasmaniosaurus triassicus (Ezcurra, 2014; UTGD 54655),

366 Fugusuchus hejiapanensis (Cheng, 1980: fig. 22), Erythrosuchus africanus (Gower, 2003;

367 NHMUK PV R3592, NM QR 1473), Shansisuchus shansisuchus (Young, 1964, figs. 1-6) and 
368 Euparkeria capensis (SAM-PK-5867). By contrast, the paired frontals are wider than long in

369 Garjainia prima (PIN 2394/5). The dorsal surface of the most anteriorly preserved region of the

370 frontal bears a few low longitudinal ridges. The facets for articulation with the prefrontals are not

371 well preserved but may be situated at the anterolateral corners of the preserved portion of the

372 frontals. The absence of a facet on the lateral surface of the frontal indicates that the bone

373 contributed extensively to the dorsal border of the orbit, resembling the condition in most early

374 archosauromorphs (e.g. Prolacerta broomi: BP/1/471; Proterosuchus fergusi: RC 96, BP/1/3993,

375 SAM-PK-K10603; “Chasmatosaurus” yuani: IVPP V4067; Sarmatosuchus otschevi: Gower \&

376 Sennikov, 1997; Euparkeria capensis (SAM-PK-5867). By contrast, in other erythrosuchids the

377 contribution of the frontal to the dorsal border of the orbit is very restricted or absent

378 (Fugusuchus hejiapanensis: Cheng, 1980; Garjainia prima: PIN 2394/5; Erythrosuchus

379 africanus: Gower, 2003, NHMUK PV R3592, NM QR 1473; Shansisuchus shansisuchus: IVPP

380 V2504, Young, 1964, fig. 5, Wang et al., 2013, fig. 2). The orbital margin of the frontal becomes

381 dorsoventrally thicker posteriorly, towards the contact with the postfrontal. The dorsal surface of

382 the frontal adjacent to the orbital border is slightly dorsally inflated and has several very thin and

383 low striations oriented perpendicular to the margin of the bone. A second dorsally inflated area is

384 situated on the midline of the skull roof on the posterior half of the paired frontals. The inflated

385 area ends posteriorly at a point well anterior to the suture between the frontals and parietals, and

386 bears a rugose ornamentation. This inflated area closely resembles in morphology and position

387 an equivalent feature in Garjainia prima (PIN 2394/5), but is flanked laterally by a pair of

388 moderately deep depressions. By contrast, no inflated median area is present in Prolacerta

389 broomi (Modesto \& Sues, 2004), Proterosuchus fergusi (RC 59, 96, BP/1/3993, SAM-PK-

390 K10603), “Chasmatosaurus” yuani (IVPP V4067), Fugusuchus hejiapanensis (Cheng, 1980), 
391 Erythrosuchus africanus (Gower, 2003, NHMUK PV R3592, NM QR 1473), Shansisuchus

392 shansisuchus (IVPP V2504, V2508) or Euparkeria capensis (SAM-PK-5867). In

393 Guchengosuchus shiguaensis the inflated area terminates anteriorly at a median depression. The

394 inflated areas on the midline and adjacent to the orbital border define a shallow concavity on the

395 frontal that becomes slightly deeper anteriorly.

396 The dorsal surface of the posterolateral corner of the frontal possesses a subtriangular

397 depression that extends posteriorly onto the parietal and is well delimited anteriorly by a

398 transverse tuberosity. Posteriorly, the paired frontals do not enclose a pineal fossa, contrasting

399 with the condition in Garjainia prima (PIN 2394/5) and some specimens of Erythrosuchus

400 africanus (BP/1/5207, NM QR 1473, NHMUK PV R3592), and they meet the parietals along a

401 suture that is poorly interdigitated medially. The parietals form a median, short subrectangular

402 projection that extends anteriorly between the frontals. The lateral portion of the frontoparietal

403 suture is strongly convex posteriorly, creating a posterior projection of the frontal resembling

404 that present in Shansisuchus shansisuchus (IVPP V2508). The posterolateral corner of the frontal

405 forms a laterally convex suture with the parietal and postfrontal, excluding contact between the

406 frontal and the postorbital.

407 The ventral surface of the frontal displays a large and slightly concave orbital depression,

408 which forms most of the roof of the orbit. This depression extends posteriorly onto the

409 postfrontal. The olfactory tract extends anteroposteriorly between the orbital depressions, from

410 which it is separated by distinct ridges (the crista cranii), and is hourglass-shaped. The olfactory

411 tract opens anteriorly into a recess for the olfactory bulbs of the anterior brain, which is

412 considerably anteroposteriorly longer than wide and laterally delimited by a ridge, as also occurs

413 in other early archosauromorphs (e.g. Shringasaurus indicus: ISIR 781, 789, 790; Prolacerta 
414 broomi: BP/1/2675; Tasmaniosaurus triassicus: Ezcurra, 2014; Sarmatosuchus otschevi: PIN

$4152865 / 68)$. The latter ridge and the ridge that defines the anterior limit of the orbital depression

416 bound a concave area at the anterolateral corner of the ventral surface of the frontal that is also

417 present in some other basal archosauriforms (e.g. Tasmaniosaurus triassicus: Ezcurra, 2014;

418 Sarmatosuchus otschevi: PIN 2865/68). This condition differs from that in other erythrosuchids

419 (e.g. Garjainia prima: Huene, 1960; Erythrosuchus africanus: Gower, 2003, NHMUK PV

420 R3592, NM QR 1473; Shansisuchus shansisuchus: Young, 1964), in which there is a median

421 longitudinal canal for the passage of the olfactory tract but no olfactory bulb impression bounded

422 by a distinct, semilunate, posteromedially-to-anterolaterally oriented ridge. On the ventral

423 surface of the skull roof, the suture between the frontal and the postfrontal is clearly visible on

424 the left side but the frontoparietal suture is only partially discernible, being evident within the left

425 facet for reception of the capitate process of the laterosphenoid and near the mid-line at the

426 posterior end of the olfactory tract. The frontal forms most of the surface of the facet for

427 reception of the capitate process. This facet is anteromedially very well delimited by a deep shelf

428 that also forms the posterior border of the orbital depression, and anterolaterally defined by the

429 posterior margin of the postfrontal.

430

431 Postfrontal. Both postfrontals are preserved in articulation with the frontal and parietal (Figs 6,

432 7; see also Supplementary Material), but they are lacking their ventral processes. The suture

433 between the postfrontal and frontal is mainly anteroposteriorly oriented and slightly medially

434 concave in dorsal view, closely resembling the condition in Garjainia prima (PIN 2394/5),

435 Shansisuchus shansisuchus (IVPP V2508) and Erythrosuchus africanus (NHMUK PV R3592).

436 This suture is V-shaped on the ventral surface of the skull roof of Guchengosuchus shiguaiensis. 
437 The postfrontal forms the posterodorsal corner of the orbit, and the ventral surface of the bone

438 forms the posterior end of the orbital depression and is therefore slightly concave. The dorsal

439 surface of the bone is slightly convex, and ornamented with low rugosities.

440

441 Parietal. The parietal possesses an anterolaterally projecting process that forms the anterior

442 border of the supratemporal fenestra and articulates with the frontal and postfrontal (Figs 6, 7;

443 see also Supplementary Material). The lateral end of this process is damaged. The dorsal surface

444 of the base of the anterolateral process is occupied by a subtriangular fossa that extends onto the

445 frontal. This feature does not represent an extension of the supratemporal fossa, being well

446 separated from the border of the supratemporal fenestra by a raised edge adjacent to this opening.

447 The medial border of the fossa is anteroposteriorly oriented, but poorly defined. To our

448 knowledge, no similar fossa is present in other early archosauriforms. The dorsal surface of the

449 parietals lacks a pineal fossa, as in some specimens of Proterosuchus fergusi (RC 59, BP/1/4016,

450 4224; Ezcurra \& Butler, 2015) and in Euparkeria capensis (Ewer, 1965). By contrast, a pineal

451 fossa is present in the skull roof of Erythrosuchus africanus (BP/1/5207, NM QR 1473,

452 NHMUK PV R3592), Garjainia prima (PIN 2394/5), Shansisuchus shansisuchus (Young, 1964;

453 IVPP V2501, V2504, V2508), Proterosuchus alexanderi (NM QR 1484), Proterosuchus goweri

454 (NM QR 880) and some specimens of Proterosuchus fergusi (BP/1/3993, SAM-PK-K9957,

455 SAM-PK-K10603, RC 96, TM 201, GHG 231). The supratemporal fossa is not dorsally exposed,

456 being restricted to the lateral and anterolateral borders of the supratemporal fenestra, but is

457 dorsoventrally very deep. The posterior margin of the paired parietals forms a thick transverse

458 eminence, as also occurs in other archosauromorphs (e.g. Prolacerta broomi, Proterosuchus

459 fergusi, Garjainia prima) (Müller, 2004; Ezcurra, 2016). The posterolateral process of the 
460 parietal is posterolaterally directed at an angle of about $50^{\circ}$ to the midline of the skull. The

461 posterior eminence of the parietal continues onto the dorsal surface of the posterolateral process

462 of the bone as a moderately low vertical flange, resembling the condition in Prolacerta broomi

463 (BP/1/471), Teyujagua paradoxa (UNIPAMPA 653 cast), Proterosuchus fergusi (SAM-PK-

464 K10603), Fugusuchus hejiapanensis (GMB V 313 photographs), Shansisuchus shansisuchus

465 (Young, 1964, fig. 6) and Euparkeria capensis (SAM-PK-5867). By contrast, the posterolateral

466 process acquires a wing-like appearance in occipital view with a strongly convex dorsal margin

467 in Garjainia prima (PIN 2394/5) and Erythrosuchus africanus (Gower, 2003, NM QR 1473,

468 NHMUK PV R3592). The posterior surface of the posterolateral process has a dorsoventrally

469 concave curvature that deepens medially, terminating in a moderately deep, posteriorly opening

470 fossa at the base of the process. It is not possible to determine whether the posterior surface of

471 the process bears a tuberosity as in Erythrosuchus africanus (Gower, 2003). The anterior surface

472 of the posterolateral process possesses a longitudinal, thick ridge. Above the ridge, the surface of

473 the bone is slightly dorsoventrally concave, and below it there is a gently concave surface that

474 represents the ventrally facing facet for the medial process of the squamosal. The facet for the

475 squamosal possesses a number of low, poorly developed longitudinal ridges.

476 The ventral surface of the parietals possesses a deep concavity on the midline of the skull

477 roof, representing the impression of the cerebrum. The concavity is laterally delimited by a thick

478 tuberosity that separates it from the facet for reception of the capitate process of the

479 laterosphenoid, as occurs in other archosauriforms (e.g. Tasmaniosaurus triassicus: Ezcurra,

480 2014; Erythrosuchus africanus: Gower, 2003; NM QR 1473). The ventral surface of the

481 anterolateral process of the parietal forms part of the posterior end of the facet for reception of

482 the laterosphenoid. The ventral surface of the posterolateral process is rugose, and articulated 
483 with the dorsolateral margin of the supraoccipital and the base of the paroccipital process.

484 Because the left posterolateral process of the parietal is missing and the ventral margin of the 485 distal half of the right process is broken, it is not possible to determine whether a post-temporal 486 opening was originally present.

487

488 Interparietal. It is not possible to discern a suture between the parietals and the interparietal, 489 assuming that the latter bone is present. A thickened region on the posterior surface of the skull

490 roof might represent an interparietal, as occurs in other basal archosauriforms (e.g.

491 Proterosuchus alexanderi: Cruickshank, 1972; Erythrosuchus africanus: Gower, 2003).

493 Supraoccipital. The supraoccipital is preserved in articulation with the otoccipital and the prootic 494 (Fig. 8; see also Supplementary Material). A sharp median vertical ridge extends ventrally across 495 the occipital surface of the supraoccipital from the posterior border of the skull roof, gradually 496 becoming lower in the ventral direction and eventually fading out entirely. A similar ridge is also 497 present in Shansisuchus shansisuchus (Gower \& Sennikov, 1996), but is absent in Proterosuchus 498 fergusi (SAM-PK-K10603), Fugusuchus hejiapanensis (Gower \& Sennikov, 1996), 499 Erythrosuchus africanus (BP/1/4645) and referred specimens of Garjainia prima (e.g. PIN $500951 / 60$ ). The occipital surface of the supraoccipital is concave lateral to the median ridge and 501 becomes flat to gently convex towards the lateral margin of the bone, which is situated at the 502 base of the paroccipital process. The suture between the supraoccipital and the otoccipital is 503 discernible as a low shelf with a dorsolateral-ventromedial orientation. It is not possible to 504 determine whether the supraoccipital contributes to the dorsal border of the foramen magnum or 505 is excluded by a median contact between the otoccipitals. The midline portion of the dorsal 
506 surface of the supraoccipital forms a convex articular surface for contact with the ventral surface

507 of the parietals. The lateral half of the dorsal surface of the supraoccipital has a rugose articular

508 facet for the ventral surface of the base of the posterolateral process of the parietal. The anterior

509 surface of the supraoccipital is strongly transversely concave, and articulates dorsolaterally with

510 the prootic and ventrolaterally with the otoccipital.

511

512 Otoccipital (opisthotic + exoccipital). The left otoccipital is largely intact (Figs 8, 9; see also

513 Supplementary Material), but is missing the ventral ramus of the opisthotic and most of the

514 peduncle that forms the lateral wall of the foramen magnum. Only the base of the right

515 otoccipital is preserved, most of the paroccipital process having broken away. The otoccipital

516 forms at least the dorsolateral border of the foramen magnum. The posterior surface of the base

517 of the paroccipital process bears a semi-circular, moderately deep depression on the posterior

518 surface, as in Garjainia prima (PIN 2394/5, 951/60), Garjainia madiba (Gower et al., 2014;

519 BP/1/5760), Fugusuchus hejiapanensis (Gower \& Sennikov, 1996: fig. 4b), Erythrosuchus

520 africanus (Gower, 1997; UMZC T700) and Sarmatosuchus otschevi (Gower \& Sennikov, 1997).

521 The paroccipital process is mainly posterolaterally directed, but also trends slightly ventrally.

522 The ventral margin of the base of the paroccipital process would originally have been situated

523 above the level of the dorsal margin of the occipital condyle. The occipital surface of the

524 paroccipital process is dorsoventrally convex. The distal end of the process is not dorsoventrally

525 expanded and bears a rounded, asymmetric lateral margin whose lateralmost point lies ventral to

526 the mid-height of the process, resembling the condition in other early archosauriforms (e.g.

527 Fugusuchus hejiapanensis: Gower \& Sennikov, 1996; Sarmatosuchus otschevi: Gower \&

528 Sennikov, 1997; Garjainia prima: PIN 2394/5). The dorsal surface of the paroccipital process is 
529 rugose. The anterior surface of the base of the paroccipital process articulates with the posterior

530 process of the prootic. The lateral half of the anterior surface of the paroccipital process is

531 weakly dorsoventrally convex, but the distal end of the anterior surface bears a shallow

532 concavity for a loose contact with the posterior surface of the squamosal. The posteroventral

533 margin of the paroccipital process is thin and sharp along its entire length.

534 The proximal half of the paroccipital process has a thin but well-developed ridge that 535 extends distally from the base of the ventral ramus of the opisthotic and delimits the stapedial 536 groove posteromedially. Only the base of the ventral ramus of the opisthotic, which divides the

537 fenestra ovalis from the anteroposteriorly narrower metotic foramen, is preserved. The ventral

538 ramus of the opisthotic expands slightly anteroposteriorly towards its ventral extremity. The

539 facets for reception of the basioccipital are not preserved.

540

541 Prootic. The left prootic is almost completely preserved (Figs 8, 9; see also Supplementary

542 Material), but lacks the distal tip of the posterior process and most of the lower anterior process

543 that would border the opening for the passage of the trigeminal nerve (cranial nerve V). Only a

544 severely damaged portion of the right prootic is preserved. The posterior process of the prootic

545 tapers posteriorly and participates in forming the base of the paroccipital process, articulating

546 with the anterior surface of the otoccipital. The lateral surface of the posterior process is

547 dorsoventrally convex. A well-developed prootic crest extends posteriorly from the anteroventral

548 corner of the prootic and forms the anterolateral wall of the stapedial groove. The prootic crest

549 decreases in height posteriorly, and eventually merges into the anterior surface of the paroccipital

550 process. The lateral surface of the prootic crest has a ventrally curved groove that is filled with

551 matrix and probably accommodated the hyomandibular branch of the facial nerve (cranial nerve 
552 VII), as in other basal archosauriforms (e.g. Sarmatosuchus otschevi: Gower \& Sennikov, 1997;

553 Fugusuchus hejiapanensis: Gower \& Sennikov, 1996). Immediately dorsal to this groove is a

554 second groove that curves gently dorsally and is anteriorly directed towards the border of the

555 foramen for the passage of the trigeminal nerve. A corresponding groove is present in

556 Sarmatosuchus otschevi (Gower \& Sennikov, 1997).

557 The prootic forms the posterodorsal, posterior and posteroventral borders of the

558 trigeminal foramen, and the upper anterior process of the prootic possesses on its dorsal surface a

559 deeply recessed articular surface to receive the laterosphenoid. The lateral surface of the upper

560 anterior process of the prootic has a thin and very low posteroventrally directed ridge, as in

561 Shansisuchus shansisuchus (Gower \& Sennikov, 1996). A thin, sharp, posteroventrally aligned

562 ridge is also present on the lateral surface of the lower anterior process of the prootic. This ridge

563 curves slightly ventrally and may represent the upper limit of the area of origination of the

564 protractor pterygoideus muscle (Gower \& Sennikov, 1996), showing a very similar morphology

565 and position to an equivalent feature in Sarmatosuchus otschevi (Gower \& Sennikov, 1997),

566 Fugusuchus hejiapanensis (Gower \& Sennikov, 1996) and Garjainia prima (Gower \& Sennikov,

567 1996; PIN 2394/5). The ventral surface of the lower anterior process of the prootic bears a

568 rugose, subrectangular articular surface to receive the clinoid process of the parabasisphenoid.

569 The broad separation between the upper and lower anterior processes of the prootic indicates that

570 the laterosphenoid participated extensively in the border of the trigeminal foramen, as occurs in

571 several other early archosauriforms (e.g. Proterosuchus fergusi: Cruickshank, 1972, BP/1/3993;

572 Proterosuchus goweri: NM QR 880; Proterosuchus alexanderi: NM QR 1484; Sarmatosuchus

573 otschevi: Gower \& Sennikov, 1997, PIN 2865/68; Erythrosuchus africanus: Gower, 1997,

574 UMZC T700; Shansisuchus shansisuchus: Gower \& Sennikov, 1996, fig. 6b). By contrast, the 
575 lower and upper anterior processes of the prootic closely approach each other anterior to the

576 trigeminal foramen in Fugusuchus hejiapanensis (Gower \& Sennikov, 1996) and contact each

577 other in Garjainia prima and probably a referred specimen of Erythrosuchus africanus (Gower

578 \& Sennikov, 1996; Gower 1997). This condition results in the laterosphenoid being nearly or

579 completely excluded from the border of the trigeminal foramen.

580 The medial surface of the prootic possesses a complex topography (Fig. 9A; see also

581 Supplementary Material). The fenestra ovalis opens medially into the deep inner ear chamber.

582 The medial surface of the lower anterior process has a large circular foramen that opens

583 ventromedially and probably represents the passage of the cranial facial nerve. On the medial

584 surface of the base of the upper anterior process is a large and moderately deep subcircular fossa

585 that represents the auricular recess. The recess seems to be subdivided by an anterodorsally

586 oriented ridge, but this might be an artefact of damage to the bone surface in the dorsal half of

587 the recess. The morphology of the area that bears the auricular recess and internal ear chamber is

588 consistent with that observed in Erythrosuchus africanus (Gower, 1997).

589

590 Pterygoid. The left pterygoid was originally relatively complete (Figure 4B; Peng 1991:pl. 1.8;

591 see also Supplementary Material), but now only a fragment of the anterior process is preserved

592 (Fig. 10). This includes a medially placed, transversely compressed, dorsally-extending sheet,

593 which expands in dorsoventral height anteriorly; a near-horizontal, dorsoventrally compressed

594 sheet that expands transversely towards its anterior end; and a small part of the sheet of bone that

595 would have connected the horizontal sheet to the ventrolateral process. The ventral surface of the

596 anterior process of the pterygoid is transversely convex and the dorsal surface transversely

597 concave. No teeth are visible on the preserved fragment, consistent with Peng's (1991) statement 
598 that palatal teeth were absent. The pterygoids of Erythrosuchus africanus (Gower, 2003),

599 Uralosaurus magnus (PIN 2973/70), Shansisuchus shansisuchus (Young, 1964, fig. 15a) and the

600 holotype of Garjainia prima (PIN 2394/5) also lack palatal teeth, but a referred specimen of

601 Garjainia prima possesses two anteroposteriorly short rows of palatal teeth that extend onto the 602 palatine (PIN 951/18).

603 The portions of the pterygoid of Guchengosuchus shiguaiensis that are no longer 604 preserved (Peng, 1991, pl. 1.8) resembled the corresponding parts of the bone in several other 605 early archosauriforms. The anterior process of the pterygoid was transversely broad along its 606 entire length, as occurs in the vast majority of non-pseudosuchian archosauromorphs (Ezcurra, 607 2016). The ventrolateral process was distinctly posteriorly oriented, as in Proterosuchus fergusi 608 (RC 59, SAM-PK-11208), Proterosuchus alexanderi (NM QR 1484), “Chasmatosaurus" yuani 609 (IVPP V4067), Sarmatosuchus otschevi (PIN 2865/68), Garjainia prima (PIN 2394/5) and 610 Erythrosuchus africanus (NHMUK PV R3592).

611

612 Mandible. The right articular and the posterior part of the right surangular are present and

613 preserved in articulation (Fig. 11; see also Supplementary Material). No fragments of the angular

614 appear to be present. The anterior end and posterior tip of the surangular are missing and the

615 ventral margin is damaged over most of its length. The medial surface of the surangular, which 616 forms the lateral wall of the adductor fossa, is mostly obscured by sediment. The lateral surface 617 of the surangular is relatively flat but is badly cracked, with no clear foramina visible. The dorsal 618 margin of the surangular anterior to the glenoid is gently convex in lateral view and laterally 619 expanded to form a shelf that overhangs the rest of the lateral surface of the surangular, 620 resembling the condition in some other archosauriforms (e.g. "Chasmatosaurus" yuani: IVPP 
621 V4067; Euparkeria capensis: SAM-PK-5867; Youngosuchus sinensis: IVPP V3239). This shelf

622 is better developed and has a more convex lateral edge in Garjainia prima (PIN 2394/5, 951/46),

623 Erythrosuchus africanus (NHMUK PV R3592), Shansisuchus shansisuchus (Young, 1964),

624 proterochampsids (e.g. Chanaresuchus bonapartei: PULR 07), and some pseudosuchians (e.g.

625 Tarjadia ruthae: Ezcurra et al., 2017; Riojasuchus tenuisceps: Baczko \& Desojo, 2016). The

626 dorsal surface of this shelf is very gently concave transversely, being dorsoventrally thickened at

627 its lateral and medial margins. The soft tissue that covered this concavity received the ventral

628 surface of the lower temporal bar and its associated soft tissue during full occlusion of the lower

629 jaw. More posteriorly the surangular forms the lateral margin of the glenoid and laterally

630 overlaps the articular. The anterior border of the glenoid is not very well preserved, but seems to

631 be low with a rugose dorsal surface. The posterior border of the glenoid is considerably higher

632 than the anterior border, and is formed primarily by the articular but incorporates a small

633 contribution from the surangular. The suture between the surangular and the articular is very

634 clear posterior to the glenoid fossa, but is not discernible on the glenoid articular surface.

635 The posteriormost part of the surangular is broken away, but would have formed at least

636 part of the lateral surface of the retroarticular process. Most of the medial side of the surangular

637 is obscured by sediment, but a ventromedially directed flange is partially visible. The posterior

638 margin of this flange would have articulated with the articular and formed the anterior margin of

639 the glenoid.

640 The articular forms most of the glenoid fossa and the retroarticular process. Almost all of

641 the articular is artificially compressed and displaced, such that the glenoid fossa faces mainly

642 medially. As a result of this distortion and the loss of the angular, the medial projection of the

643 articular is artificially well exposed in lateral view. The glenoid fossa is transversely expanded 
644 and saddle-shaped, with a smaller lateral concavity separated by a low convexity from a larger

645 and deeper medial concavity. The size discrepancy between the concavities suggests that the

646 medial ventral condyle of the quadrate was considerably transversely wider than the lateral

647 ventral condyle. By contrast, the ventral condyles of the quadrate are subequal in width in

648 Garjainia prima (PIN 2394/5). A raised, posteriorly convex ridge of bone forms the posterior

649 border of the glenoid. This ridge is separated by a deep, smooth concavity from the retroarticular

650 process, as occurs in Proterosuchus fergusi (BSPG 1934 VIII 514), Garjainia prima (PIN

651 2394/5), referred specimens of Garjainia prima (PIN 951/33), and Garjainia madiba (NM QR

652 3051). The retroarticular process is relatively short and not upturned at its distal end, resembling

653 the condition in Erythrosuchus africanus (Gower, 2003) and Garjainia prima (PIN 2394/5). The

654 medial surface of the retroarticular process displays the broken base of a dorsomedial projection.

655 Behind the medial part of the posterior margin of the glenoid fossa is a ventromedial process that

656 extends a very short distance medial to the medial edge of the fossa in dorsal view. An

657 anteroposteriorly extending ridge on the ventral surface of the articular separates the facet for the

658 angular on the ventrolateral surface from the facet for the prearticular on the ventromedial

659 surface. The foramen for the passage of the chorda tympani is not preserved. The lateral surface

660 of the retroarticular process is dorsoventrally concave and would have been covered by the

661 posterior tip of the surangular.

662

663 Vertebrae. Peng (1991) originally listed three cervical, six dorsal and three caudal vertebrae as

664 present in the type specimen. Only two cervical vertebrae (the only vertebrae that were figured

665 by Peng, 1991, fig. 5, pl. 2.1, 2.2) are now present (Figs 12-15; see also Supplementary

666 Material), along with a poorly preserved dorsal vertebra and one other vertebral fragment. The 
667 two cervical vertebrae are postaxial but probably from a relatively anterior position within the

668 neck. They were figured in articulation by Peng (1991) and fit together well. In both vertebrae

669 (as well as in the dorsal vertebra) the neurocentral suture appears fused, suggesting that the

670 holotype of Guchengosuchus shiguaiensis does not represent a juvenile individual. Preservation

671 is relatively poor.

672 The first cervical ('cervical a'; Figs 12-14) has a centrum that is anteroposteriorly longer

673 than dorsoventrally high, its length being approximately $150 \%$ of its height, resembling the

674 condition in Teyujagua paradoxa (UNIPAMPA 653 cast), Proterosuchus fergusi (BSPG 1934

675 VIII 514, SAM-PK-11208) and Euparkeria capensis (SAM-PK-5867). By contrast, the cervical

676 centra are only slightly longer than tall in Sarmatosuchus otschevi (PIN 2865/68) and Garjainia

677 prima (PIN 2394/5), and considerably anteroposteriorly shorter than tall in Erythrosuchus

678 africanus (Gower, 2003; SAM-PK-3028) and Shansisuchus shansisuchus (Young, 1964, fig.

679 20e). The ventral margin of the centrum is strongly concave in lateral view. The centrum is

680 parallelogram-shaped in lateral view, with the anterior articular surface being more dorsally

681 positioned than the posterior one, resembling the condition in several other early

682 archosauromorphs (Ezcurra, 2016). The anterior and posterior articular surfaces of the centrum

683 have oval outlines (although the anterior articular face is broken along its right lateral margin and

684 damaged dorsally and ventrally), being dorsoventrally deeper than transversely wide, and are

685 deeply concave. The oval outlines of the centra may however be exaggerated by post-mortem

686 transverse compression of the elements. The lateral surfaces of the centrum are strongly pinched

687 inwards, giving the centrum an hourglass-like outline in ventral view. The ventral surface of the

688 centrum is flattened but bears a low midline ridge, lateral to which is a shallow,

689 anteroposteriorly-extending furrow that deepens slightly anteriorly below the parapophysis. A 
690 median ventral ridge is also present in the anterior postaxial centra of Sarmatosuchus otschevi

691 (PIN 2865/68), Erythrosuchus africanus (BP/1/4680), Garjainia prima (PIN 2394/5), Prolacerta

692 broomi (BP/1/2675), Proterosuchus fergusi (BSPG 1934 VIII 514) and Euparkeria capensis

693 (SAM-PK-5867). The lateral surface of the centrum is deeply excavated, forming a deep

694 centrodiapophyseal fossa ventral to the inferred position of the neurocentral suture and

695 posteroventral to the diapophysis. This fossa undercuts the ventral surface of the diapophysis.

696 The parapophysis is broken away on the right side, but on the left side is positioned on the

697 anteroventral corner of the centrum and has fused to the capitulum of the cervical rib. There is no

698 indication on either side of a third articular surface for the rib, although this area of the vertebra

699 is not well preserved.

700 The diapophysis is broken away on both sides, but its articular facet would have been set

701 at the end of a ventrolaterally directed process, the base of which is placed approximately on the

702 neurocentral suture, just anterior to the midlength of the centrum. The ventral orientation of the

703 diapophyses is probably exaggerated by post-mortem transverse compression. A well-defined

704 and thick postzygodiapopohyseal lamina arches posterodorsally from the base of the diapophysis

705 to connect to the anterior margin of the postzygapophysis. A low posterior centrodiapophyseal

706 lamina extends posteroventrally from the base of the diapophysis onto the posterodorsal portion

707 of the centrum, forming the posterodorsal wall of the centrodiapophyseal fossa described above.

708 The postzygodiapopohyseal lamina and the weakly developed posterior centrodiapophyseal

709 lamina together frame a postzygapophyseal centrodiapophyseal fossa positioned posterior to the

710 diapophysis and anteroventral to the postzygapophysis, as occurs in the cervical and dorsal

711 vertebrae of several other archosauriforms (e.g. Erythrosuchus africanus: NHMUK PV R3592;

712 Gower, 2001, 2003). This fossa is divided into anterior and posterior parts by an unusual and 
713 likely autapomorphic lamina that extends ventrally from the postzygodiapopohyseal lamina. A

714 low thickening extending from the base of the diapophysis to the underside of the

715 prezygapophysis is in an equivalent position to a prezygodiapophyseal lamina, as in

716 Tanystropheus longobardicus (Wild, 1973, figs. 52-54), Protorosaurus speneri (BSPG 1995 I

717 5), Cuyosuchus huenei (MCNAM 2669), Erythrosuchus africanus (NHMUK PV R3592, Gower,

718 2003), Shansisuchus shansisuchus (Young, 1964, fig. 21) and Euparkeria capensis (UMZC

719 T921). The prezygodiapophyseal lamina of Guchengosuchus shiguaiensis was probably

720 originally placed further laterally to the base of the prezygapophysis before post-mortem

721 compression. Although poorly preserved in this vertebra, this low thickening forms the

722 anteroventral border of a shallow fossa on the lateral wall of the neural canal. This fossa

723 represents a prezygapophyseal centrodiapophyseal fossa. Just ventral to the base of the neural

724 spine, the lateral surface of the neural arch bears another deep fossa, which is bounded by the

725 postzygodiapophyseal lamina, the weakly developed prezygodiapophyseal lamina, and a

726 spinoprezygapophyseal lamina that extends from the posterior margin of the prezygapophysis

727 onto the lateral surface of the neural spine. This is a spinodiapophyseal fossa and resembles the

728 excavation present immediately lateral to the base of the neural spine in the postaxial cervical

729 vertebrae of several other archosauromorphs, such as Protorosaurus speneri (BSPG 1995 I 5 ,

730 cast of WMsNP47361), Eorasaurus olsoni (PIN 156/108-110), Proterosuchus alexanderi (NM

731 QR1484), Vonhuenia fredericki (PIN 1025/11), Garjainia prima (PIN 2394/5), Cuyosuchus

732 huenei (MCNAM PV 2669) and Euparkeria capensis (SAM-PK-5867).

733 The right prezygapophysis is broken away, but the left one is a large triangular process

734 that extends anterodorsally a substantial distance beyond the anterior margin of the centrum. The

735 articular face of the left prezygapophysis is poorly preserved, but faces dorsomedially at a low 
736 angle to the horizontal. The articular facet of the prezygapophysis is oval and almost flat.

737 Between and ventral to the prezygapophyses, the anterior opening of the neural canal is poorly

738 preserved because the dorsal margin of the centrum is broken, but appears to have been

739 subcircular. Posteriorly, the postzygapophyses flare mainly laterally, and project a short distance

740 beyond the centrum; their articular surfaces face ventrolaterally and are sub-circular. Below the

741 postzygapophyses the posterior opening of the neural canal is poorly preserved. A well-

742 developed hyposphene is present ventrally between the postzygapophyses, overhanging the

743 neural canal; anteriorly, the presence of a hypantrum cannot be confirmed due to damage. The

744 hyposphene is formed by medioventral projections of the postzygapophyses and forms the floor

745 of the spinopostzygapophyseal fossa.

746 The neural spine is anteroposteriorly broad and set above the posterior $80 \%$ of the

747 centrum, resembling the condition in Sarmatosuchus otschevi (PIN 2865/68), Teyujagua

748 paradoxa (UNIPAMPA 653 cast), Garjainia prima (PIN 2394/5), some specimens of

749 Proterosuchus fergusi (BSPG 1934 VIII 514; SAM-PK-11208) and Euparkeria capensis (SAM-

750 PK-5867). The spine is inclined slightly anteriorly, an unusual condition among early

751 archosauromorphs that also occurs in the anterior postaxial cervical vertebrae of Proterosuchus

752 alexanderi (NM QR 1484) and some specimens of Proterosuchus fergusi (GHG 231). The neural

753 spine expands anteroposteriorly towards its apex, the degree of expansion being greater in the

754 anterior direction. The distal third of the spine also forms a strong transverse expansion, which is

755 strongly rugose and dorsally convex. This rugose transverse expansion is well developed

756 ventrally, extending along the distal third of the neural spine. This feature is also present in

757 several isolated neural spines from the Lower Triassic Rewan Formation of Queensland

758 (Thulborn, 1979; QM F10125) and the aphanosaurian avemetatarsalians Teleocrater rhadinus 
759 (Nesbitt et al., 2018) and Yarasuchus deccanensis (ISIR 334). Anterior to the base of the spine is

760 a well-developed spinoprezygapophyseal fossa bounded laterally by the prezygapophyses and

761 dorsolaterally by the spinoprezygapophyseal laminae. The ventral part of this fossa is divided

762 into left and right halves by an anterior, flange-like projection of the base of the neural spine.

763 Posteriorly, a well-developed spinopostzygapophyseal fossa is placed between the

764 postzygapophyses and extends onto the ventral half of the neural spine.

765 The second cervical vertebra ('cervical b'; Figs 12,15) is generally very similar to the

766 first. The low ridge on the ventral surface of the centrum is less well developed. There is no clear

767 bevelling for articulation with an intercentrum (a characteristic that cannot be assessed in

768 'cervical a' because of damage). The diapophysis is completely preserved on the left side, and

769 the articular facet for the rib is set at the end of a short ventrolaterally extending process. The

770 parapophyseal articular facet is larger than the diapophyseal one, and is situated on the

771 anteroventral corner of the centrum. The parapophysis is not situated on a significant

772 prominence, and in this case is not fused to the capitulum of the rib on either side of the vertebra.

773 On the anterodorsal corner of the centrum, at the same horizontal level as the diapophysis, is a

774 third facet for rib articulation. This condition differs from that observed in other species with

775 three-headed ribs (e.g. Prolacerta broomi: BP/1/2675; Proterosuchus alexanderi: NM QR 1484;

776 Chasmatosuchus rossicus: PIN 2252/381; Erythrosuchus africanus: Gower, 2003; Cuyosuchus

777 huenei: MCNAM PV 2669; Teleocrater rhadinus: NHMUK PV R6795), in which the third facet

778 is situated anteroventral to the diapophysis on a thick paradiapophyseal lamina. The third

779 articular facet is separated from the diapophyseal facet by a small non-articular area, but lies

780 adjacent to the anterior margin of the transverse process. A moderately thin lamina extends

781 posteriorly from the base of the third articular facet and subdivides the centrodiapophyseal fossa 
782 of the centrum, extending as far posteriorly as does the base of the diapophysis. To our

783 knowledge, this lamina is not present in other non-archosaurian archosauromorphs.

784 The same set of neural arch fossae and laminae are present as in cervical a, but the

785 prezygapophyseal centrodiapophyseal fossa is better preserved and more clearly developed. The

786 hyposphene is well developed, and what appears to be a flat, oval hypantral facet is present on

787 the base of the right prezygapophysis. The neural spine of cervical $b$ is similar to that of cervical

788 a, but is taller, more vertically oriented, and both absolutely and proportionately narrower

789 anteroposteriorly.

790 The partial dorsal vertebra (Fig. 16) includes the dorsal part of the posterior articular face

791 of the centrum, as well as the neural spine, transverse processes, and zygapophyses. This

792 vertebra is probably an anterior dorsal because of the presence of strongly laterally projecting

793 transverse processes, the anterodorsal orientation of the prezygapophyses and the lateroventrally

794 facing facets of the postzygapophyses. The neurocentral suture is fully closed. The dorsal part of

795 the posterior articular face of the centrum is gently concave, and above it there is a subcircular

796 neural canal. The diapophyseal facet is set at the end of an elongate, laterally directed transverse

797 process. A well-developed posterior centrodiapophyseal lamina extends posteroventrally from

798 the diapophysis, as also occurs in the non-crocopod archosauromorphs Tanystropheus

799 longobardicus (Wild, 1973: figs. 52-54) and Protorosaurus speneri (BSPG 1995 I 5), and the

800 early archosauriforms Cuyosuchus huenei (MCNAM 2669), Garjainia prima (PIN 2394/5-16),

801 Erythrosuchus africanus (NHMUK PV R3592; Gower, 2003), Shansisuchus shansisuchus

802 (Young, 1964: fig. 21), and Euparkeria capensis (UMZC T921). A paradiapophyseal lamina, if

803 one was originally present, has broken away. The posterior centrodiapophyseal lamina extends

804 longitudinally along the entire ventral surface of the transverse process and gives it a 
805 subtriangular cross-section, resembling the condition in Garjainia prima (PIN 2394/5-16). The

806 facet of the diapophysis is subtriangular and strongly concave. A deep postzygapophyseal

807 centrodiapophyseal fossa is present posterior to the diapophysis; it seems likely that

808 prezygopophyseal centrodiapophyseal and centrodiapophyseal fossae were also present, although

809 the area they would have occupied is damaged. A deep spinodiapophyseal fossa is present dorsal

810 to the transverse process, resembling the condition in Erythrosuchus africanus (NHMUK PV

811 R3592), but contrasting with the distinctly shallower fossa present in Garjainia prima (PIN

812 2394/5-16) and Garjainia madiba (BP/1/7135). Spinoprezygapophyseal and

813 spinopostzygapophyseal fossae are present anterior and posterior to the base of the neural spine

814 in Guchengosuchus shiguaiensis. An accessory, posteroventrally oriented lamina divides the

815 postzygapophyseal centrodiapophyseal fossa, as also occurs in the cervical vertebrae. The

816 prezygapophysis projects anterodorsally and its articular surface faces dorsomedially at around

$81745^{\circ}$ to the horizontal; the postzygapophysis faces ventrolaterally at a similar angle. A well-

818 preserved hyposphene with the same morphology as those of the cervical vertebrae is present

819 posteriorly, resembling the condition in the dorsal vertebrae of Erythrosuchus africanus

820 (NHMUK PV R3592) and Sarmatosuchus otschevi (PIN 2865/68). The neural spine is elongate

821 and anteroposteriorly narrow; it widens slightly anteroposteriorly towards its apex, but

822 considerably less than occurs in the cervicals. The morphology of this neural spine closely

823 resembles that of the cervico-dorsal vertebrae of Garjainia prima (PIN 2394/5-16). The neural

824 spine apex is rugose and slightly expanded transversely.

825 A fragment of an additional vertebra (Fig. 17) includes the concave articular face of a

826 centrum, and a small part of the neural canal and arch, but provides no useful anatomical data. A

827 ventral keel is present as in the other vertebrae. 
829 Ribs. Four partial ribs are preserved (Fig. 18), although in each case the distal portion is lacking.

830 A left cervical rib (Fig. 18A-C) has a well-separated capitulum and tuberculum. The articular

831 surface of the capitulum has broken away, but the process is flattened from anteroventral to

832 posterodorsal. The tuberculum is an elongate process bearing a triangular articular facet. At the

833 intersection of the capitulum and tuberculum the rib is drawn out into a tapering anterior process,

834 as occurs in other archosauromorphs (Ezcurra, 2016). The shaft of the rib is slightly laterally

835 convex along its length and has a T-shaped cross section produced by grooves lying along the

836 ventro- and dorsomedial edges.

837 Two 'pectoral' ribs are preserved. One of these is clearly three-headed (Fig. 18I, J), but

838 the probable third head of the second (Fig. $18 \mathrm{~F}-\mathrm{H})$ is damaged at its putative articular end. At

839 least one three-headed 'pectoral' rib also occurs in Prolacerta broomi, proterosuchids,

840 Vonhuenia fredericki, Chasmatosuchus rossicus, Sarmatosuchus otschevi, Cuyosuchus huenei,

841 other erythrosuchids, aphanosaurs, and some paracrocodylomorphs (Nesbitt, 2011; Ezcurra,

842 2016; Nesbitt et al., 2018). The less complete of the two pectoral ribs is from the left side and

843 has a broadly separated capitulum and tuberculum. As in the cervical rib, the capitulum is

844 anteroposteriorly compressed whereas the tuberculum has a nearly circular cross section. A third

845 process extends proximally from the base of the capitulum and is anteroposteriorly compressed,

846 but its articular end is incomplete. The rib shaft is strongly T-shaped at its base, the lateral

847 margin of the shaft being symmetrically expanded anteriorly and posteriorly. In this region the

848 lateral surface of the shaft is gently concave. More distally the rib acquires a nearly oval cross-

849 section with a convex lateral surface, but the posterior margin of the lateral surface is still drawn

850 out slightly posteriorly. 
852 side, although the proximal end is not well preserved. The capitulum is again anteroposteriorly

853 compressed, whereas the tuberculum has an oval cross section. A very well-developed third

854 process extends proximally from the base of the capitulum, and is anteroposteriorly compressed

855 with an oval articular surface. More distally, the anterolateral surface of the proximal end of the

856 shaft bears an anteromedially projecting flange, and the posterior surface of the shaft is grooved.

857 Towards its distal end the shaft has an almost oval cross section, the posterior margin of the

858 lateral surface being very slightly drawn out posteriorly.

859 The fourth rib (Fig. 18D, E) may be from the middle or posterior dorsal region and is

860 from the right side. The capitulum is much longer than the tuberculum and is anteroposteriorly

861 compressed, whereas the tuberculum ends in a subcircular articular surface. The capitulum and

862 tuberculum are connected to one another at their bases by a thin web of bone. The shaft is T-

863 shaped, with well-developed grooves on the anterior and posterior surfaces and a flattened lateral 864 surface.

865

866 Shoulder girdle (currently lost). The anterior margin of the scapular blade (Peng 1991, fig. 7, pl.

867 2.3; Fig. 19A; see also Supplementary Material) is strongly concave in lateral view whereas the

868 posterior margin is almost straight, as also occurs in Euparkeria capensis (SAM-PK-5867),

869 Garjainia prima (PIN 2394/5; Huene, 1960, plate 14, fig. 10), Erythrosuchus africanus (Gower, 870 2003; NHMUK PV R3762a) and Shansisuchus shansisuchus (Young, 1964, fig. 26a). By

871 contrast, in Prolacerta broomi (BP/1/2575), Proterosuchus alexanderi (NM QR 1484),

872 “Chasmatosaurus” yuani (IVPP V2719), Sarmatosuchus otschevi (PIN 2865/68), and

873 Cuyosuchus huenei (MCNAM 2669) the anterior margin of the scapular blade is convex and the 
874 posterior margin is posterodistally directed. Peng (1991) figured a low, posteriorly oriented

875 tuberosity on the posterior margin of the scapular blade which is visible in his line drawing (Fig.

876 S2), although it is less apparent in his photograph (Fig. 19A). This tuberosity is positioned at the

877 level of the minimum anteroposterior width of the scapular blade and closely resembles in

878 morphology and position the thin, vertical ridge present in Erythrosuchus africanus (Gower,

879 2003) and Shansisuchus shansisuchus (Young, 1964, fig. 26). Nesbitt (2011) interpreted this

880 ridge as possibly associated with the origin of the scapular head of the $M$. triceps. This tuberosity

881 is absent in Proterosuchus alexanderi (NM QR 1484), Garjainia prima (PIN 2394/5), Garjainia

882 madiba (BP/1/7152) and Sarmatosuchus otschevi (PIN 2865/68-37). A similar tuberosity or

883 ridge is present at or very close to the base of the supraglenoid lip in several archosauriforms

884 (e.g. Halazhaisuchus qiaoensis: Sookias et al., 2014; Batrachotomus kupferzellensis: Gower \&

885 Schoch, 2009), being therefore more proximally placed than in Guchengosuchus shiguaiensis

886 and Erythrosuchus africanus.

887

888 Forelimb (currently lost). The humerus (Peng 1991, fig. 8A, B; pl. 2.4; Fig. 19B; see also

889 Supplementary Material) has strong, symmetrical transverse expansions at the proximal and

890 distal ends, and appears to have a robust, well-developed deltopectoral crest. The ulna (Peng

891 1991, fig. 8C, pl. 2.5; Fig. 19C; see also Supplementary Material) is very similar to that of

892 Garjainia madiba (BP/1/6232r), including in the presence of a squared-off distal end in lateral

893 view. The distal end of the radius (Peng 1991, fig. 8D, pl. 2.6; Fig. 19D; see also Supplementary

894 Material) is strongly expanded anteroposteriorly, as in Garjainia prima (Huene, 1960),

895 Erythrosuchus africanus (Gower, 2003; SAM-PK-905), Shansisuchus shansisuchus (Young,

896 1964) and the pseudosuchian Riojasuchus tenuisceps (PVL 3828). 
898 Metapodial (currently lost). A bone interpreted as a non-ungual phalanx by Peng (1991, pl. 2.7;

899 Fig. 19E; see also Supplementary Material) is relatively large with respect to the other

900 postcranial bones and is elongate relative to its width, indicating that it represents a metapodial.

901 Little information can be derived from the single photograph presented by Peng (1991). An

902 ungual phalanx was also figured by Peng (1991, pl. 2.8; Fig. 19F).

903

904 Phylogenetic position

905 Our phylogenetic analysis recovered 27 most parsimonious trees (MPTs) of 3585 steps, with a

906 consistency index (CI) of 0.2519 and a retention index (RI) of 0.6477 . As in a previous analysis

907 by Ezcurra (2016), Guchengosuchus shiguaiensis was recovered within Erythrosuchidae, as the

908 sister-taxon of a clade composed of the genus Garjainia and the Middle Triassic species

909 Erythrosuchus africanus $+($ Shansisuchus shansisuchus + Chalishevia cothurnata) (Fig. 20). The

910 Chinese archosauriform Fugusuchus hejiapanensis was found to be the sister taxon of all the

911 other erythrosuchids. None of the character states recovered in the analysis as erythrosuchid

912 synapomorphies could be coded as present or absent in Guchengosuchus shiguaiensis, but this

913 species possesses the following synapomorphies of the clade that includes all erythrosuchids to

914 the exclusion of Fugusuchus hejiapanensis: maxilla with a low tuberosity delimiting anteriorly

915 the antorbital fenestra and forming a gradual transition with the external surface of the anterior

916 process (character $46: 0 \rightarrow 1$ ); maxilla with lateroventrally facing neurovascular foramina on the

917 lateral surface of the anterior and horizontal processes and extending ventrally as deep, well-

918 defined grooves (character 53: $0 \rightarrow 1$ ); maxillary alveolar margin distinctly upturned on the

919 anterior third of the bone (anterior to the level of the anterior border of the antorbital fenestra if 
920 present) (character 70: $0 \rightarrow 1$ ); parietal with posterolateral process with a strongly transversely

921 convex dorsal margin elevated from the median line of the posterior margin of the skull roof

922 (character 169: $0 \rightarrow 1$ ); and radius with a strongly anteroposteriorly expanded distal end

923 (character 438: $0 \rightarrow 1$ ). However, Bremer support for this branch is minimal, and the absolute and

924 GC bootstrap frequencies are $58 \%$ and $53 \%$, respectively.

925 The branch that includes both species of Garjainia and Middle Triassic erythrosuchids

926 possesses the following synapomorphies that are absent in Guchengosuchus shiguaiensis:

927 maxilla and nasal with a high maxillo-nasal tuberosity, delimiting anteriorly the antorbital

928 fenestra or fossa, forming a distinct change of slope with the external surface of the anterior

929 process (character 46: $1 \rightarrow 2$ ); maxilla with an antorbital fossa exposed in lateral view (character

$93054: 0 \rightarrow 1 / 2$ ); maxilla with a sub-vertical anterior margin of the base of the ascending process

931 (character 58: $1 \rightarrow 2$ ); frontal with an only slightly constricted longitudinal canal for the passage

932 of the olfactory tract and no olfactory bulb moulds and distinct semilunate posteromedially-to-

933 anterolaterally oriented ridge on the orbital roof (character 120: $0 \rightarrow 1$ ); parietals with a pineal

934 fossa on the median line of their dorsal surface (character 162: $0 \rightarrow 1$ ); surangular with a strongly

935 laterally projecting shelf with a strongly convex lateral edge on the dorsolateral surface of the

936 bone (character 286: $2 \rightarrow 3$ ); anterior cervical centra with a median, ventral longitudinal keel that

937 extends ventral to the centrum rim in at least one vertebra (character $327: 1 \rightarrow 2$ ); and postaxial

938 cervical vertebrae with a shallow, posterolaterally facing fossa ventral to the postzygapophysis

939 (character 335: $0 \rightarrow 1$ ). This branch is very well supported, with a Bremer support of 4 and

940 absolute and GC bootstrap frequencies of $82 \%$ and $78 \%$, respectively.

941 Under suboptimal searches, four additional steps are needed to place Guchengosuchus

942 shiguaiensis as the sister taxon of all other erythrosuchids (including Fugusuchus hejiapanensis), 
943 six steps to force its recovery as the sister taxon of Erythrosuchus africanus + (Chalishevia

944 cothurnata + Shansisuchus shansisuchus) and eight steps to make it the sister taxon of Garjainia.

945 Finally, six additional steps are needed to position Guchengosuchus shiguaiensis outside

946 Erythrosuchidae, either as one of the closest sister taxa of Erythrosuchidae + Eucrocopoda or as

947 the earliest branching member of Eucrocopoda.

948

949 DISCUSSION

950 The phylogenetic relationships of Erythrosuchidae found in our analysis are congruent with those

951 previously recovered by Ezcurra (2016) and Ezcurra et al. (2018). The interrelationships within

952 Erythrosuchidae are relatively robust and do not generate substantial ghost lineages. By contrast,

953 ghost lineages longer than 3 million years are common among other Permo-Triassic

954 archosauromorph clades, such as rhynchosaurs and allokotosaurs (Nesbitt et al., 2015; Ezcurra,

955 2016; Ezcurra et al., 2016; Sengupta et al., 2017). The current potential for direct morphological

956 comparisons between the oldest and earliest branching erythrosuchids is highly limited, mainly

957 because of the fragmentary condition of the holotype and only known specimen of

958 Guchengosuchus shiguaiensis. By contrast, the hypodigms of the Early Triassic erythrosuchids

959 Fugusuchus hejiapanensis and Garjainia prima include fairly complete skulls (Ochev, 1958;

960 Cheng, 1980), although the whereabouts of the type specimen of the former are currently

961 unknown (Ezcurra, 2016). The most striking putative difference between Guchengosuchus

962 shiguaiensis on the one hand, and Fugusuchus and Garjainia on the other, lies in Peng's (1991)

963 interpretation of Guchengosuchus shiguaiensis as possessing a secondary antorbital fenestra, like

964 the more derived Middle Triassic erythrosuchids Shansisuchus shansisuchus and Chalishevia

965 cothurnata. Phylogenetic relationships within Erythrosuchidae indicate that if a secondary 
966 antorbital fenestra was actually present in Guchengosuchus shiguaiensis, as proposed by Peng

967 (1991), this feature must have evolved independently from the corresponding structure in the

968 clade that includes Shansisuchus shansisuchus and Chalishevia cothurnata.

969 Peng (1991) identified a secondary antorbital fenestra in Guchengosuchus shiguaiensis

970 based on the morphology of the ascending process of the maxilla, which he described as

971 possessing a distinctly concave anterior margin. Unfortunately, this process has been lost since

972 the original description of the specimen. Peng (1991) reconstructed the secondary antorbital

973 fenestra as a slit-like opening between the postnarial process of the premaxilla and the ascending

974 process of the maxilla, with limited or no participation by the nasal (Peng, 1991: fig. 2b). The

975 secondary antorbital fenestra of other erythrosuchids (Shansisuchus shansisuchus and

976 Chalishevia cothurnata) is also formed by the premaxilla and maxilla, but the nasal contributes

977 substantially to the opening. Indeed, the secondary antorbital fenestra of Shansisuchus

978 shansisuchus and Chalishevia cothurnata is in part a result of the presence of a long, non-

979 articular margin on the anteroventral margin of the nasal, between the articular facets for the

980 reception of the postnarial process of the premaxilla and the ascending process of the maxilla.

981 This non-articular margin is absent in Guchengosuchus shiguaiensis, the articular facets of the

982 premaxilla and maxilla being adjacent to each other. If an opening was present between the

983 premaxilla and maxilla, as originally suggested by Peng (1991), this would have been more

984 similar in its position and relationships with the surrounding bones to the subnarial fenestra that

985 has been described for some loricatan pseudosuchians (e.g. Decuriasuchus quartacolonia:

986 França et al., 2013; Prestosuchus chiniquensis: Roberto-Da-Silva et al., 2016; but see Nesbitt \&

987 Desojo [2017] for an alternative interpretation of these openings as the result of deformation

988 during taphonomic processes) and the early dinosaur Herrerasaurus ischigualastensis (Sereno \& 
989 Novas, 1993). As a result, we think it is likely that Guchengosuchus shiguaiensis did not have a

990 secondary antorbital fenestra homologous with that present in some Middle Triassic

991 erythrosuchids, and we cannot confirm the presence of an opening between the premaxilla and

992 maxilla because the specimen has been damaged since its original description. Despite the

993 uncertainties around this character, however, the phylogenetic position of Guchengosuchus

994 shiguaiensis as an erythrosuchid is still relatively well supported, and this species provides useful 995 information about the anatomy of members of this clade during their early evolutionary history. 996

997 Acknowledgements. We thank Michael Parrish and Felipe Pinheiro for helpful review comments, 998 and Andrew Farke for editorial comments. Michael Parrish provided photographs of some of the 999 Guchengosuchus material as preserved during his 1990 visit to Beijing.

1000

1001

REFERENCES

1002

1003 Baczko MB von, Desojo JB. 2016. Cranial anatomy and palaeoneurology of the archosaur 1004 Riojasuchus tenuisceps from the Los Colorados Formation, La Rioja, Argentina. PLoS ONE $1005 \quad$ 11:e0148575.

1006 Bandyopadhyay S. 1999. Gondwana vertebrate faunas of India. PINSA 3:285-313.

1007 Cheng ZW. 1980. Vertebrate fossils. In: Mesozoic stratigraphy and paleontology of the Shan1008 Gan-Ning Basin 2. Beijing: Publishing House of Geology. 114-171.

1009 Cruickshank ARI. 1972. The proterosuchian thecodonts. In: Joysey KA, Kemp TS, eds. Studies 1010 in Vertebrate Evolution. Edinburgh: Oliver and Boyd. 89-119. 
1011 Evans SE. 1980. The skull of a new eosuchian reptile from the Lower Jurassic of South Wales.

1012 Zoological Journal of the Linnean Society 70:203-264.

1013 Ewer RF. 1965. The anatomy of the thecodont reptile Euparkeria capensis Broom.

1014 Philosophical Transactions of the Royal Society of London B 751:379-435.

1015 Ezcurra MD. 2014. The osteology of the basal archosauromorph Tasmaniosaurus triassicus

1016 from the Lower Triassic of Tasmania, Australia. PLoS ONE 9:e86864.

1017 Ezcurra MD. 2016. The phylogenetic relationships of basal archosauromorphs, with an

1018 emphasis on the systematics of proterosuchian archosauriforms. PeerJ 4:e1778.

1019 Ezcurra MD, Butler RJ. 2015. Post-hatchling cranial ontogeny in the Early Triassic diapsid

1020 reptile Proterosuchus fergusi. Journal of Anatomy 226:387-402.

1021 Ezcurra MD, Butler RJ. 2018. The rise of the ruling reptiles and ecosystem recovery from the 1022 Permian-Triassic mass extinction. Proceedings of the Royal Society B.

1023 Ezcurra MD, Lecuona A, Martinelli A. 2010. A new basal archosauriform diapsid from the 1024 Lower Triassic of Argentina. Journal of Vertebrate Paleontology 30:1433-1450.

1025 Ezcurra MD, Gower DJ, Sennikov AG, Butler RJ. 2018. The osteology of the holotype of the 1026 early erythrosuchid Garjainia prima Ochev, 1958 (Diapsida: Archosauromorpha) from the

1027 upper Lower Triassic of European Russia. Zoological Journal of the Linnean Society. doi:

$1028 \quad$ 10.1093/zoolinnean/zly061

1029 Ezcurra MD, Butler RJ, Gower DJ. 2013. 'Proterosuchia': the origin and early history of

1030 Archosauriformes. In: Nesbitt SJ, Desojo JB, Irmis RB, eds. Anatomy, phylogeny and 1031 palaeobiology of early archosaurs and their kin. London: Geological Society, Special

1032 Publications. Vol. 379:9-33. 
1033 Ezcurra MD, Desojo JB, Rauhut OWM. 2014. Redescription and phylogenetic relationships

1034 of the proterochampsid Rhadinosuchus gracilis (Diapsida: Archosauriformes) from the early

1035 Late Triassic of Southern Brazil. Ameghiniana 52:391-417.

1036 Ezcurra MD, Fiorelli LE, Martinelli AG, Rocher S, von Baczko MB, Ezpeleta M, Taborda

1037 JR, Hechenleitner EM, Trotteyn MJ, Desojo JB. 2017. Deep faunistic turnovers preceded

1038 the rise of dinosaurs in southwestern Pangaea. Nature Ecology \& Evolution 1:1477.

1039 França MAG, Langer MC, Ferigolo J. 2013. The skull anatomy of Decuriasuchus

1040 quartacolonia (Pseudosuchia: Suchia: Loricata) from the middle Triassic of Brazil. In:

1041 Nesbitt SJ, Desojo JB, Irmis RB, eds. Anatomy, phylogeny and palaeobiology of early

1042 archosaurs and their kin. London: Geological Society, Special Publications. Vol. 379:469-

1043501.

1044 Gauthier JA, Kluge AG, Rowe T. 1988. Amniote phylogeny and the importance of fossils.

$1045 \quad$ Cladistics 4:105-209.

1046 Goloboff PA, Catalano SA. 2016. TNT version 1.5, including a full implementation of

1047 phylogenetic morphometrics. Cladistics 32:221-238.

1048 Goloboff PA, Farris JS, Källersjö M, Oxelman B, Ramírez M, Szumik C. 2003.

1049 Improvements to resampling measures of group support. Cladistics 19:324-332.

1050 Goloboff PA, Farris JS, Nixon KC. 2008. TNT, a free program for phylogenetic analysis.

$1051 \quad$ Cladistics 24:774-786.

1052 Gow CE 1970. The anterior of the palate in Euparkeria. Palaeontologia africana 13:61-62.

1053 Gower DJ. 1997. The braincase of the early archosaur Erythrosuchus. Journal of Zoology,

$1054 \quad$ London 242:557-576. 
1055 Gower DJ. 2003. Osteology of the early archosaurian reptile Erythrosuchus africanus Broom. 1056 Annals of the South African Museum 110:1-84.

1057 Gower DJ, Schoch R. 2009. Postcranial anatomy of the rauisuchian archosaur Batrachotomus 1058 kupferzellensis. Journal of Vertebrate Paleontology 29:103-122.

1059 Gower DJ, Sennikov AG. 1996. Morphology and phylogenetic informativeness of early $1060 \quad$ archosaur braincases. Palaeontology 39:883-906.

1061 Gower DJ, Sennikov AG. 1997. Sarmatosuchus and the early history of the Archosauria.

1062 Journal of Vertebrate Paleontology 17:60-73.

1063 Gower DJ, Sennikov AG. 2000. Early archosaurs from Russia. In: Benton MJ, Kurochkin EN,

1064 Shishkin MA, Unwin DM, eds. The age of dinosaurs in Russia and Mongolia. Cambridge:

1065 Cambridge University Press. 140-159.

1066 Gower DJ, Hancox PJ, Botha-Brink J, Sennikov AG, Butler RJ. 2014. A new species of

1067 Garjainia Ochev, 1958 (Diapsida: Archosauriformes: Erythrosuchidae) from the Early $1068 \quad$ Triassic of South Africa. PLoS ONE 9:e111154.

1069 Huene F von. 1960. Ein großer Pseudosuchier aus der Orenburger Trias. Palaeontographica $1070 \quad$ Abteilung A 114:105-111.

1071 Irmis RB 2007. Axial skeleton ontogeny in the Parasuchia (Archosauria: Pseudosuchia) and its 1072 implications for ontogenetic determination in archosaurs. Journal of Vertebrate Paleontology $1073 \quad 27: 350-361$.

1074 Liu J, Ramezani J, Li L, Shang Q-H, Xu G-H, Wang Y-Y, Yang J-S. 2018. High-precision 1075 temporal calibration of Middle Triassic vertebrate biostratigraphy: $\mathrm{U}-\mathrm{Pb}$ zircon constraints 1076 for the Sinokannemeyeria Fauna and Yonghesuchus. Vertebrata PalAsiatica 56:16-24. 
1077 Modesto SP, Sues H-D. 2004. The skull of the Early Triassic archosauromorph reptile

1078 Prolacerta broomi and its phylogenetic significance. Zoological Journal of the Linnean

1079 Society 140:335-351.

1080 Müller J. 2004. The relationships among diapsid reptiles and the influence of taxon selection.

1081 In: Arratia G, Wilson MVH, Cloutier R, eds. Recent advances in the origin and early

1082 radiation of vertebrates. München: Verlag Dr. Friedrich Pfeil. 379-408.

1083 Nesbitt SJ, Desojo JB. 2017. The osteology and phylogenetic position of Luperosuchus fractus

1084 (Archosauria: Loricata) from the latest Middle Triassic or earliest Late Triassic of Argentina.

1085 Ameghiniana 54:261-282.

1086 Nesbitt SJ, Butler RJ, Gower DJ. 2013. A new archosauriform (Reptilia: Diapsida) from the

1087 Manda Beds (Middle Triassic) of southwestern Tanzania. PLoS ONE 8:e72753

1088 Nesbitt SJ, Flynn JJ, Pritchard AC, Parrish JM, Ranivoharimanana L, Wyss AR. 2015.

1089 Postcranial anatomy and relationships of Azendohsaurus madagaskarensis. Bulletin of the

1090 American Museum of Natural History 398:1-126.

1091 Nesbitt SJ, Butler RJ, Ezcurra MD, Barrett PM, Stocker MR, Angielczyk KD, Smith

1092 RMH, Sidor CA, Niedźwiedzki G, Sennikov AG, Charig AJ. 2017. The earliest bird-line

1093 archosaurs and the assembly of the dinosaur body plan. Nature 544:484-487.

1094 Nesbitt SJ, Butler RJ, Ezcurra MD, Charig AJ, Barrett PM. 2018. The anatomy of

1095 Teleocrater rhadinus, an early avemetatarsalian from the lower portion of the Lifua Member

1096 of the Manda Beds (Middle Triassic). In Sidor CA, Nesbitt SJ, eds. Vertebrate and Climatic

1097 Evolution in the Triassic Rift Basins of Tanzania and Zambia. Society of Vertebrate

1098 Paleontology Memoir 17. 142-177. 
1099 Ochev VG. 1958. New data concerning the pesudosuchians of the USSR. Doklady Akademi

$1100 \quad$ Nauk 123:749-751.

1101 Parrish JM. 1992. Phylogeny of the Erythrosuchidae (Reptilia: Archosauriformes). Journal of

1102 Vertebrate Paleontology 12:93-110.

1103 Peng J-H. 1991. A new genus of Proterosuchia from the Lower Triassic of Shaanxi, China.

1104 Vertebrata PalAsiatica 29:95-107.

1105 Pinheiro FL, França MA, Lacerda MB, Butler RJ, Schultz CL. 2016. An exceptional fossil

1106 skull from South America and the origins of the archosauriform radiation. Scientific Reports

$1107 \quad 6: 22817$.

1108 Roberto-Da-Silva L, França MAG, Cabreira SF, Müller RT, Dias-da-Silva S. 2016. On the

1109 presence of the subnarial foramen in Prestosuchus chiniquensis (Pseudosuchia: Loricata)

1110 with remarks on its phylogenetic distribution. Anais da Academia Brasileira de Ciências

$1111 \quad$ 88:1309-1323.

1112 Sengupta S, Ezcurra MD, Bandyopadhyay S. 2017. A new horned and long-necked

1113 herbivorous stem-archosaur from the Middle Triassic of India. Scientific Reports 7:8366.

1114 Sereno PC, Novas FE. 1993. The skull and neck of the basal theropod Herrerasaurus

1115 ischigualastensis. Journal of Vertebrate Paleontology 13:451-476.

1116 Sookias RB, Sullivan C, Liu J, Butler RJ. 2014. Systematics of putative euparkeriids

1117 (Diapsida: Archosauriformes) from the Triassic of China. PeerJ 2:e658.

1118 Spielmann JA, Lucas SG, Rinehart LF, Heckert AB. 2008. The Late Triassic

1119 archosauromorph Trilophosaurus. Bulletin of the New Mexico Museum of Natural History

$1120 \quad$ and Sciences 43:1-177. 
1121 Stocker MR, Zhao LJ, Nesbitt SJ, Wu XC, Li C. 2017. A short-snouted, Middle Triassic

1122 phytosaur and its implications for the morphological evolution and biogeography of

1123 Phytosauria. Scientific Reports 7:46028.

1124 Thulborn RA. 1979. A proterosuchian thecodont from the Rewan Formation of Queensland.

1125 Memoirs of the Queensland Museum 19:331-355.

1126 Wang R, Xu S, Wu X, Li C, Wang S. 2013. A new specimen of Shansisuchus shansisuchus

1127 Young, 1964 (Diapsida: Archosauriformes) from the Triassic of Shanxi, China. Acta

$1128 \quad$ Geologica Sinica 87:1185-1197.

1129 Watson DMS. 1917. A sketch classification of the Pre-Jurassic tetrapod vertebrates.

$1130 \quad$ Proceedings of the Zoological Society of London, 1917:167-186.

1131 Wild R. 1973. Die Triasfauna dr Tessiner Kalkalpen. XXIII Tanystropheus longobardicus

1132 (Bassani) (Neue Ergebnisse). Abhandlungen der Schweizerischen Paläontologischen

1133 Gesellschaft 95:1-162.

1134 Young C-C. 1964. The pseudosuchians in China. Palaeontologia Sincia, New Series, C 151:1205.

1136

1137

1138

1139

1140

1141

1142

1143 


\section{FIGURE CAPTIONS}

1145 Figure 1. Locality information for Guchengosuchus shiguaiensis. (a) Maps showing the location

1146 of the locality of Guchengosuchus. The exact coordinates of the locality are unknown, but it is

1147 reported as being near the village of Shiguai in Gucheng township. Star indicates Shiguai on

1148 each map. Colours in largest-scale map: white=People's Republic of China; light grey=other

1149 countries; dark grey=ocean; thick grey lines=national borders; thin grey lines=province borders

1150 Colours in larger-scale inset: black lines=roads; grey lines=province borders; black

1151 circles=major settlements. Colours in smaller-scale inset: larger black lines: larger roads; smaller

1152 black lines: smaller roads; grey lines=larger rivers; black circles=named settlements. (b)

1153 Stratigraphic column based on figure 1 of Liu et al. (2018) showing correspondence of the

1154 Ermaying Formation to international Middle Triassic stage dates. Guchengosuchus is reported to

1155 be from the lower part of the Ermaying Formation, but no more precise information is available.

1156

1157 Figure 2. Left maxilla of Guchengosuchus shiguaiensis, IVPP V8808, in lateral (A), medial

1158 (B), dorsal (C) and ventral (D) views. Abbreviations: anp, anterior process; asp, ascending

1159 process; ect.ct, contact surface for the ectopterygoid; for, foramina; gr, groove; hp, horizontal

1160 process; ?maaf, proposed margin of the accessory antorbital fenestra identified by Peng (1991) -

1161 see Discussion for details; nf, nutrient foramina; palp, base of broken palatal process; pal.ct,

1162 contact surface for the palatine; rc, replacement crown; ri, ridge; thg, thickening of maxilla along

1163 the posterior margin of the ascending process and anteroventral margin of the antorbital fenestra;

1164 vmaf, ventral margin of the antorbital fenestra.

1165 
1166 Figure 3. Close-ups of the left maxilla of Guchengosuchus shiguaiensis, IVPP V8808,

1167 focusing on the base of the ascending process (A) and tooth positions 1-6 (B). Abbreviation:

1168 bat, bone of attachment.

1169

1170 Figure 4. Selected cranial elements of Guchengosuchus shiguaiensis, IVPP V8808, as

1171 originally preserved and figured by Peng (1991). Photographs show the left maxilla in lateral

1172 view (A) and the left pterygoid in ventral view (B). Both elements have been damaged since

1173 their description by Peng (1991) - see Figure 2 and Figure 10 for details. Peng (1991) did

1174 provide reduction factors (e.g. $\mathrm{x} \frac{1}{2}$ ) for individual bones in his plates; however, the accuracies of

1175 these are unclear. As such, the present figure should not be used to estimate relative proportions

1176 of individual bones.

1177

1178 Figure 5. Left nasal of Guchengosuchus shiguaiensis, IVPP V8808, in lateral (A), dorsal

1179 (B), and medial (C) views, and with close-up of the anterior end in lateral (D) view.

1180 Abbreviations: conc, concavity; fc.ap.mx, facet for the ascending process of the maxilla; fc.1,

1181 facet, possibly for articulation with the lacrimal; fc.ponp.pmx, facet for the postnarial process of

1182 the premaxilla; fc.prnp.pmx, facet for the prenarial process of the premaxilla; gr, groove on

1183 medial margin for articulation with opposing nasal; na, border of external naris; rg, knob-like

1184 rugosities; sf, surface separating the postnarial process of the premaxilla from the ascending

1185 process of the maxilla.

1186

1187 Figure 6. Skull roof of Guchengosuchus shiguaiensis, IVPP V8808, in dorsal (A), posterior

1188 (B), ventral (C) and right lateral (D) views. Abbreviations: alp, anterolateral process of the 
1189 parietal; cb, impression of the cerebrum; conc, concavity between the impression of the olfactory

1190 bulbs and the orbital depression; dia, dorsally inflated area of the nasals; fc.cp.ls, facet for the

1191 capitate process of the laterosphenoid; ?fc.prf, possible facet for prefrontal; fc.sq, facet for the

1192 squamosal; fos, fossa on the base of the posterolateral process of the parietal; ob, impression of

1193 olfactory bulbs; od, orbital depression; ot, olfactory tract; prj, median projection of the parietals;

1194 re, raised edge on parietal posteriorly delimiting a subtriangular fossa; ri1, longitudinal ridges on

1195 the anterior parts of the frontals; ri2, ridge laterally delimiting impression of the olfactory bulbs;

1196 ri3, ridge on the anterior surface of the posterolateral process of the parietal; sbtf, subtriangular

1197 fossa on parietal; stdp, subtriangular depression on posterolateral corner of frontal; stf,

1198 supratemporal fossa; str, striations; te, transverse eminence on posterior margin of parietals; ttub,

1199 transverse tuberosity on the frontal; tub, tuberosity separating impression of cerebrum from the

1200 facet for the capitate process of the laterosphenoid; vf, vertical flange.

1201

1202 Figure 7. Skull roof of Guchengosuchus shiguaiensis, IVPP V8808, in dorsal view.

1203 Abbreviations: alp, anterolateral process of the parietal; dia, dorsally inflated area of the nasals;

1204 ?fc.prf, possible facet for prefrontal; fos, fossa on the base of the posterolateral process of the

1205 parietal; fr, frontal; pa, parietal; pf, postfrontal; prj, median projection of the parietals; re, raised

1206 edge on parietal posteriorly delimiting a subtriangular fossa; ri1, longitudinal ridges on the

1207 anterior parts of the frontals; sbtf, subtriangular fossa on parietal; stdp, subtriangular depression

1208 on posterolateral corner of frontal; stf, supratemporal fossa; str, striations; te, transverse

1209 eminence on posterior margin of parietals; ttub, transverse tuberosity on the frontal; vf, vertical

1210 flange.

1211 
1212 Figure 8. Partial braincase of Guchengosuchus shiguaiensis, IVPP V8808, in posterior (A),

1213 anterior (B), dorsal (C), ventral (D) and left lateral (E) views. Abbreviations: art.clp, articular

1214 surface to receive the clinoid process of the basisphenoid; art.ls, articular surface for the

1215 laterosphenoid; art.p, articular surface for the parietals; $\mathrm{CNV}$, foramen for cranial nerve V; dp,

1216 depression; fac.p, facet for articulation with ventral surface of the base of the posterolateral

1217 process of the parietal; fo, fenestra ovalis; gr, groove; hy, groove for hyomandibular branch of

1218 the facial nerve; mf, metotic foramen; pop, paraoccipital process; pr.cr, prootic crest; ri1, median

1219 ridge on the supraoccipital; ri2, ridge on lateral surface of upper anterior process of the prootic;

1220 ri3, ridge on lateral surface of lower anterior process of the prootic; vrop, ventral process of the

1221 opisthotic.

1222

1223 Figure 9. Partial braincase of Guchengosuchus shiguaiensis, IVPP V8808. Medial surface of

1224 the prootic (A) and close-up of the braincase in ventral (B) view. Abbreviations: aur,

1225 auricular recess; CNV, foramen for cranial nerve V; ?CN VII, foramen, possibly for passage of

1226 cranial nerve VII; fo, fenestra ovalis; iec, inner ear chamber; mf, metotic foramen; pr.cr, prootic

1227 crest; ?ri4, possible ridge dividing the auricular recess; vrop, ventral process of the opisthotic.

1228

1229

1230

Figure 10. Fragment of left pterygoid of Guchengosuchus shiguaiensis, IVPP V8808, in ventral (A), and dorsal (B) views.

1231

1232 Figure 11. Posterior right mandible of Guchengosuchus shiguaiensis, IVPP V8808, in

1233 lateral (A), medial (B), ventral (C) and dorsal (D) views. Abbreviations: ar, articular; cncv,

1234 deep concavity separating the glenoid fossa from the retroarticular process; dmp, dorsomedial 
1235 projection of the articular; fl, ventromedially directed flange of the surangular, anteriorly

1236 bordering the articular; gl, glenoid fossa; ri, ridge forming the posterior border of the glenoid;

1237 ri.ang.pre, ridge on ventral surface of articular separating the articular facets for the angular and

1238 the prearticular; rp, retroarticular process; sa, surangular; sa.ar.s, suture between the surangular

1239 and the articular; sh, shelf on dorsal margin of surangular; vmp, ventromedial process of the

1240 articular.

1241

1242 Figure 12. Articulated cervical vertebrae of Guchengosuchus shiguaiensis, IVPP V8808, in

1243 left lateral (A) and right lateral (B) views.

Figure 13. 'Cervical a' of Guchengosuchus shiguaiensis, IVPP V8808, in left lateral (A), right lateral (B), anterior (C), posterior (D), dorsal (E) and ventral (F) views. Abbreviations:

1247 b.dp, base of the diapophysis; cap, capitulum; cdf, centrodiapophyseal fossa; flp, flange-like

1248 projection at the base of the neural spine; fu, furrow; hys, hyposphene; lam, lamina; m.ri, midline

1249 ridge; nc, neural canal; pp, parapophysis; pcdl, posterior centrodiapophyseal lamina; pocdf,

1250 postzygapophyseal centrodiapophyseal fossa; poz, postzygopophysis; podl,

1251 postzygodiapophyseal lamina; prcdf, prezygapophyseal centrodiapophyseal fossa; prdl,

1252 prezygodiapophyseal lamina; prz, prezygapophysis; sdf, spinodiapophyseal fossa; spof,

1253 spinopostzygapophyseal fossa; sprf, spinoprezygapophyseal fossa; sprl, spinoprezygopophyseal

1254 lamina; 3af, third articular facet.

1255

1256 Figure 14. 'Cervical a' of Guchengosuchus shiguaiensis, IVPP V8808, in close-up left

1257 lateral (A) and right lateral (B) views. 
1259 Figure 15. 'Cervical b’ of Guchengosuchus shiguaiensis, IVPP V8808, in left lateral (A),

1260 right lateral (B), anterior (C), posterior (D), dorsal (E) and close-up left lateral (F) views.

1261 Abbreviations: dp, diapophysis; hys, hyposphene; lam, lamina; pp, parapophysis; 3af, third

1262 articular facet.

1263

1264 Figure 16. Partial dorsal vertebra of Guchengosuchus shiguaiensis, IVPP V8808, in

1265 anterior (A), left lateral (B), posterior (C) and dorsal (D) views. Abbreviations: dp,

1266 diapophysis; hys, hyposphene; lam, accessory lamina; nc, neural canal; pcdl, posterior

1267 centrodiapophyseal lamina; pocdf, postzygapophyseal centrodiapophyseal fossa; poz,

1268 postzygapophysis; prz, prezygapophysis; sdf, spinodiapophyseal; spof, spinopostzygapophyseal

1269 fossa; sprf, spinoprezygapophyseal fossa; tp, transverse process.

1270

1271 Figure 17. Vertebral fragment, Guchengosuchus shiguaiensis, IVPP V8808. Because of the

1272 incompleteness of the specimen, the orientations of views (A) and (B) are uncertain.

1273

1274 Figure 18. Partial ribs, Guchengosuchus shiguaiensis, IVPP V8808. Left cervical rib in lateral

1275 (A), medial (B) and dorsal (C) views. Right dorsal rib in anterior (D) and posterior (E) views.

1276 Left 'pectoral' rib in anterior $(\mathrm{F})$, posterior $(\mathrm{G})$ and lateral $(\mathrm{H})$ views. Right 'pectoral' rib in

1277 anterior (I) and posterior (J) views. Abbreviations: atp, anterior process; cap, capitulum; fl,

1278 flange; gr, groove; tu, tuberculum; wb, web of bone between the capitulum and tuberculum; 3p,

1279 third process of the rib.

1280 
1281 Figure 19. Non-vertebral postcranial elements of Guchengosuchus shiguaiensis, IVPP

1282 V8808, as originally preserved and figured by Peng (1991). All specimens are now missing.

1283 Right scapula in lateral view (A), right humerus in anterior view (B), ulna (C), radius (D),

1284 metatarsal (E) and ungual phalanx (F). No scale bars were presented in the original figures. Peng

1285 (1991) did provide reduction factors (e.g. x 1/2) for individual bones in his plates; however, the

1286 accuracies of these are unclear. As such, the present figure should not be used to estimate relative

1287 proportions of individual bones..

1288

1289 Figure 20. Phylogenetic relationships within Erythrosuchidae. Numbers above branches are

1290 Bremer support values and absolute and GC bootstrap frequencies.

1291

1292

1293

1294

1295

1296

1297

1298

1299

1300

1301

1302

1303 


\section{APPENDIX}

1305 Characters modified from the data matrix of Ezcurra et al. (2018):

1306 Character 46. Maxilla-nasal, maxillo-nasal tuberosity, delimiting anteriorly the antorbital

1307 fenestra or fossa if it is present: absent (0); present but low, with a gradual transition with the

1308 external surface of the anterior process (1), present and high, with a distinct change of slope

1309 between it and the external surface of the anterior process (2). ORDERED.

1310 Character 393. Scapula, lateral tuber or ridge on the posterior edge: absent (0); present, just

1311 dorsal to the glenoid fossa (1); present, around the level of maximum anteroposterior

1312 narrowing of the scapular blade (2).

1313 Here we propose that the ridge on the scapular blade of some erythrosuchids (e.g.

1314 Guchengosuchus shiguaiensis, Erythrosuchus africanus, Shansisuchus shansisuchus) is

1315 homologous with the tuberosity or ridge present immediately dorsal to the supraglenoid lip in

1316 several other archosauriforms (Gower, 2003; Nesbitt, 2011).

1318 Scorings changed from the data matrix of Ezcurra et al. (2018):

1319 Character 15 (Secondary antorbital fenestra, immediately anterior to the antorbital fenestra).

1320 Guchengosuchus shiguaiensis (based on IVPP V8808): changed from (1: present) to (0:

1321 absent).

1322 Character 46 (Maxilla-nasal, maxillo-nasal tuberosity, delimiting anteriorly the antorbital

1323 fenestra or fossa if it is present). Guchengosuchus shiguaiensis: changed from (0) to (1).

1324 Garjainia prima, Erythrosuchus africanus, Shansisuchus shansisuchus, Chalishevia

1325 cothurnata, and Batrachotomus kupferzellensis: changed from (1) to (2) because of the

1326 addition of a new character-state. See above for character-states. 
1327 Character 56 (Maxilla, secondary antorbital fossa anteriorly to the antorbital fossa and adjacent

1328 to the dorsal margin of the anterior process). Guchengosuchus shiguaiensis (based on IVPP

1329 V8808): changed from (0: absent) to (-: inapplicable).

1330 Character 69 (Maxilla, edentulous anterior portion of the ventral margin of the bone).

1331 Guchengosuchus shiguaiensis (based on IVPP V8808): changed from (0: absent) to (?:

1332 missing data).

1333 Character 393 (Scapula, lateral tuber or ridge on the posterior edge). Guchengosuchus

1334 shiguaiensis (based on Peng, 1991), Erythrosuchus africanus (based on Gower, 2003),

1335 Shansisuchus shansisuchus (based on Young, 1964): changed from (0) to (2) because of the

1336 addition of a new character-state. See above for character-states.

1337 Character 652 (Articular, medial surface). "Chasmatosaurus" yuani (based on IVPP V4067),

1338 Guchengosuchus shiguaiensis (based on IVPP V8808), Proterosuchus alexanderi (based on

1339 NM QR 1484), Proterosuchus fergusi (based on BSPG 1934 VIII 514): changed from (0:

1340 without dorsomedial projection posterior to the glenoid fossa) to (1: with dorsomedial

1341 projection separated from glenoid fossa by a clear concave surface). 


\section{Figure 1}

Locality information for Guchengosuchus shiguaiensis.

(a) Maps showing the location of the locality of Guchengosuchus. The exact coordinates of the locality are unknown, but it is reported as being near the village of Shiguai in Gucheng township. Star indicates Shiguai on each map. Colours in largest-scale map: white=People's Republic of China; light grey=other countries; dark grey=ocean; thick grey lines=national borders; thin grey lines=province borders. Colours in larger-scale inset: black lines=roads; grey lines=province borders; black circles=major settlements. Colours in smaller-scale inset: larger black lines: larger roads; smaller black lines: smaller roads; grey lines=larger rivers; black circles=named settlements. (b) Stratigraphic column based on figure 1 of Liu et al. (2018) showing correspondence of the Ermaying Formation to international Middle Triassic stage dates. Guchengosuchus is reported to be from the lower part of the Ermaying Formation, but no more precise information is available. 
(a)

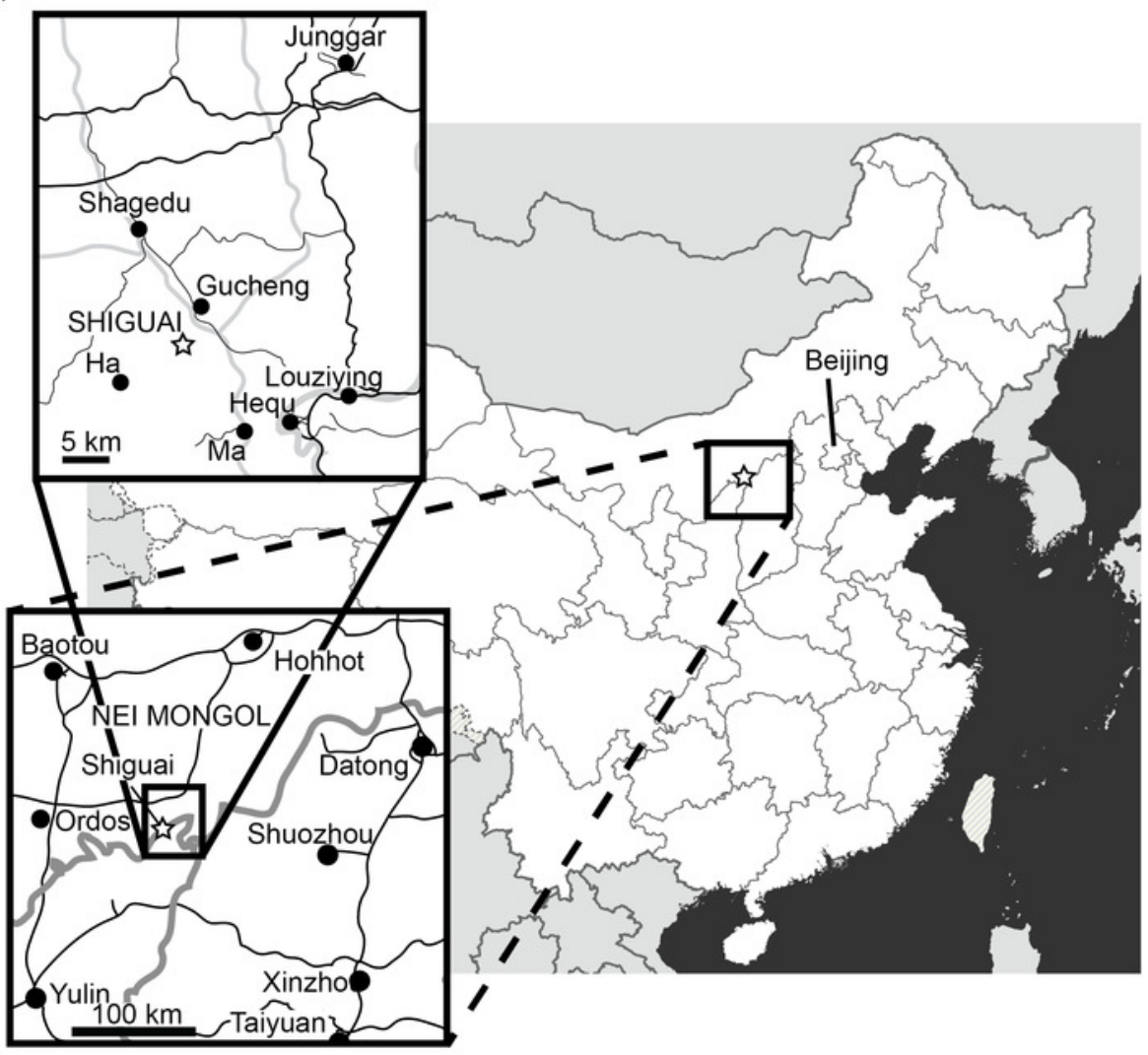

(b)

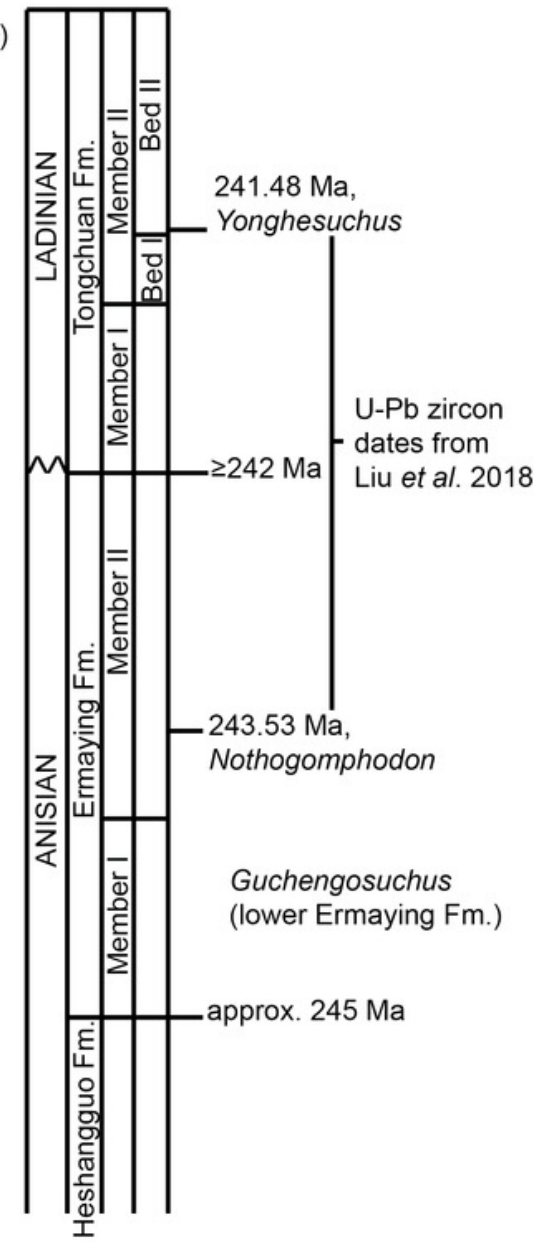




\section{Figure 2}

Left maxilla of Guchengosuchus shiguaiensis, IVPP V8808, in lateral (A), medial (B), dorsal (C) and ventral (D) views.

Abbreviations: anp, anterior process; asp, ascending process; ect.ct, contact surface for the ectopterygoid; for, foramina; gr, groove; hp, horizontal process; ?maaf, proposed margin of the accessory antorbital fenestra identified by Peng (1991) - see Discussion for details; nf, nutrient foramina; palp, base of broken palatal process; pal.ct, contact surface for the palatine; rc, replacement crown; ri, ridge; thg, thickening of maxilla along the posterior margin of the ascending process and anteroventral margin of the antorbital fenestra; vmaf, ventral margin of the antorbital fenestra. 


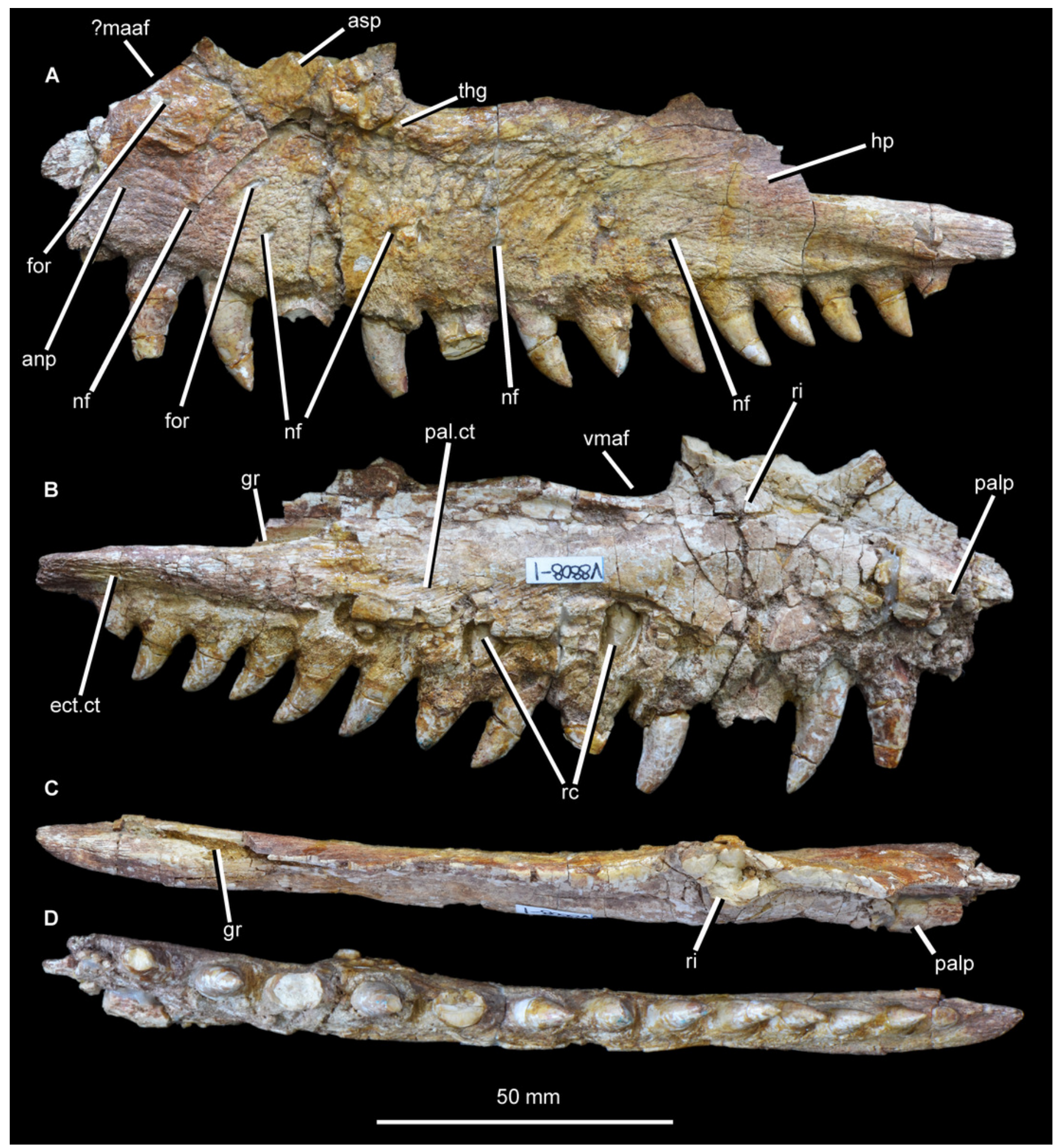


Figure 3

Close-ups of the left maxilla of Guchengosuchus shiguaiensis, IVPP V8808, focusing on the base of the ascending process $(A)$ and tooth positions 1-6 (B).

Abbreviation: bat, bone of attachment.

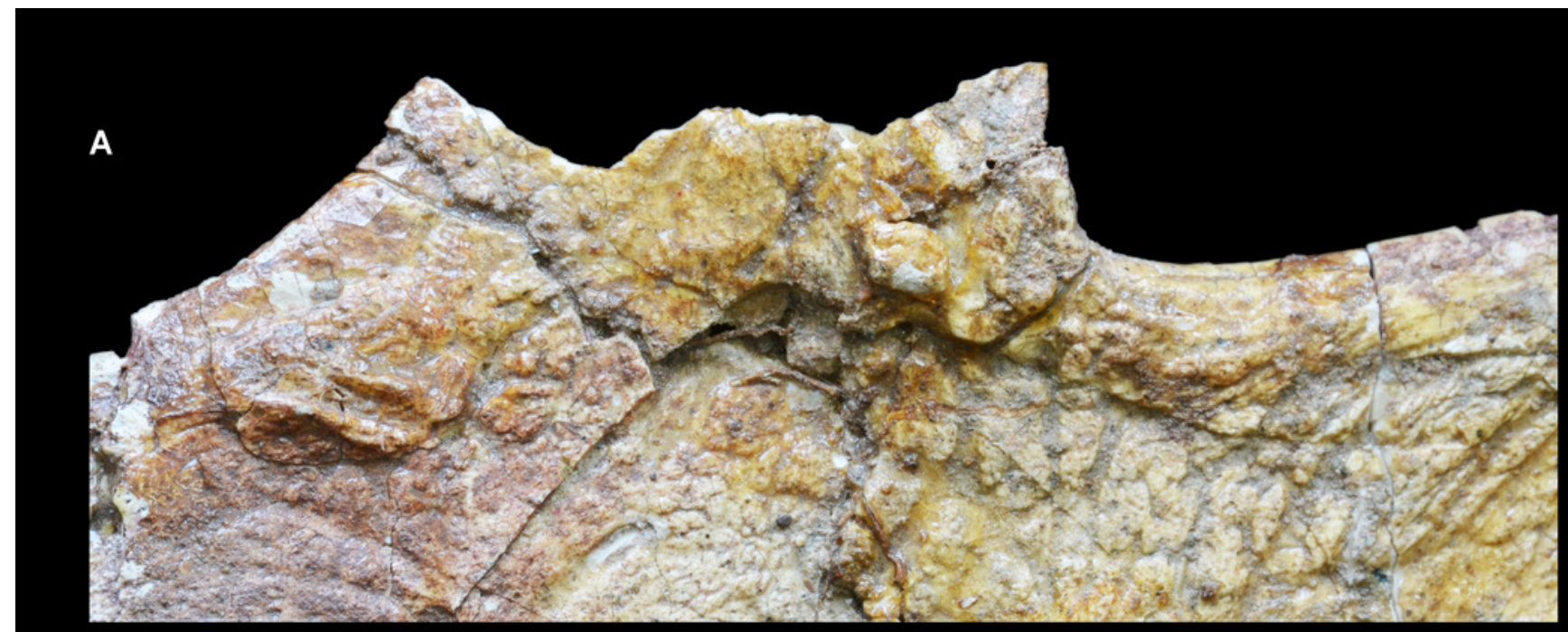

B

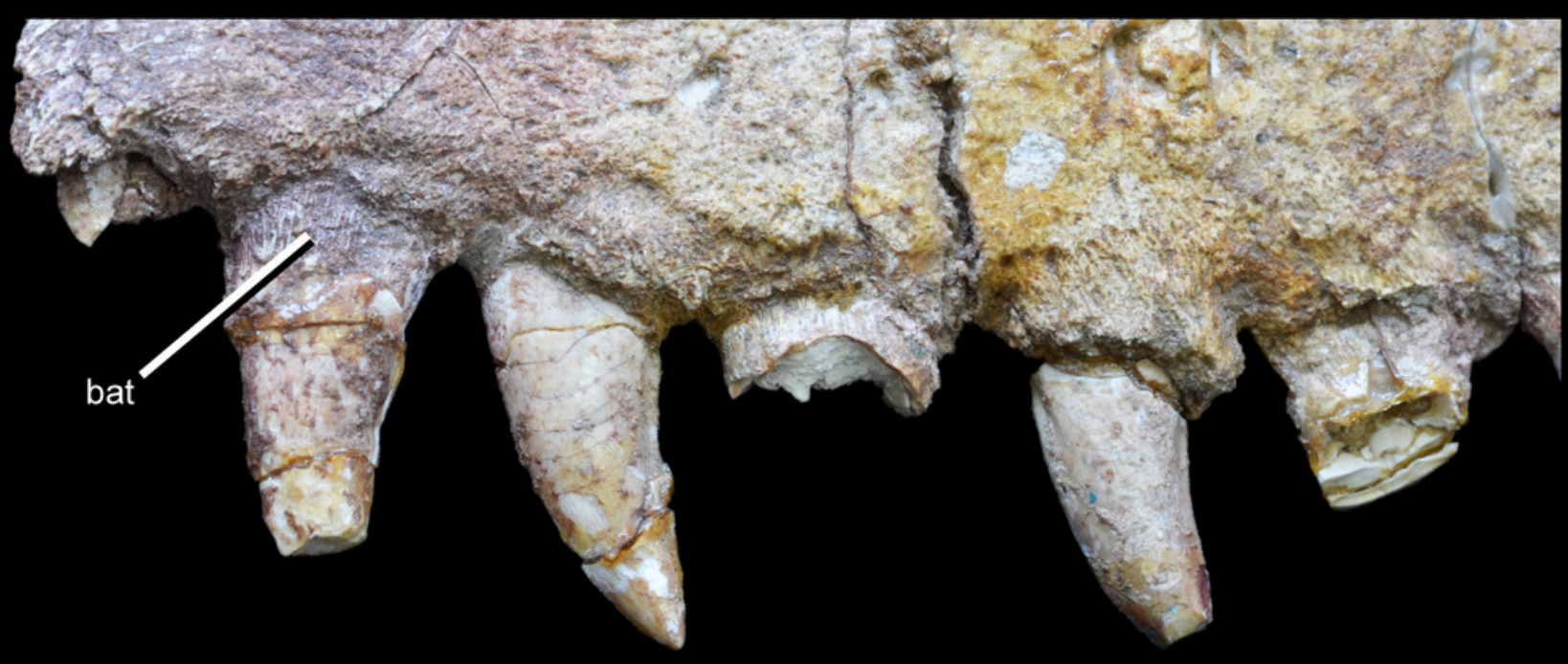




\section{Figure 4}

Selected cranial elements of Guchengosuchus shiguaiensis, IVPP V8808, as originally preserved and figured by Peng (1991).

Photographs show the left maxilla in lateral view $(A)$ and the left pterygoid in ventral view (B). Both elements have been damaged since their description by Peng (1991) - see Figure 2 and Figure 10 for details. Peng (1991) did provide reduction factors (e.g. $\times 1 / 2$ ) for individual bones in his plates; however, the accuracies of these are unclear. As such, the present figure should not be used to estimate relative proportions of individual bones.

*Note: Auto Gamma Correction was used for the image. This only affects the reviewing manuscript. See original source image if needed for review.

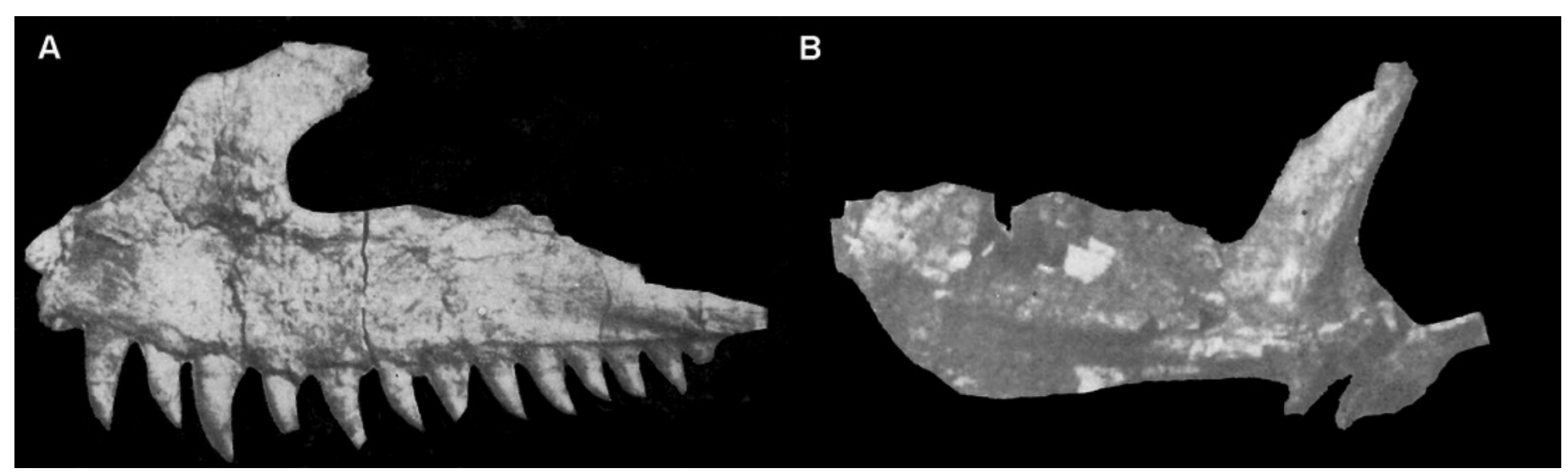




\section{Figure 5}

Left nasal of Guchengosuchus shiguaiensis, IVPP V8808, in lateral (A), dorsal (B), and medial (C) views, and with close-up of the anterior end in lateral (D) view.

Abbreviations: conc, concavity; fc.ap.mx, facet for the ascending process of the maxilla; fc.l, facet, possibly for articulation with the lacrimal; fc.ponp.pmx, facet for the postnarial process of the premaxilla; fc.prnp.pmx, facet for the prenarial process of the premaxilla; gr, groove on medial margin for articulation with opposing nasal; na, border of external naris; rg, knoblike rugosities; sf, surface separating the postnarial process of the premaxilla from the ascending process of the maxilla. 


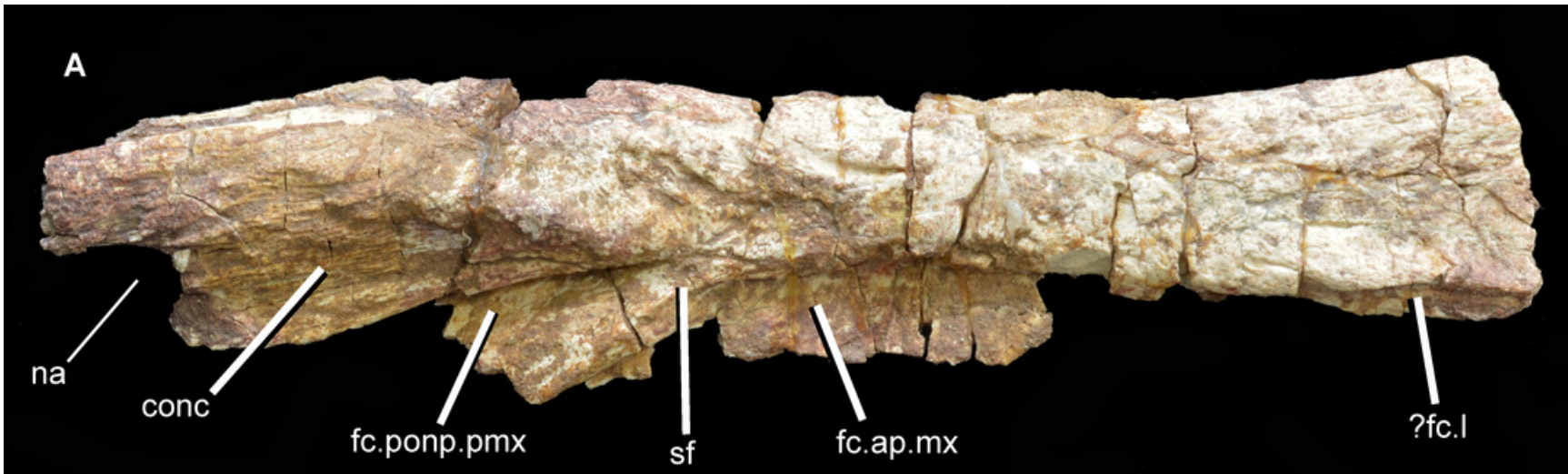

B
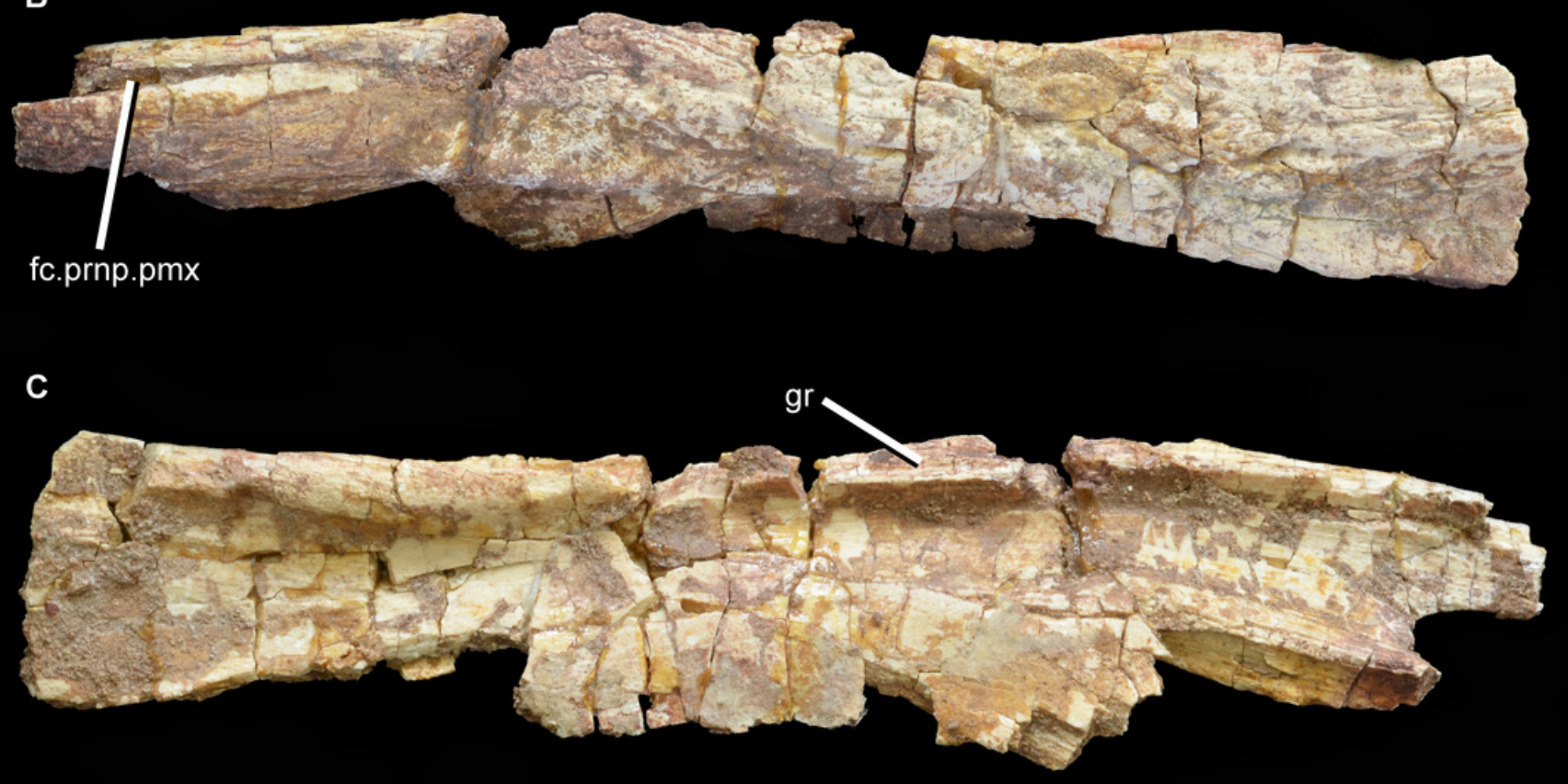

$50 \mathrm{~mm}$

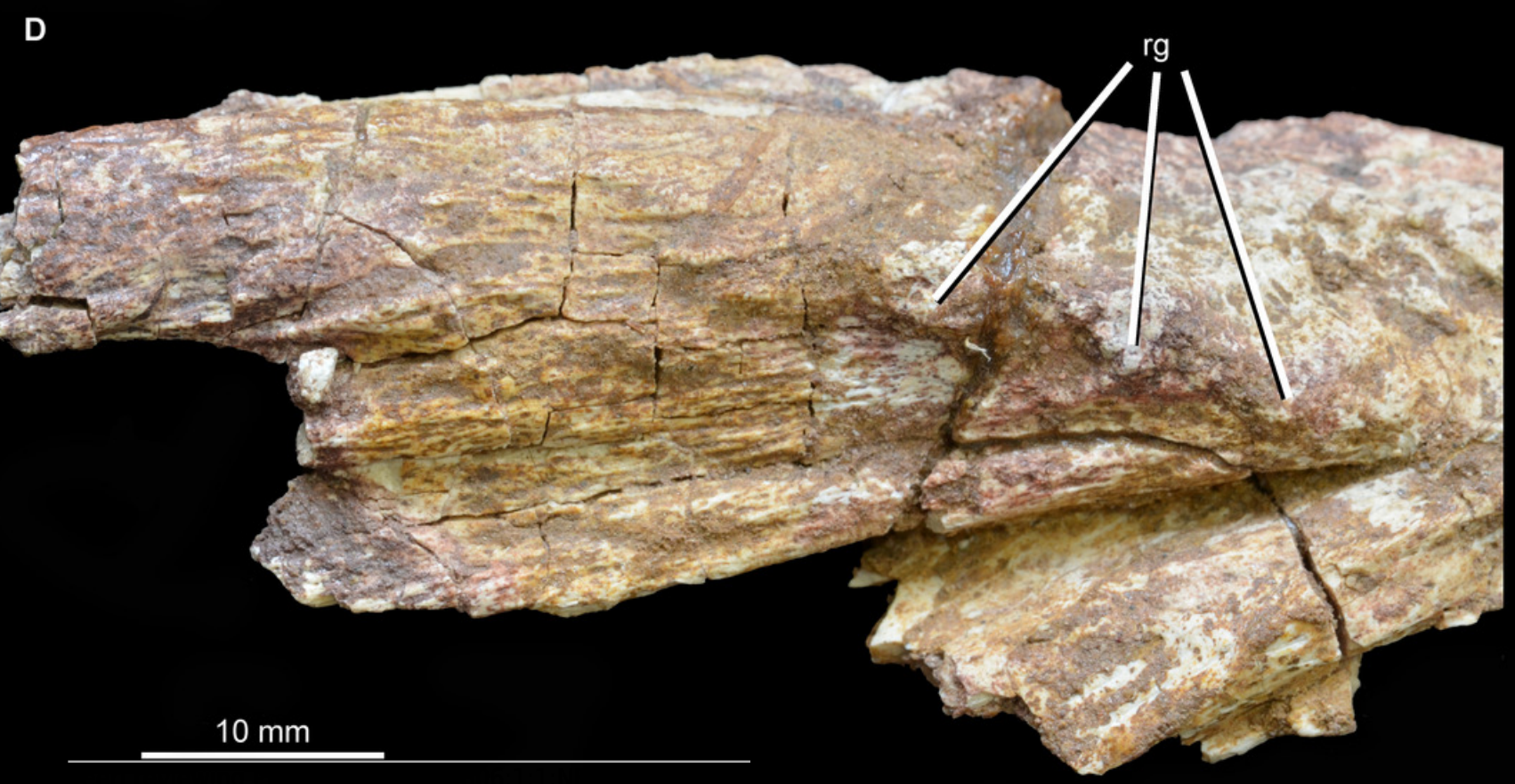




\section{Figure 6}

Skull roof of Guchengosuchus shiguaiensis, IVPP V8808, in dorsal (A), posterior (B), ventral (C) and right lateral (D) views.

Abbreviations: alp, anterolateral process of the parietal; $\mathrm{cb}$, impression of the cerebrum; conc, concavity between the impression of the olfactory bulbs and the orbital depression; dia, dorsally inflated area of the nasals; fc.cp.ls, facet for the capitate process of the laterosphenoid; ?fc.prf, possible facet for prefrontal; fc.sq, facet for the squamosal; fos, fossa on the base of the posterolateral process of the parietal; ob, impression of olfactory bulbs; od, orbital depression; ot, olfactory tract; prj, median projection of the parietals; re, raised edge on parietal posteriorly delimiting a subtriangular fossa; ril, longitudinal ridges on the anterior parts of the frontals; ri2, ridge laterally delimiting impression of the olfactory bulbs; ri3, ridge on the anterior surface of the posterolateral process of the parietal; sbtf, subtriangular fossa on parietal; stdp, subtriangular depression on posterolateral corner of frontal; stf, supratemporal fossa; str, striations; te, transverse eminence on posterior margin of parietals; ttub, transverse tuberosity on the frontal; tub, tuberosity separating impression of cerebrum from the facet for the capitate process of the laterosphenoid; vf, vertical flange. 


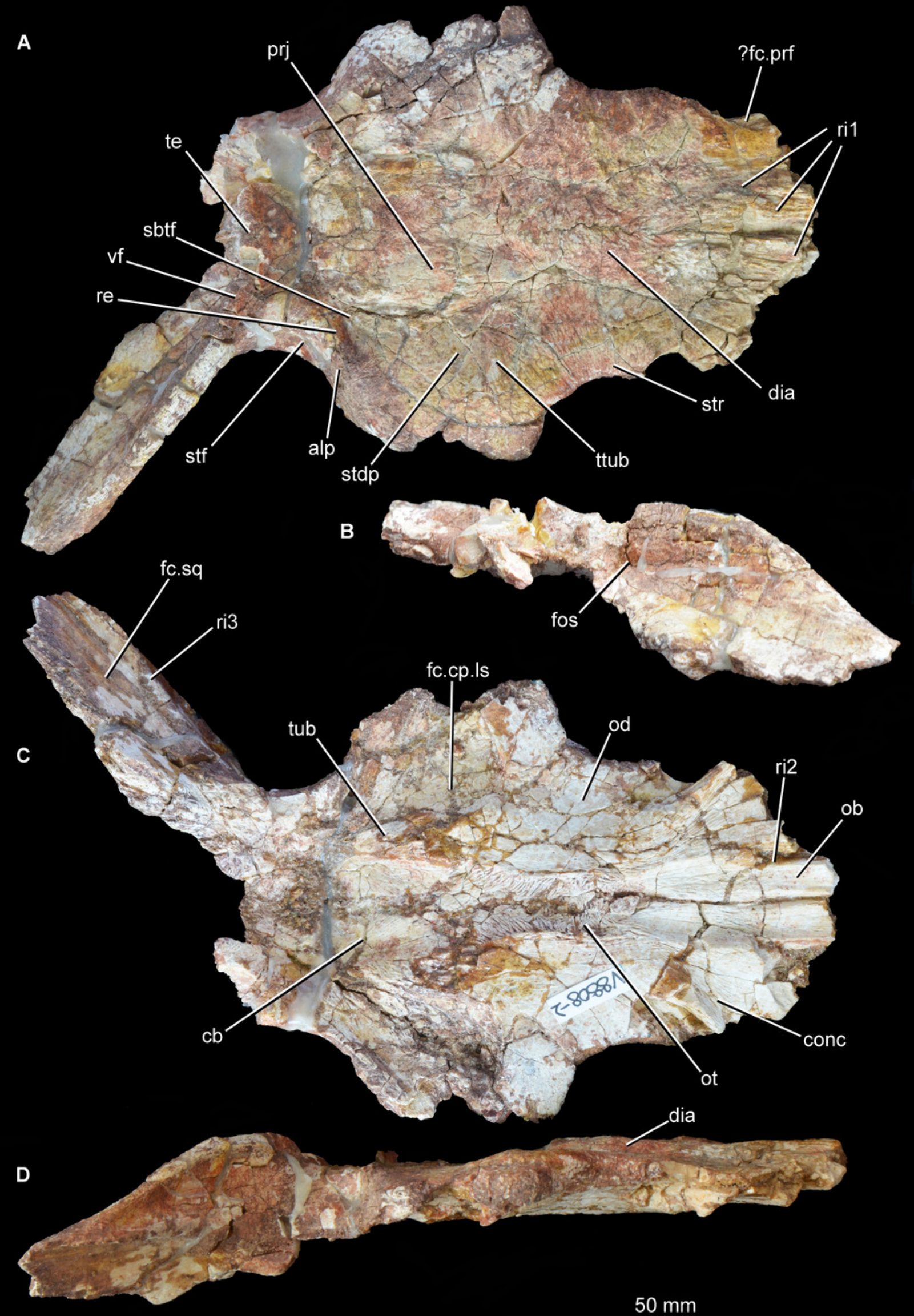


Figure 7

Skull roof of Guchengosuchus shiguaiensis, IVPP V8808, in dorsal view.

Abbreviations: alp, anterolateral process of the parietal; dia, dorsally inflated area of the nasals; ?fc.prf, possible facet for prefrontal; fos, fossa on the base of the posterolateral process of the parietal; fr, frontal; pa, parietal; pf, postfrontal; prj, median projection of the parietals; re, raised edge on parietal posteriorly delimiting a subtriangular fossa; ri1, longitudinal ridges on the anterior parts of the frontals; sbtf, subtriangular fossa on parietal; stdp, subtriangular depression on posterolateral corner of frontal; stf, supratemporal fossa; str, striations; te, transverse eminence on posterior margin of parietals; ttub, transverse tuberosity on the frontal; vf, vertical flange.

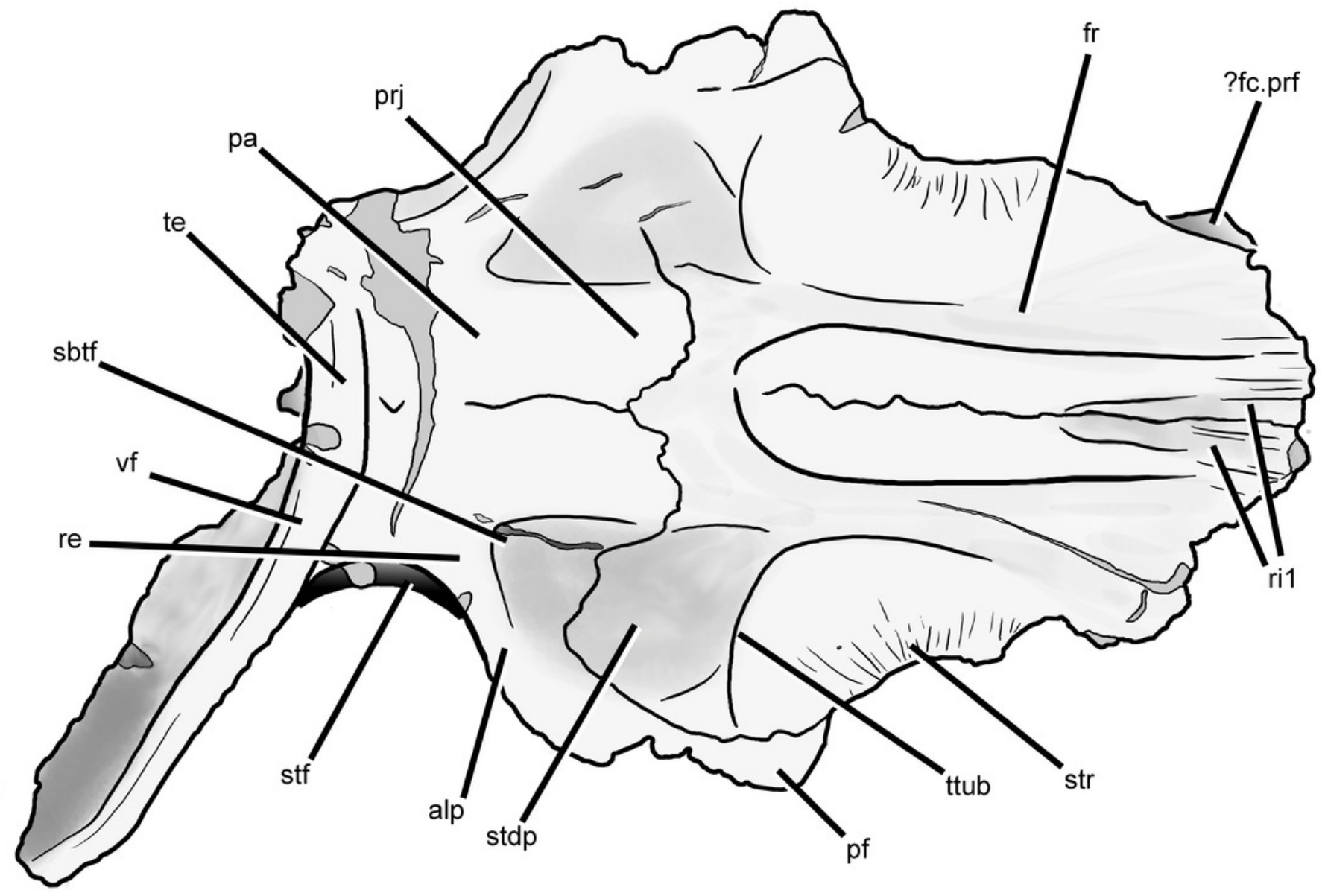




\section{Figure 8}

Partial braincase of Guchengosuchus shiguaiensis, IVPP V8808, in posterior (A), anterior $(B)$, dorsal $(C)$, ventral $(D)$ and left lateral $(E)$ views.

Abbreviations: art.clp, articular surface to receive the clinoid process of the basisphenoid; art.Is, articular surface for the laterosphenoid; art.p, articular surface for the parietals; CNV, foramen for cranial nerve $\mathrm{V}$; $d p$, depression; fac.p, facet for articulation with ventral surface of the base of the posterolateral process of the parietal; fo, fenestra ovalis; gr, groove; hy, groove for hyomandibular branch of the facial nerve; $\mathrm{mf}$, metotic foramen; pop, paraoccipital process; pr.cr, prootic crest; ri1, median ridge on the supraoccipital; ri2, ridge on lateral surface of upper anterior process of the prootic; ri3, ridge on lateral surface of lower anterior process of the prootic; vrop, ventral process of the opisthotic. 


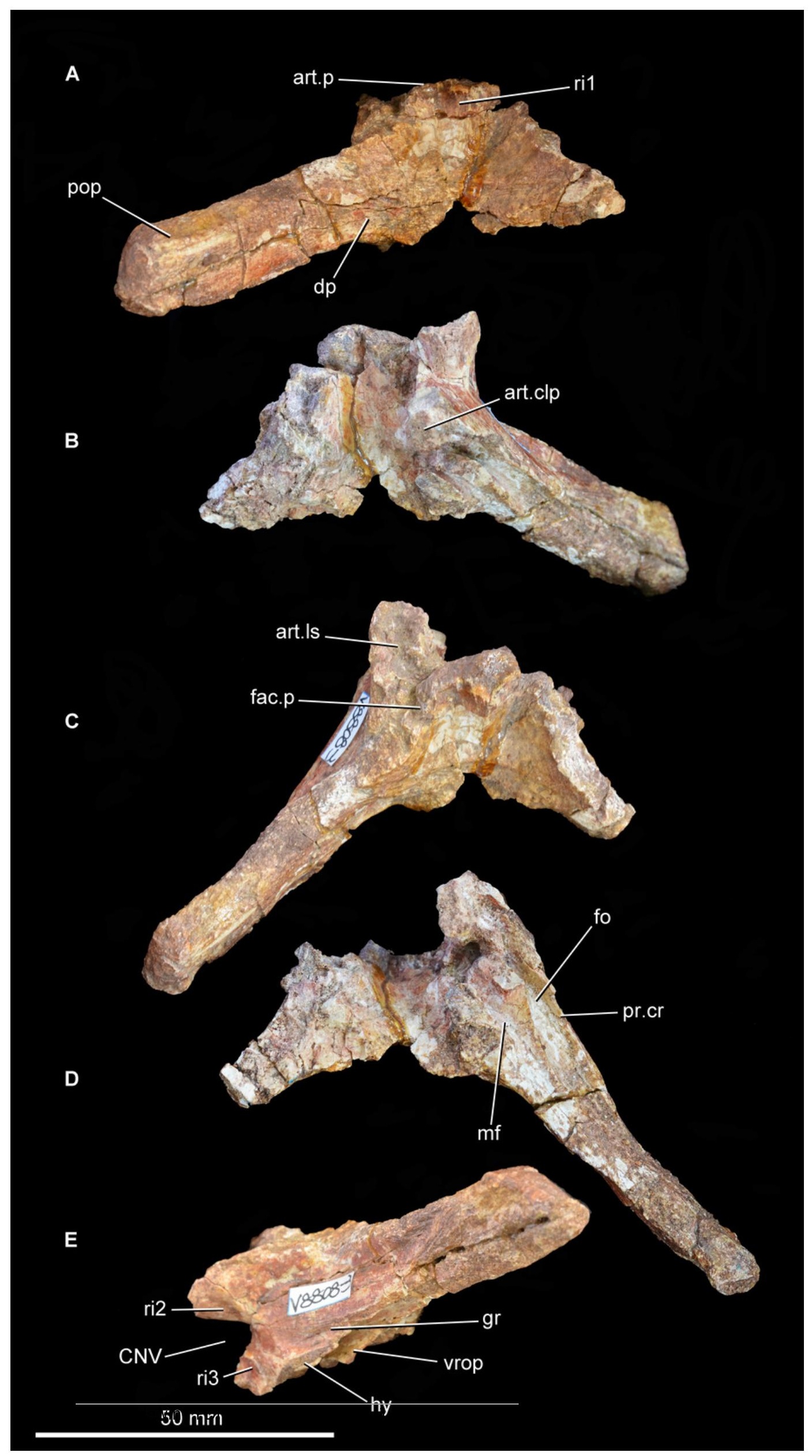




\section{Figure 9}

Partial braincase of Guchengosuchus shiguaiensis, IVPP V8808. Medial surface of the prootic (A) and close-up of the braincase in ventral (B) view.

Abbreviations: aur, auricular recess; CNV, foramen for cranial nerve V; ?CN VII, foramen, possibly for passage of cranial nerve VII; fo, fenestra ovalis; iec, inner ear chamber; mf, metotic foramen; pr.cr, prootic crest; ?ri4, possible ridge dividing the auricular recess; vrop, ventral process of the opisthotic. 


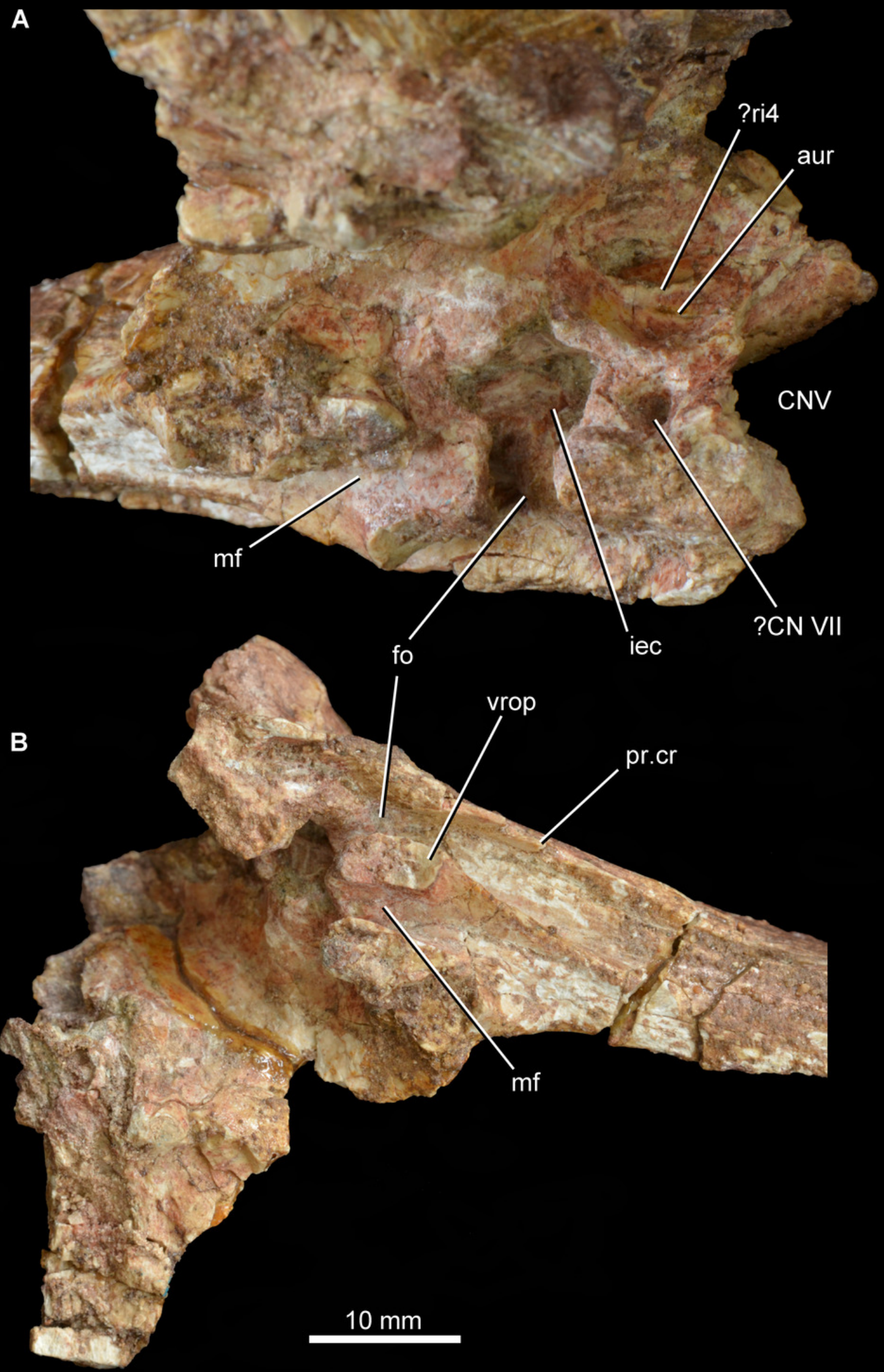




\section{Figure 10}

Fragment of left pterygoid of Guchengosuchus shiguaiensis, IVPP V8808, in ventral (A), and dorsal (B) views.

A

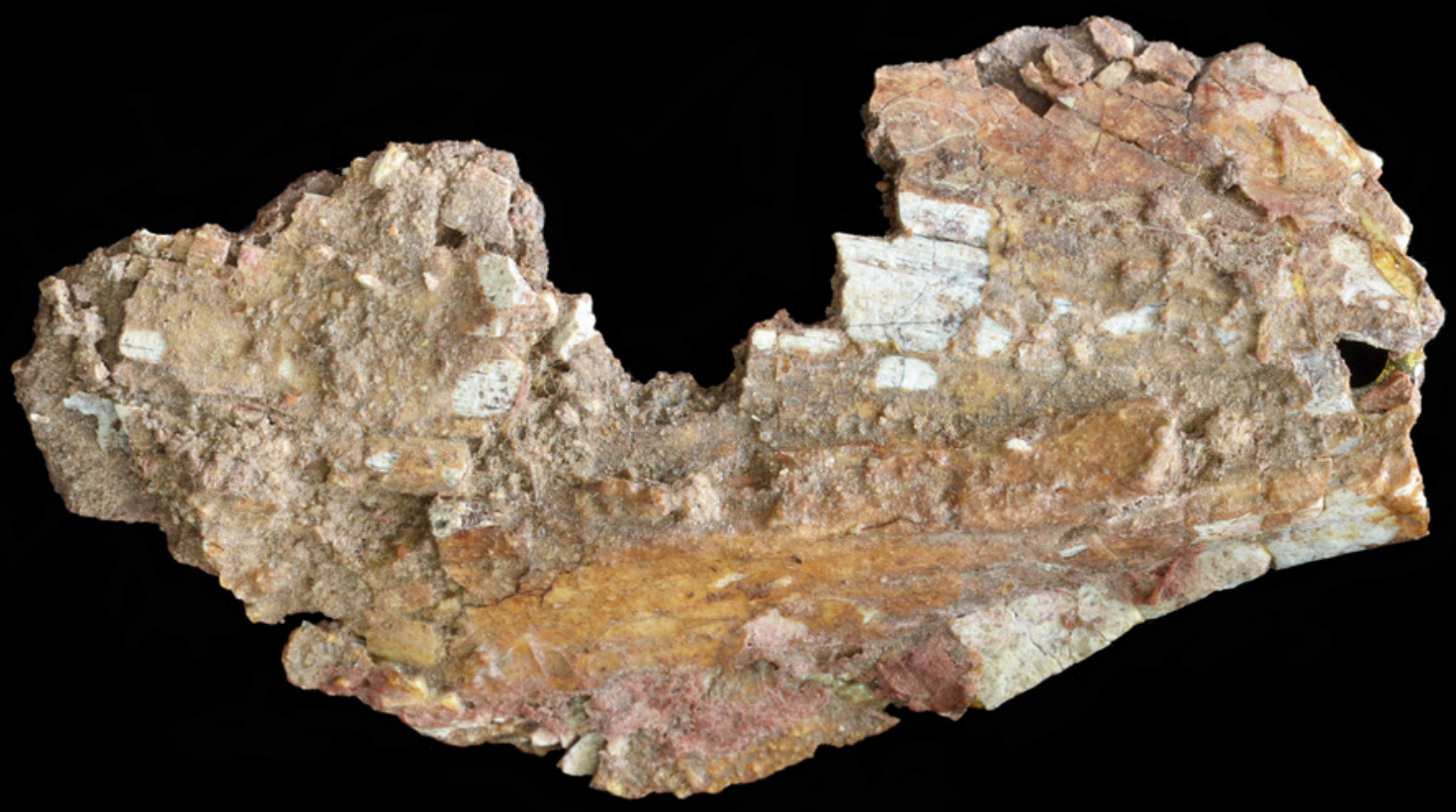

B

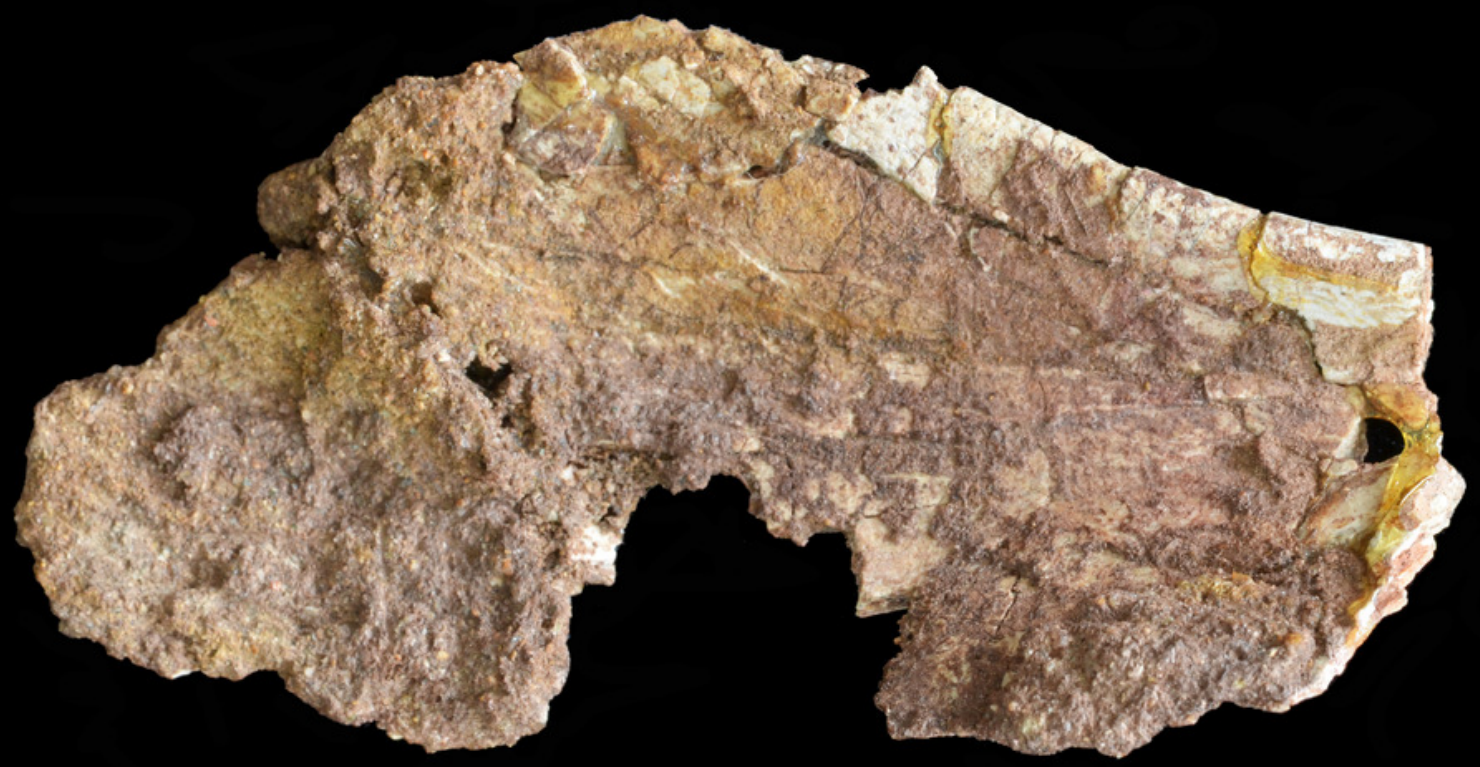




\section{Figure 11}

Posterior right mandible of Guchengosuchus shiguaiensis, IVPP V8808, in lateral (A), medial (B), ventral (C) and dorsal (D) views.

Abbreviations: ar, articular; cncv, deep concavity separating the glenoid fossa from the retroarticular process; $\mathrm{dmp}$, dorsomedial projection of the articular; $\mathrm{fl}$, ventromedially directed flange of the surangular, anteriorly bordering the articular; gl, glenoid fossa; ri, ridge forming the posterior border of the glenoid; ri.ang.pre, ridge on ventral surface of articular separating the articular facets for the angular and the prearticular; rp, retroarticular process; sa, surangular; sa.ar.s, suture between the surangular and the articular; sh, shelf on dorsal margin of surangular; vmp, ventromedial process of the articular. 


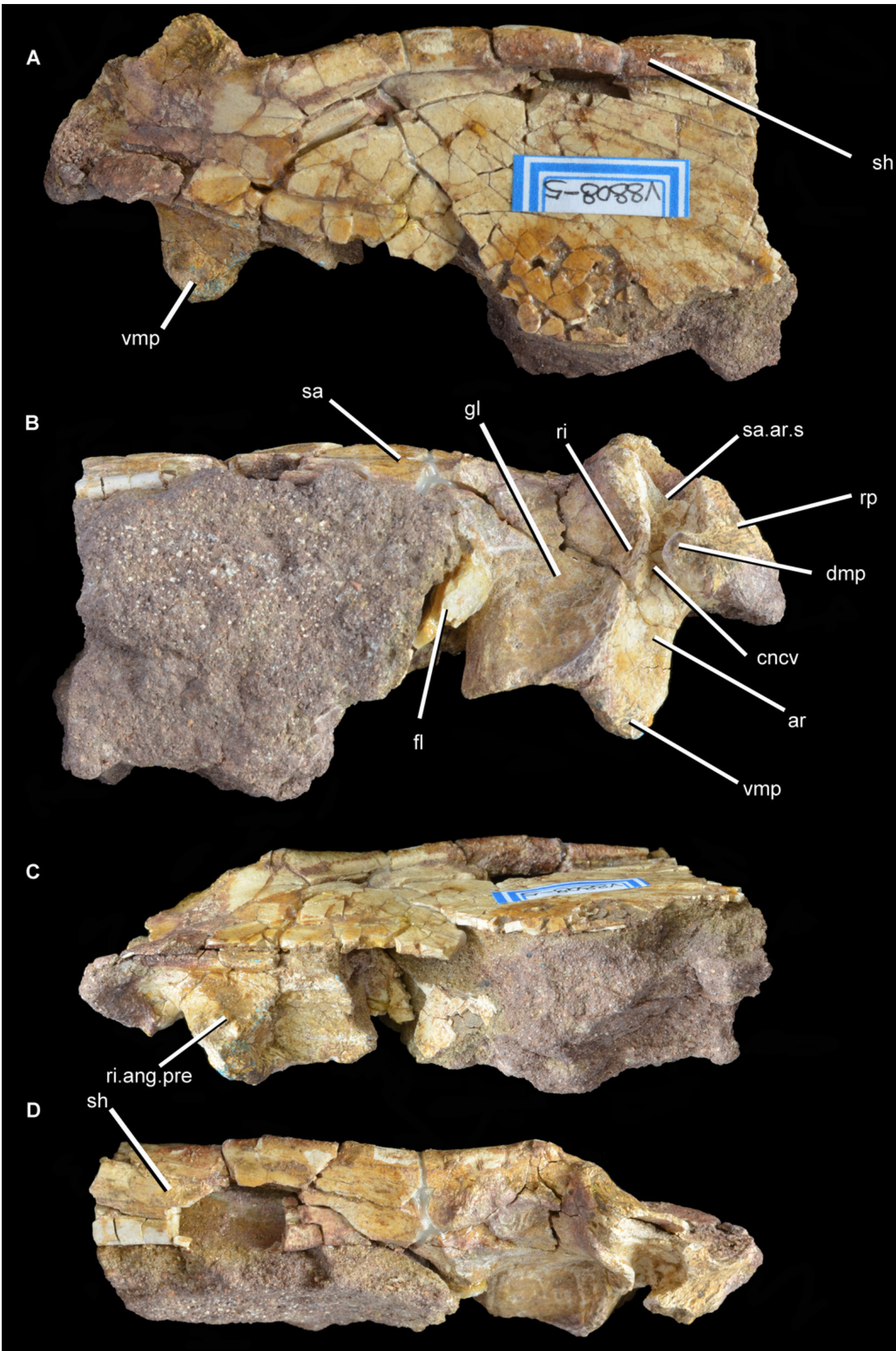


Figure 12

Articulated cervical vertebrae of Guchengosuchus shiguaiensis, IVPP V8808, in left lateral (A) and right lateral (B) views. 


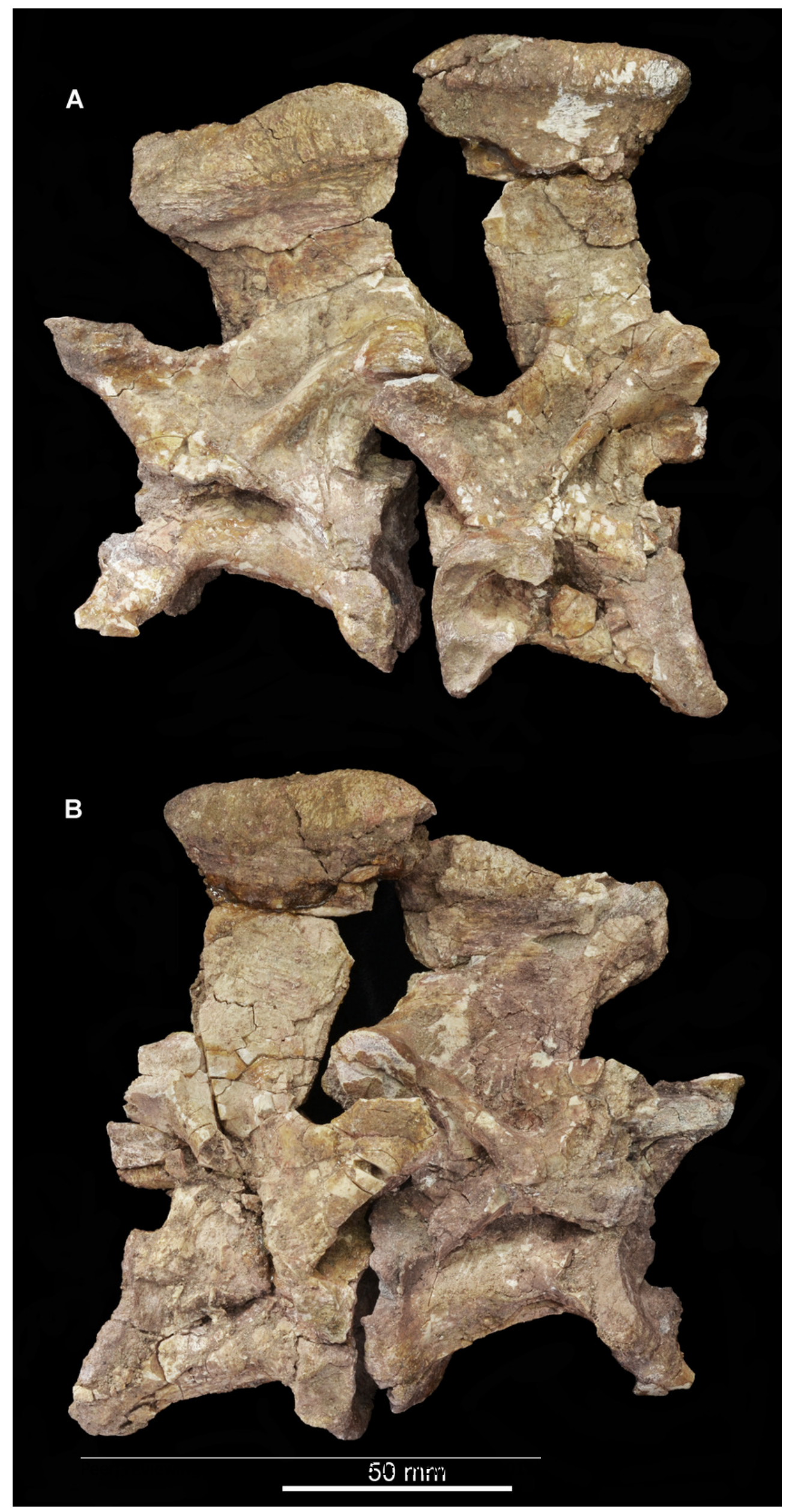




\section{Figure 13}

'Cervical a' of Guchengosuchus shiguaiensis, IVPP V8808, in left lateral (A), right lateral $(B)$, anterior $(C)$, posterior $(D)$, dorsal $(E)$ and ventral $(F)$ views.

Abbreviations: b.dp, base of the diapophysis; cap, capitulum; cdf, centrodiapophyseal fossa; flp, flange-like projection at the base of the neural spine; fu, furrow; hys, hyposphene; lam, lamina; m.ri, midline ridge; nc, neural canal; pp, parapophysis; pcdl, posterior centrodiapophyseal lamina; pocdf, postzygapophyseal centrodiapophyseal fossa; poz, postzygopophysis; pp.af, parapophyseal articular facet; podl, postzygodiapopohyseal lamina; prcdf, prezygapophyseal centrodiapophyseal fossa; prdl, prezygodiapopyseal lamina; prz, prezygapophysis; sdf, spinodiapophyseal fossa; spof, spinopostzygapophyseal fossa; sprf, spinoprezygapophyseal fossa; sprl, spinoprezygopophyseal lamina; 3af, third articular facet. 


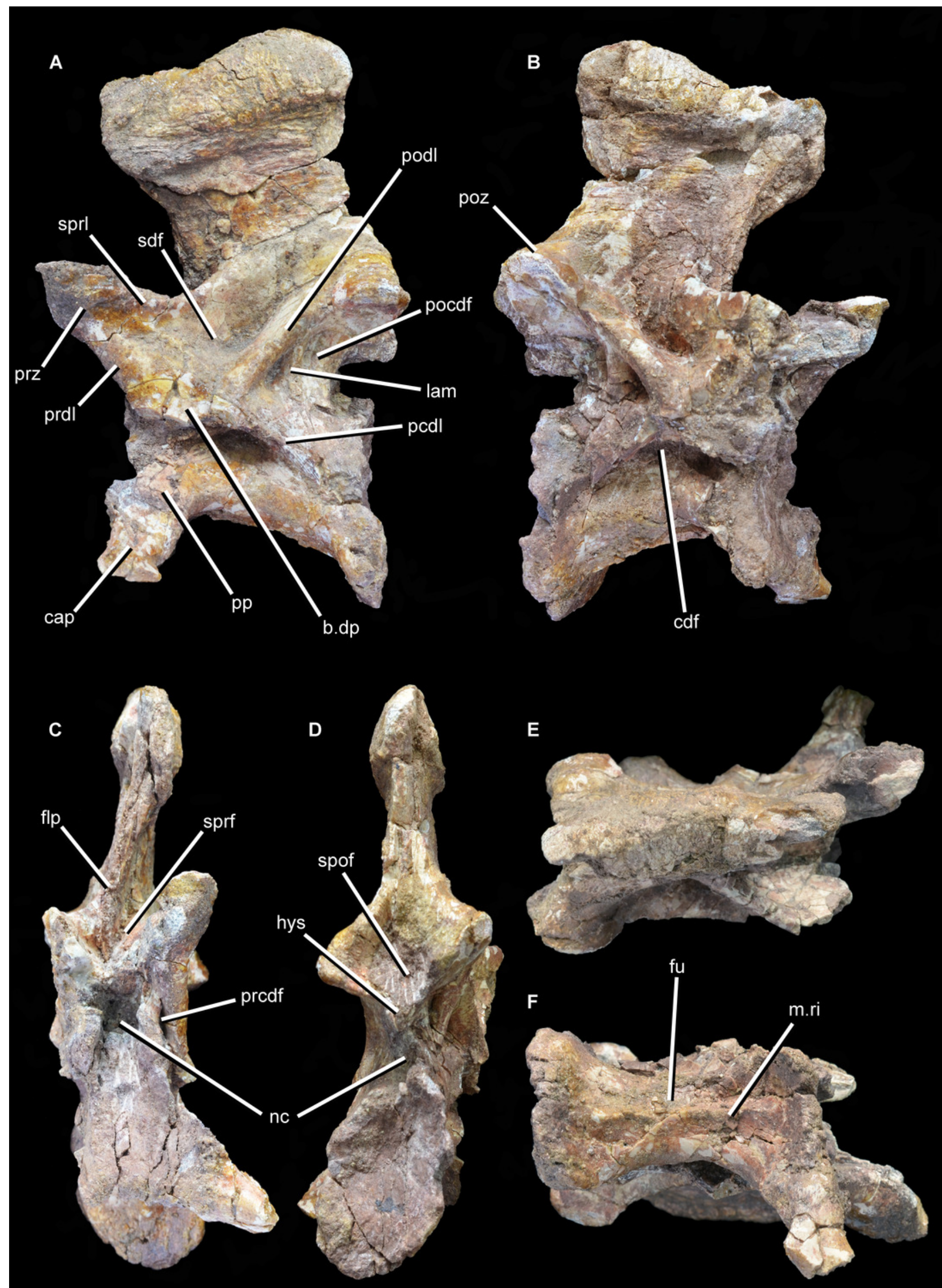


Figure 14

'Cervical a' of Guchengosuchus shiguaiensis, IVPP V8808, in close-up left lateral (A) and right lateral (B) views. 
A
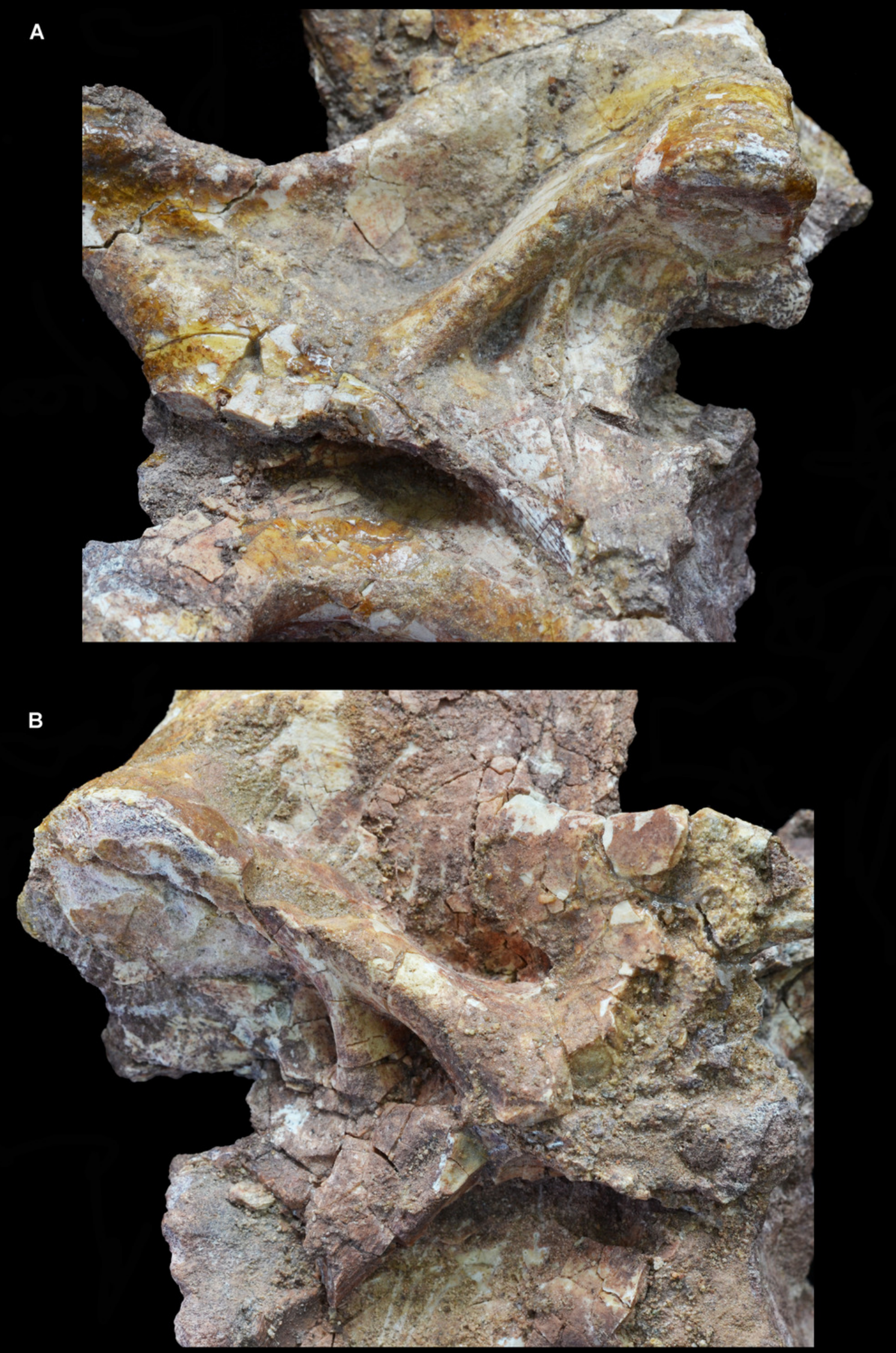


\section{Figure 15}

'Cervical b' of Guchengosuchus shiguaiensis, IVPP V8808, in left lateral (A), right lateral $(B)$, anterior (C), posterior (D), dorsal (E) and close-up left lateral $(F)$ views.

Abbreviations: dp, diapophysis; hys, hyposphene; lam, lamina; pp, parapophysis; 3af, third articular facet. 


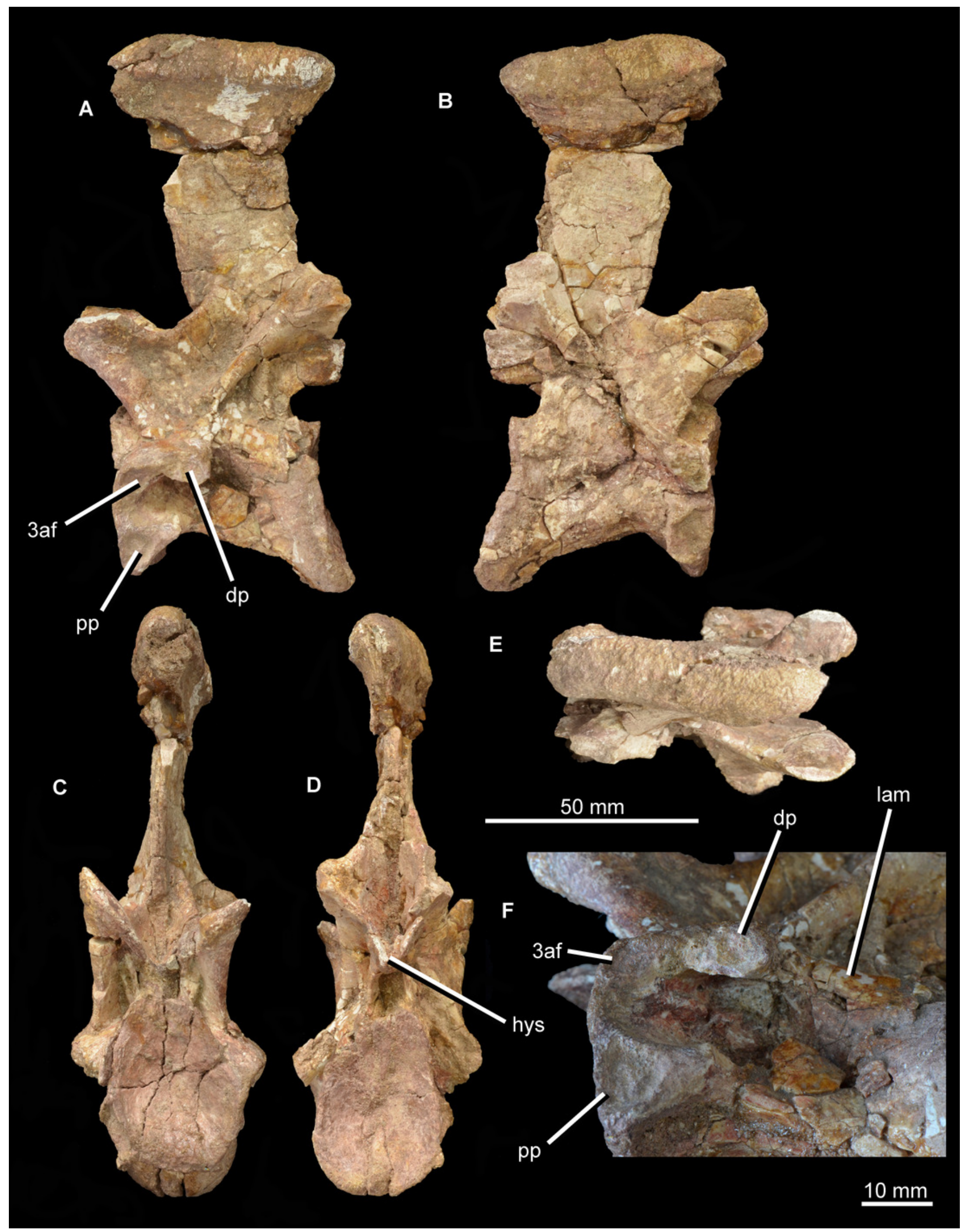




\section{Figure 16}

Partial dorsal vertebra of Guchengosuchus shiguaiensis, IVPP V8808, in anterior (A), left lateral (B), posterior (C) and dorsal (D) views.

Abbreviations: dp, diapophysis; hys, hyposphene; lam, accessory lamina; nc, neural canal; pcdl, posterior centrodiapophyseal lamina; pocdf, postzygapophyseal centrodiapophyseal fossa; poz, postzygapophysis; prz, prezygapophysis; sdf, spinodiapophyseal; spof, spinopostzygapophyseal fossa; sprf, spinoprezygapophyseal fossa; tp, transverse process.

*Note: Auto Gamma Correction was used for the image. This only affects the reviewing manuscript. See original source image if needed for review. 


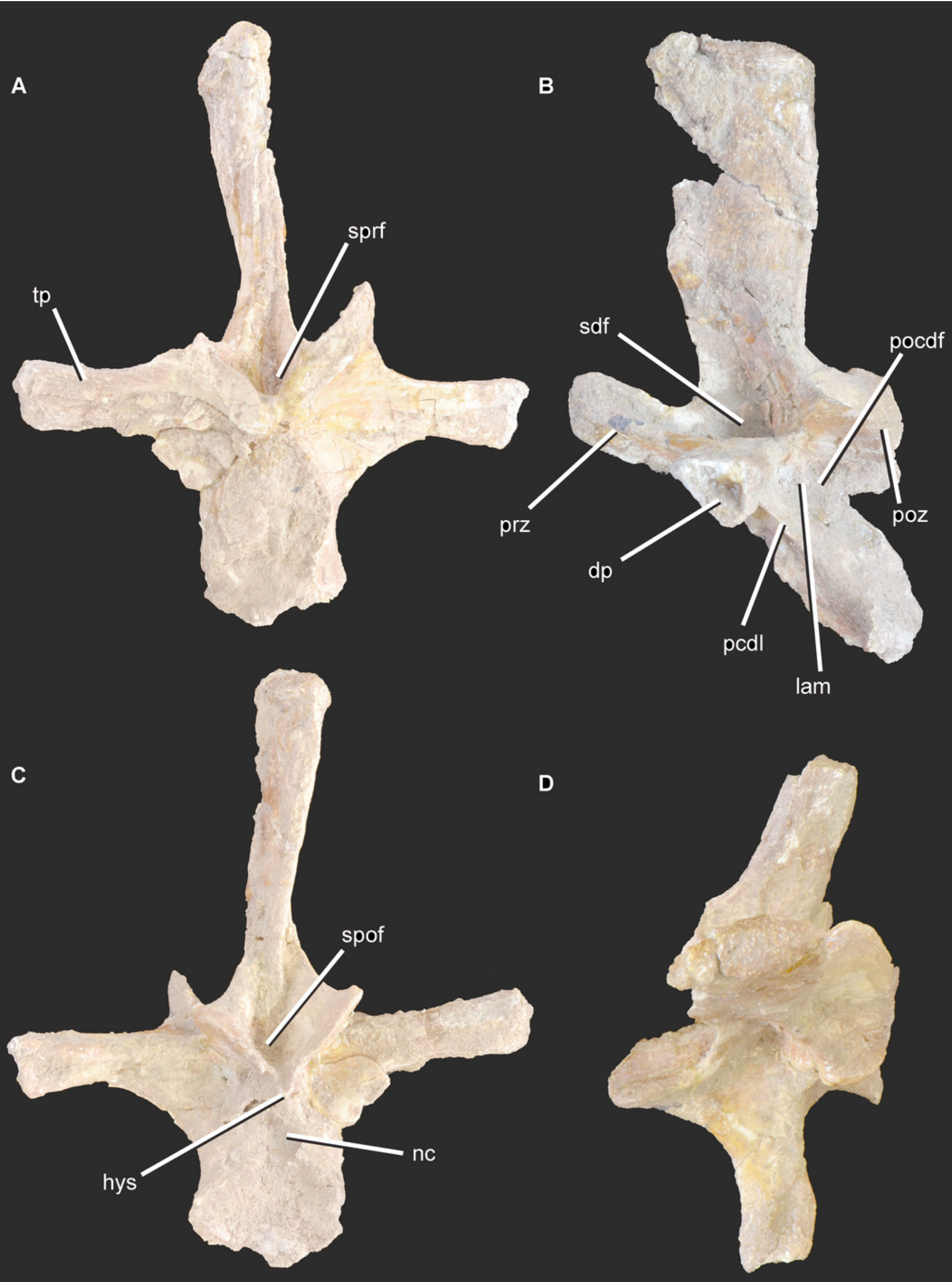




\section{Figure 17}

Vertebral fragment, Guchengosuchus shiguaiensis, IVPP V8808.

Because of the incompleteness of the specimen, the orientations of views (A) and (B) are uncertain.

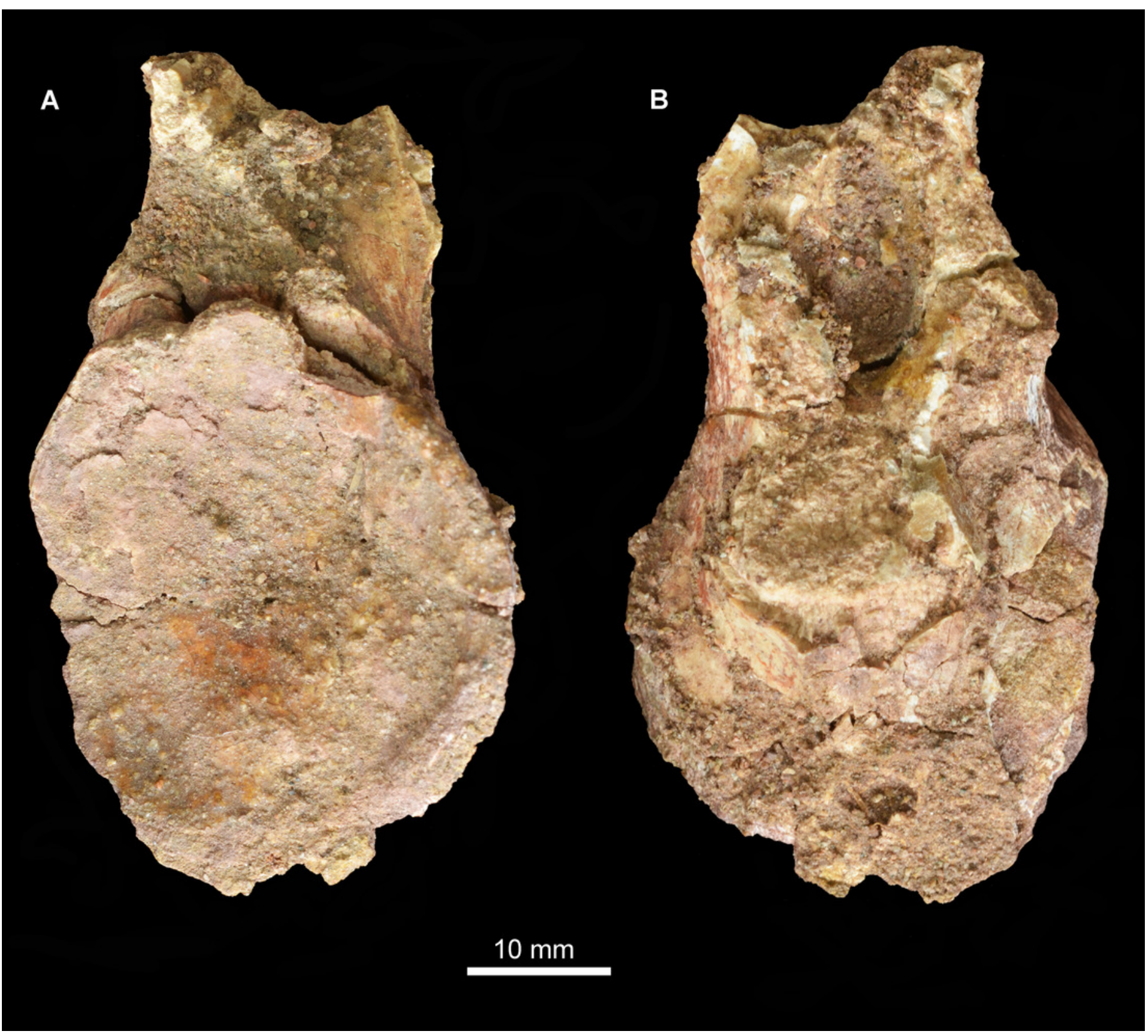




\section{Figure 18}

Partial ribs, Guchengosuchus shiguaiensis, IVPP V8808.

Left cervical rib in lateral (A), medial (B) and dorsal (C) views. Right dorsal rib in anterior (D) and posterior $(E)$ views. Left 'pectoral' rib in anterior $(F)$, posterior $(G)$ and lateral $(H)$ views. Right 'pectoral' rib in anterior (I) and posterior (J) views. Abbreviations: atp, anterior process; cap, capitulum; fl, flange; gr, groove; tu, tuberculum; wb, web of bone between the capitulum and tuberculum; $3 p$, third process of the rib. 

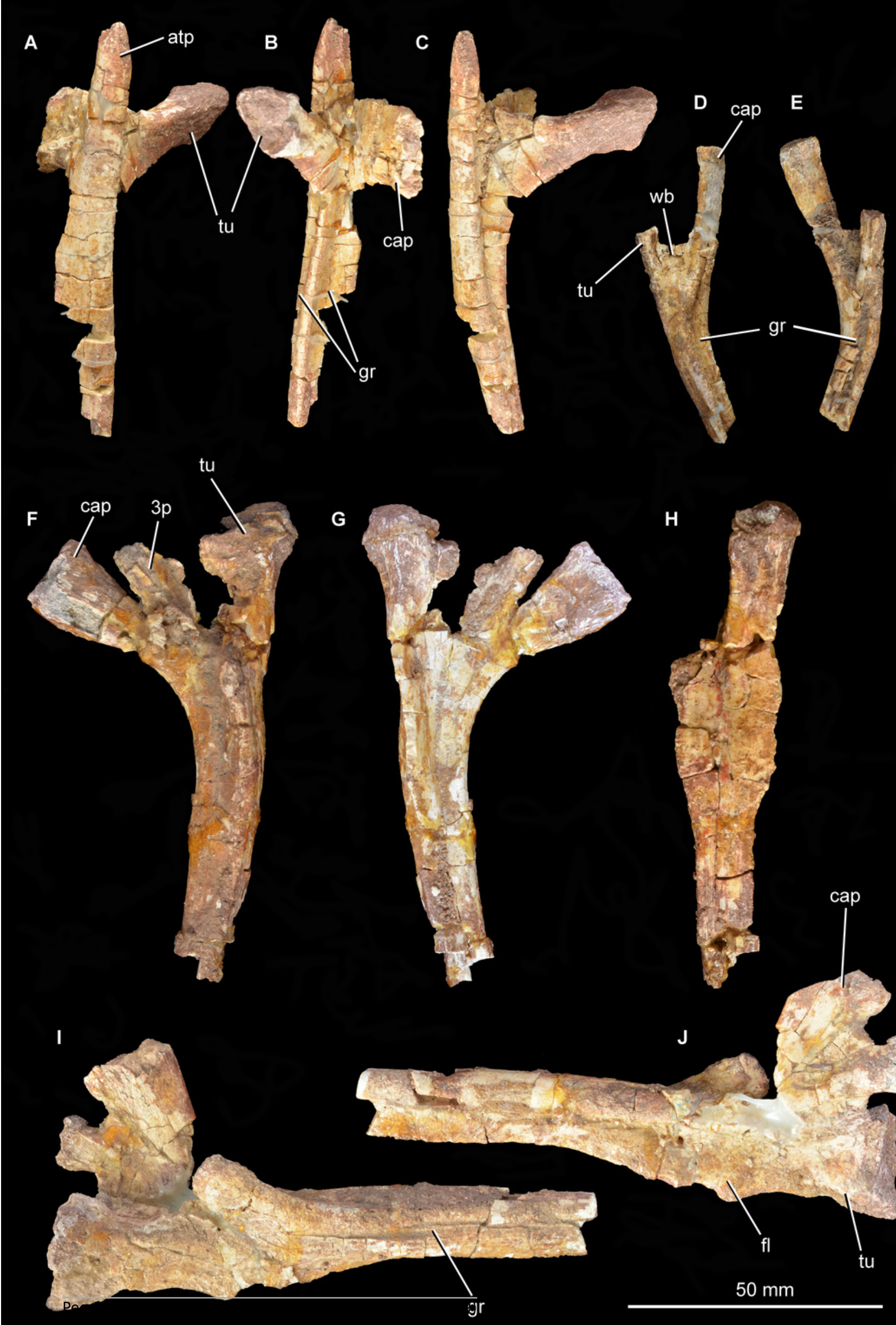


\section{Figure 19}

Non-vertebral postcranial elements of Guchengosuchus shiguaiensis, IVPP V8808, as originally preserved and figured by Peng (1991). All specimens are now missing.

Right scapula in lateral view (A), right humerus in anterior view (B), ulna (C), radius (D), metatarsal (E) and ungual phalanx (F). No scale bars were presented in the original figures. Peng (1991) did provide reduction factors (e.g. $\times 1 / 2$ ) for individual bones in his plates; however, the accuracies of these are unclear. As such, the present figure should not be used to estimate relative proportions of individual bones.

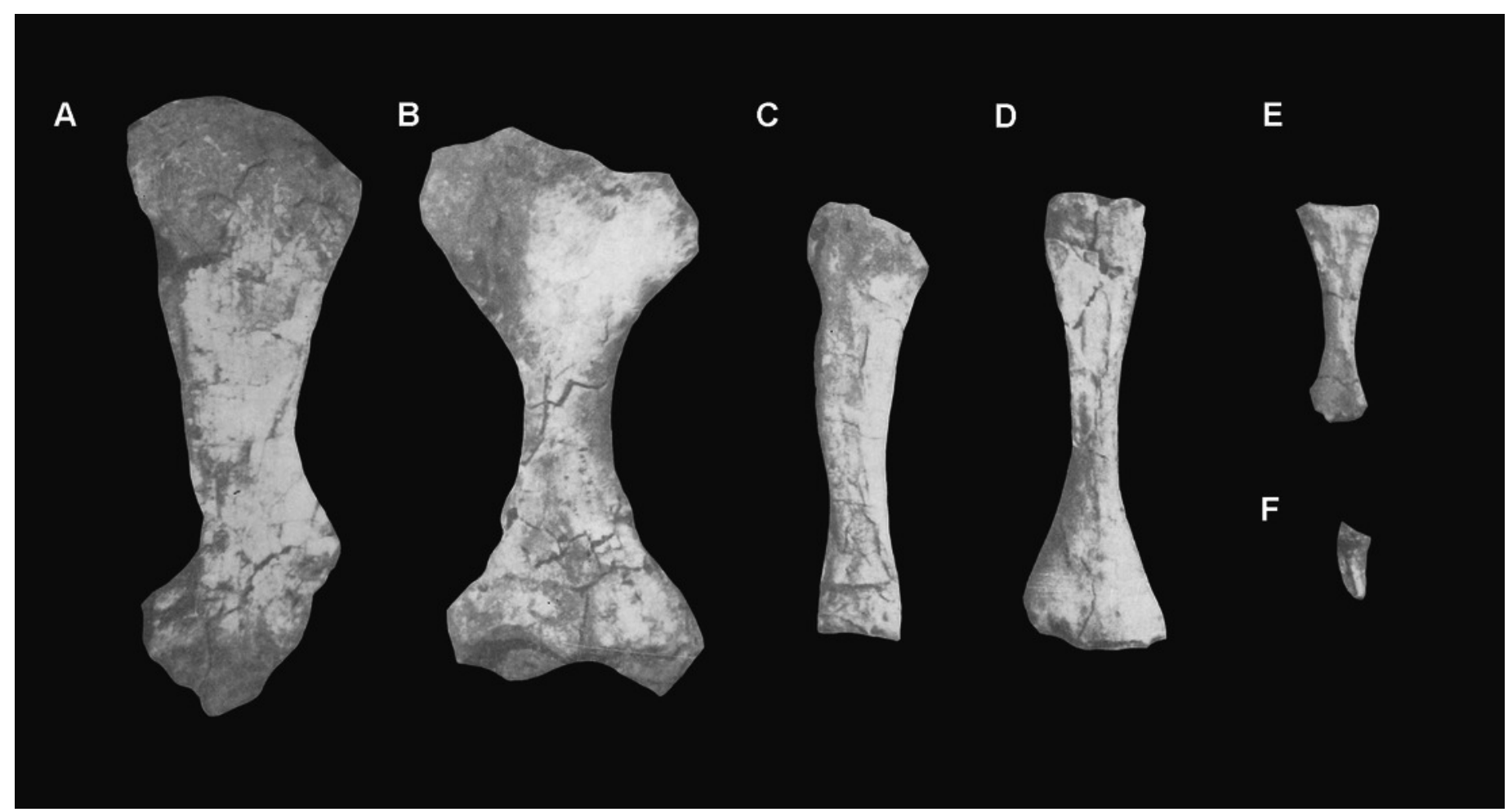




\section{Figure 20}

Phylogenetic relationships within Erythrosuchidae.

Numbers above branches are Bremer support values and absolute and GC bootstrap frequencies.

*Note: Auto Gamma Correction was used for the image. This only affects the reviewing manuscript. See original source image if needed for review.

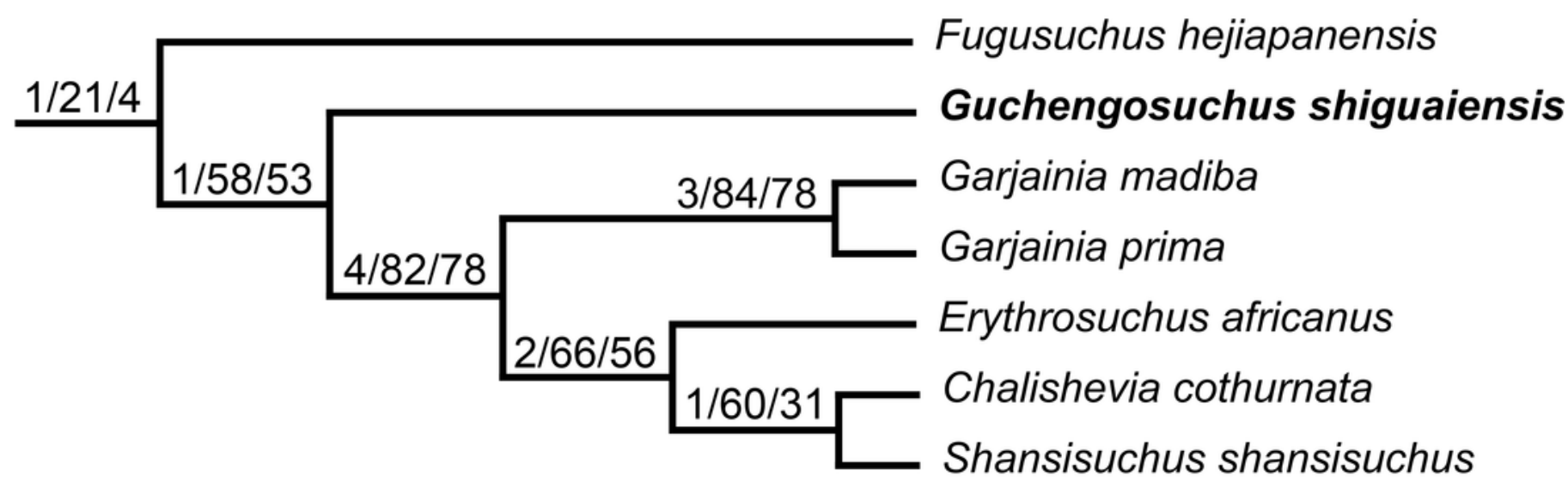

